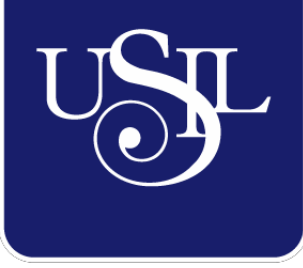

UNIVERSIDAD

SAN IGNACIO

DE LOYOLA

FACULTAD DE INGENIERÍA

Carrera de Ingeniería Industrial y Comercial

\title{
IMPACTO DE LA POBLACIÓN MIGRANTE VENEZOLANA EN LIMA NORTE EN LA DEMANDA DE NUEVOS PRODUCTOS DE CONSUMO MASIVO
}

Tesis para optar el Título Profesional de Ingeniero Industrial y Comercial

YAJAYRA LESLY BARZOLA VELÁSQUEZ

(0000-0002-7047-9593)

ARTURO HAMILTON URQUIZO GOMEZ

(0000-0002-7376-5843)

Asesor:

Mg. MIGUEL AUGUSTO MEDINA MILLAN

(0000-0001-7053-2342)

Lima - Perú

2021 
JURADO DE LA SUSTENTACIÓN ORAL

Presidente

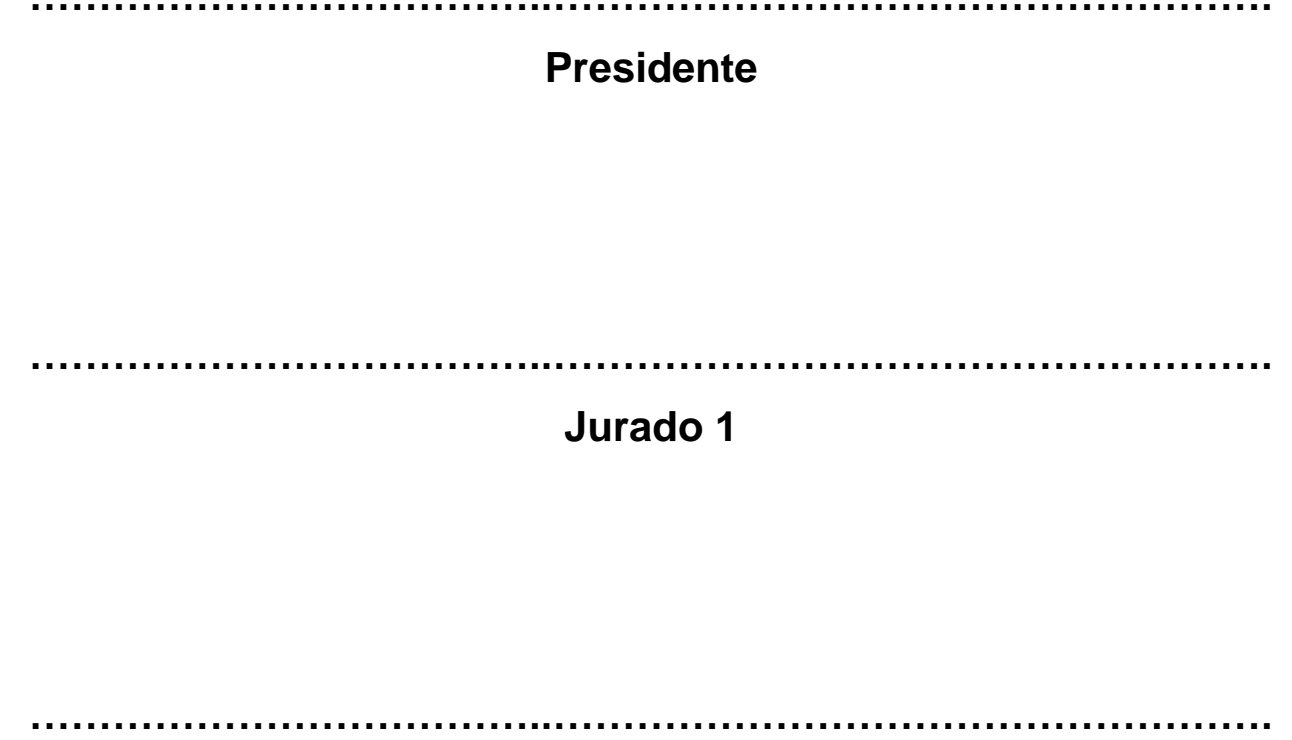

Jurado 2

Entregado el: ... / .../2021

Aprobado por:

Yajayra L. Barzola Velásquez Graduando

Arturo H. Urquizo Gómez

Graduando
Miguel Augusto Medina M., Asesor de Tesis 


\section{UNIVERSIDAD SAN IGNACIO DE LOYOLA \\ FACULTAD DE INGENIERIA}

\section{DECLARACIÓN DE AUTENTICIDAD}

Nosotros, Yajayra Lesly Barzola Velásquez con DNI 73984793 y Arturo Hamilton Urquizo Gómez con DNI 48007044, ambos con el grado de Bachiller del Programa Académico de la Carrera de Ingeniería Industrial y Comercial de la Facultad de Ingeniería de la Universidad San Ignacio de Loyola, presentamos la tesis titulada:

"Impacto de la población migrante venezolana en Lima Norte en la demanda de nuevos productos de consumo masivo"

Declaramos en honor a la verdad, que el trabajo de tesis es de nuestra autoría; que los datos, los resultados y su análisis e interpretación, constituyen nuestro aporte. Todas las referencias han sido debidamente consultadas y reconocidas en la investigación.

En tal sentido, asumimos la responsabilidad que corresponda ante cualquier falsedad u ocultamiento de la información aportada. Por todas las afirmaciones ratificamos lo expresado, a través de nuestras firmas correspondientes.

Lima, Febrero de 2021.

Yajayra L. Barzola Velásquez

DNI 73984793
Arturo H. Urquizo Gómez

DNI 48007044 


\section{EPÍGRAFE}

"El éxito consiste en obtener lo que se desea. La felicidad, en disfrutar lo que se obtiene".

(Emerson, 1841) 


\section{ÍNDICE DE CONTENIDOS}

$\begin{array}{ll}\text { DEDICATORIA } & 14\end{array}$

$\begin{array}{ll}\text { AGRADECIMIENTOS } & 15\end{array}$

$\begin{array}{ll}\text { RESUMEN } & 16\end{array}$

$\begin{array}{ll}\text { ABSTRACT } & 17\end{array}$

$\begin{array}{ll}\text { INTRODUCCIÓN } & 18\end{array}$

PROBLEMA DE INVESTIGACIÓN 20

$\begin{array}{ll}\text { Identificación del problema } & 20\end{array}$

Formulación del problema $\quad 21$

MARCO REFERENCIAL 22

$\begin{array}{ll}\text { Antecedentes } & 22\end{array}$

$\begin{array}{ll}\text { Estado del arte } & 30\end{array}$

$\begin{array}{ll}\text { Marco teórico } & 45\end{array}$

$\begin{array}{ll}\text { Migración } & 45\end{array}$

$\begin{array}{ll}\text { Oferta } & 46\end{array}$

$\begin{array}{ll}\text { Demanda } & 46\end{array}$

$\begin{array}{ll}\text { Productos masivos } & 46\end{array}$

$\begin{array}{ll}\text { Shopper } & 47\end{array}$

$\begin{array}{lr}\text { Canasta básica } & 47\end{array}$

$\begin{array}{ll}\text { Canal tradicional } & 53\end{array}$

$\begin{array}{ll}\text { Canal Moderno } & 53\end{array}$

Los Estilos de Vida (EdV) 53

$\begin{array}{ll}\text { PEST } & 62\end{array}$

IBM SPSS Statistics 62

$\begin{array}{ll}\text { Pronóstico } & 62\end{array}$

$\begin{array}{ll}\text { Pronóstico con promedio móvil ponderado } & 63\end{array}$ 
Pronóstico con suavizamiento exponencial simple

Pronóstico con el modelo Holt

Pronóstico con aditivo de Winters

Error porcentual absoluto medio

Prueba de normalidad de Shapiro-Wilk

Coeficiente de correlación de Spearman

OBJETIVOS

Objetivo General

Objetivos Específicos

JUSTIFICACIÓN

Teórica

Práctica

Social

HIPÓTESIS

Hipótesis General

Hipótesis Específicas

Alcance

Limitaciones

MATRIZ DE CONSISTENCIA

MARCO METODOLÓGICO

Paradigma

Enfoque

Método

VARIABLES

Variable Independiente 75

Variable Dependiente 
$\begin{array}{ll}\text { UNIDAD DE ANÁLISIS } & 79\end{array}$

INSTRUMENTOS Y TÉCNICAS $\quad 80$

$\begin{array}{lr}\text { Instrumentos } & 80\end{array}$

$\begin{array}{ll}\text { Técnicas } & 83\end{array}$

PROCEDIMIENTO Y MÉTODO DE ANÁLISIS

$\begin{array}{ll}\text { Procedimiento } & 85\end{array}$

Método de análisis $\quad 85$

$\begin{array}{ll}\text { RESULTADOS } & 86\end{array}$

CONTRASTACIÓN DE HIPÓTESIS

DISCUSIÓN

$\begin{array}{ll}\text { CONCLUSIONES } & 151\end{array}$

$\begin{array}{ll}\text { RECOMENDACIONES } & 153\end{array}$

$\begin{array}{ll}\text { REFERENCIAS } & 154\end{array}$

$\begin{array}{lr}\text { ANEXOS } & 159\end{array}$ 


\section{ÍNDICE DE TABLAS}

Tabla 1: Productos venezolanos que ya se venden en Perú 34

Tabla 2: Análisis del estado de arte 43

Tabla 3: Consumo per cápita de los principales alimentos 2009

Tabla 4: Matriz de consistencia $\quad 72$

Tabla 5: Variable independiente $\quad 75$

Tabla 6: Variable dependiente $\quad 76$

Tabla 7: Grupo Etario - población venezolana 77

Tabla 8: Zonas de residencia - migrantes venezolanos $\quad 78$

Tabla 9: Muestreo estratificado $\quad 79$

Tabla 10: Alfa de Cronbach $\quad 82$

Tabla 11: Registro de expertos en la validación del instrumento 83

Tabla 12: Sexo 86

Tabla 13: Estado civil $\quad 86$

Tabla 14: Edad $\quad 87$

Tabla 15: Grado de instrucción $\quad 88$

Tabla 16: En el Perú, ¿con quién está viviendo? $\quad 89$

Tabla 17: Año de residencia en el Perú 90

Tabla 18: Razones de migración al Perú $\quad 92$

Tabla 19: Personas que influenciaron en la decisión de migrar al Perú 93

Tabla 20: Ocupación principal $\quad 94$

Tabla 21: Situación actual del migrante venezolano 95

Tabla 22: Opciones de migrar a causa de Covid-19 96

Tabla 23: Salario mensual de inmigrantes venezolanos 97

Tabla 24: Monto mensual enviado en remesas a Venezuela 98

Tabla 25: Canales de compra $\quad 99$

Tabla 26: Alimentos $\quad 100$

Tabla 27: Productos con mayor volumen debido al confinamiento Covid-19 101

Tabla 28: Productos con menor volumen debido al confinamiento Covid-19 102

Tabla 29: Variables valoradas en la elección del canal de compra 103

Tabla 30: Frecuencia de adquisición de alimentos 104 
Tabla 31: Frecuencias de presupuesto mensual para gastos de alimentación 105

Tabla 32: Grado de reconocimiento de marcas 107

Tabla 33: Marcas venezolanas más extrañadas $\quad 108$

Tabla 34: Aceptación de nuevo producto 109

Tabla 35: Paquetes de harina de consumo en el hogar $\quad 110$

Tabla 36: Marca favorita de harina de maíz 111

Tabla 37: Disponibilidad de la harina de maíz en el punto de venta 112

Tabla 38: PET, PEA ocupada de migrantes venezolanos 2020

Tabla 39: Recaudación fiscal de IGV de inmigración venezolana en $2020 \quad 115$

Tabla 40: Recaudación fiscal de IR de inmigración venezolana en $2020 \quad 116$

Tabla 41: Gasto fiscal en educación pública de inmigración venezolana en 2020119

Tabla 42: Gasto fiscal en salud pública de inmigración venezolana en $2020 \quad 121$

Tabla 43: Procesamiento de datos P4 vs P5 133

Tabla 44: Ocupación principal vs situación actual 133

Tabla 45: Procesamiento de datos P7 vs P13 135

Tabla 46: Importaciones de harina de maíz en Tm en Perú 137

Tabla 47: Pronóstico con promedio móvil ponderado 139

Tabla 48: Pronóstico con el suavizamiento exponencial simple 140

Tabla 49: Pronóstico con el modelo Holt 141

Tabla 50: Venezolanos en Perú vs harina importada de maíz 143

Tabla 51: Prueba de normalidad $\quad 144$

Tabla 52: Correlación de coeficiente de Spearman 144

Tabla 53: Marcas venezolanas más extrañadas $\quad 145$

Tabla 54: Aceptación de nuevo producto 146 


\section{ÍNDICE DE FIGURAS}

Figura 1. Proyección de venezolanos 2019-2025 32

Figura 2. Estados provenientes de los migrantes venezolanos 32

Figura 3. Venezolanos en Perú 2017-2019 33

Figura 4. Ranking categorías con mayor crecimiento/caída 35

Figura 5. Ingreso Neto mensual de venezolanos a Perú 2018-2019 36

Figura 6. Inmigrantes venezolanos en el Perú 37

Figura 7. Mapa de impactos fiscales 38

Figura 8. Recaudación fiscal por IGV de inmigrantes venezolanos. 39

Figura 9. Recaudación fiscal por Impuesto a la Renta de inmigrantes venezolanos 39

Figura 10. Gasto fiscal por educación pública de inmigrantes venezolanos $\quad 40$

Figura 11. Gasto fiscal por salud pública en inmigrantes venezolanos. 41

Figura 12. Impacto fiscal de la población migrante venezolana a Perú. 42

Figura 13. Canasta básica de alimentos. 48

Figura 14. Productos de la canasta básica familiar. 49

Figura 15. Top 5 marcas por sectores Perú $\quad 52$

Figura 16. Sexo en encuestados 86

Figura 17. Estado civil $\quad 87$

Figura 18. Edad $\quad 88$

Figura 19. Grado de instrucción $\quad 89$

Figura 20. Personas con quienes viven 90

Figura 21. Año de residencia en Perú 91

Figura 22. Las razones de migración de venezolanos 92

Figura 23. La influencia de migrar al Perú 93

Figura 24. Ocupación principal $\quad 94$

Figura 25. Situación actual de los migrantes en coyuntura Covid-19 96

Figura 26. Opciones de migrar a causa de Covid-19 97

Figura 27. Salario de inmigrantes venezolanos 98

Figura 28. Monto mensual de remesas enviadas 99

Figura 29. Lugares donde se adquiere los alimentos para el hogar 100

Figura 30. Alimentos con mayor volumen de compra durante el confinamiento 102 
Figura 31. Alimentos con menor volumen de compra durante el confinamiento por Covid-19

Figura 32. Variables valoradas cuando se selecciona el canal de compra $\quad 104$

Figura 33. Frecuencia de compra de alimentos para el hogar 105

Figura 34. Presupuesto mensual para gastos de alimentación 106

Figura 35. Grado de reconocimiento de marca 107

Figura 36. Marcas de productos venezolanos 108

Figura 37. Aceptación de inserción al mercado peruano de la marca venezolana extrañada

Figura 38. Cantidad de harina de maíz consumida en el hogar $\quad 110$

Figura 39. Marca favorita de harina de maíz 111

Figura 40. Disponibilidad de harina de maíz en el punto de venta 112

Figura 41. Detalle de impactos fiscales 113

Figura 42. Fórmula para la recaudación fiscal en IGV 114

Figura 43. Fórmula para la recaudación fiscal en IR 116

Figura 44. Fórmula para el cálculo de gasto fiscal en educación pública 117

Figura 45. Número estimado de población en edad escolar 118

Figura 46. Asistencia a algún centro educativo de población venezolana $\quad 119$

Figura 47. Fórmula planteada para el gasto fiscal en salud pública 120

Figura 48. Población venezolana asegurada por fuente de aseguramiento. $\quad 120$

Figura 49. Impacto fiscal de inmigración venezolana en 2020

Figura 50. Impacto fiscal estimado 2018-2020 122

Figura 51. Razones de migración al Perú $\quad 124$

Figura 52. Gráfica de PEST aplicado al país durante el 2018

Figura 53. Canales de compra para los alimentos 126

Figura 54. Alimentos básicos para la dieta de los migrantes venezolanos 127

Figura 55. Alimentos con mayor volumen de compra durante el confinamiento 128

Figura 56. Alimentos con menor volumen de compra durante el confinamiento Covid19

Figura 57. Variables valoradas para elegir el canal de compra 130

Figura 58. Presupuesto mensual destinado a gastos de alimentos $\quad 130$

Figura 60. Paquetes de harina de maíz consumidos al mes en el hogar 131

Figura 61. Marca favorita de harina de maíz 132 
Figura 62. Disponibilidad de harina de maíz en el punto de venta

Figura 63. Ocupación principal vs situación actual

Figura 64. Salario básico vs variables de compra en el tiempo de Covid-19 136

Figura 65. Histórico de importaciones de harina de maíz en Perú

Figura 66. Importaciones de harina de maíz en los últimos 3 años en Perú

Figura 68. Marcas de productos venezolanos

Figura 67. Potencial aceptación de inserción de la marca venezolana extrañada 147 


\section{ÍNDICE DE ANEXOS}

Anexo A: Requisitos para tramitar el PTP en Perú 159

Anexo B: Encuesta 160

Anexo C: Formato de validación de instrumento por el primer experto 170

Anexo D: Formato de validación de instrumento por el segundo experto 173 


\section{DEDICATORIA}

A mis abuelos Fortunato y Paulina por haberme forjado como la persona que soy en la actualidad, a mis padres Eulogio y Lucila por haber siempre confiado en mí.

A mis tíos Juan y Germán por haber tenido el papel de Méntor tal cual epopeya cuando Ulises deja a su hijo Telémaco.

Por último, a mi fiel perro Spock quien me acompañó largas horas de trabajo.

Hago mención a la frase apócrifa del Quijote para que perdure durante mis años de vida profesional.

"Sancho, si los perros ladran es señal de que avanzamos".

Arturo Urquizo Gómez

A Dios por haberme dado tantas alegrías que jamás me las había imaginado y por las fuerzas para luchar por lo que quiero.

A mis queridos padres quienes siempre me dieron su apoyo incondicional y los valores de lo que soy como persona. También a mis hermanos por estar presente en los mejores momentos de mi vida.

A mis abuelitos que desde el cielo me han permitido ser parte de su orgullo.

$Y$ para finalizar a mis adoradas mascotas por todos esos días de invierno por permanecer largas horas conmigo sin importar la circunstancia.

Lesly Barzola Velásquez 


\section{AGRADECIMIENTOS}

Nuestro agradecimiento a Dios por habernos permitido llegar hasta este momento de nuestras vidas, por darnos salud durante la pandemia Covid19 que afecta al mundo y de habernos otorgado el gran privilegio de dejar huella.

A la universidad San Ignacio de Loyola, nuestra alma mater, la cual abre las puertas a jóvenes como nosotros a quienes prepara para un futuro competitivo y nos enseña a no abandonar nuestros sueños.

A la Dra. Yvone Cruz Castañeda, por su orientación en el desarrollo de nuestro plan de tesis, quien creyó en nuestras ideas y nos guio con sus sabios consejos. A nuestro asesor Miguel Medina Millán, con quien compartimos largas horas de debate durante el confinamiento con una nueva modalidad de asesoramiento virtual, el cual se realizó con las herramientas tecnológicas de nuestra universidad.

Sencillo no ha sido el proceso, pero gracias a cada una de las personas que compartieron y aportaron sus ideas para alcanzar un objetivo muy importante en el desarrollo de nuestras vidas. 


\section{RESUMEN}

La tesis se ha elaborado con el fin de dar a conocer cómo impacta la migración venezolana en el canal tradicional de ventas para Lima Norte con la inserción de nuevos productos y la demanda interna.

Este estudio usa el método explicativo y correlacional. A través del análisis se identificaron diferentes causas que originaron la migración hacia el Perú, siendo las principales la falta de alimentos y medicina.

Los datos obtenidos demuestran que los migrantes venezolanos se adaptaron rápidamente a los productos ofrecidos en el mercado nacional, tales como el consumo de arroz, pollo, vegetales, entre otros, pero destaca la harina de maíz cuya marca más preferida es P.A.N. Se demuestra que el crecimiento de importaciones de ese producto se da a partir del mes de marzo del año 2018 y que está relacionado directamente con el flujo migratorio.

Mencionado producto ya se encuentra dentro de la cartera de ventas en el mercado tradicional de Lima Norte, los datos obtenidos indican que actualmente los migrantes prefieren realizar sus compras en mercados y bodegas. También se obtuvo información valiosa del potencial para el ingreso de productos como Maltín Polar y Diablitos.

Permitió concluir que la migración venezolana (860 mil aproximadamente, equivalente al $2.7 \%$ de la población peruana) puede beneficiar al Perú al dinamizar la economía local, incrementar el consumo interno con las nuevas marcas.

Palabras claves: Migración, demanda, pronóstico, canal tradicional, ventas. 


\begin{abstract}
The thesis has been prepared in order to make known how Venezuelan migration affects the traditional sales channel for North Lima with the insertion of new products and internal demand.
\end{abstract}

This study uses the explanatory and correlational method. Through the analysis carried out, it was possible to identify different causes that originated migration to Peru, the main ones being the lack of food and medicine.

We verify that Venezuelan migrants quickly adapted to the products offered in the national market, such as the consumption of rice, chicken, vegetables, among others, but highlights a product little consumed before 2017 for Peru, which is corn flour whose most preferred brand is P.A.N. It is shown that the growth of imports of that product occurs since March of the year 2018 and that it is directly related to the migratory flow.

The mentioned product is within the sales portfolio in the traditional market of North Lima, the indicated data that migrants currently prefer to make their purchases in neighborhood markets and mom-and-pop stores where they usually find corn flour at the point of sale. Obtaining valuable information on the potential for the entry of products is also obtained, such as Maltin Polar and Diablitos.

We conclude that Venezuelan migration (approximately 860 thousand, equivalent to $2.7 \%$ of the Peruvian population) can benefit Peru by boosting the local economy, increasing domestic consumption with the new brands.

Keywords: Migration, demand, forecast, traditional channel, sales. 


\section{INTRODUCCIÓN}

Las últimas tendencias en migración internacional dada por la ONU (2019) señalan que la cifra oscila en 272 millones de personas al 2019. A pesar de que el número de migrantes en todo el mundo representan un porcentaje pequeño respecto a la población total, hubo un aumento del $2.8 \%$ en 2000 al $3.5 \%$ en 2019.

Además de países como España, Italia o Estados Unidos, la emigración sudamericana tiene el elemento interregional, siendo Argentina y Brasil quienes más emigrantes han recibido de sus países vecinos de acuerdo con el anuario de migración y remesas 2019 de BBVA Research.

Algo nunca visto se dio en Sudamérica, especialmente en Venezuela, donde se da una migración masiva para países de la región, tales como Colombia, Perú, Brasil, Ecuador y Chile, entre otros. Esto se debe a la aguda crisis económica y social de Venezuela, debido al gran bloqueo económico generado por Estados Unidos y apoyado por los países sudamericanos.

La migración venezolana sería la ola migratoria más importante del siglo XXI para el Perú al albergar la mayor cantidad de venezolanos inmigrantes después de Colombia. El $86.6 \%$ de los migrantes venezolanos se concentran en Lima y Callao.

El presente estudio de investigación se ha llevado a cabo para analizar el impacto de la migración venezolana en el canal tradicional de ventas dentro de Lima Norte a través de la inclusión de nuevos productos típicos del perfil de consumidor venezolano y la demanda interna.

Esta investigación iniciará con detallar la problemática de la investigación, su identificación y formulación.

Posteriormente, se establece el marco referencial y estado del arte donde se explicará la evolución de los aportes en cuanto a migración venezolana, así como el marco teórico los 
cuales fundamentas y avalan nuestra tesis. De la misma manera se ha establecido los objetivos e hipótesis, los cuales están estrechamente relacionados.

Asimismo, este trabajo de investigación estará delimitado a los migrantes que residen en Lima Norte.

Consecutivamente, se hizo el levantamiento y procesamiento de datos para obtener los resultados finales que dan como resultado el impacto positivo de la migración venezolana en el canal tradicional. Por último, se presenta las conclusiones y recomendaciones obtenidas en el desarrollo de la presente tesis. 


\section{PROBLEMA DE INVESTIGACIÓN}

\section{Identificación del problema}

Perú ha sido el segundo país que más emigrantes venezolanos ha recibido. Hay más de 800 mil de ellos en Perú, con un influjo anual que alcanzó su pico en 2018. La mayor parte de estos inmigrantes venezolanos se concentra en Lima. Esto conlleva a una contribución en la demanda agregada, es decir, el total de bienes y servicios demandados por el país y modificando la oferta de factores productivos en la economía peruana (BBVA Research, 2019).

La incorporación de los migrantes venezolanos al mercado laboral peruano no se ha dado en las mejores condiciones. Esto se refleja en los indicadores de informalidad que es muy elevada. Tan solo alrededor de 30000 venezolanos se encontraban en el sector formal para el 2019 pues gran parte de los inmigrantes no cuenta con permiso legal para trabajar y no ha convalidado sus estudios (BBC, 2019).

En un periodo bastante corto, los migrantes venezolanos en edad de trabajar han inyectado alrededor de un $2.5 \%$ adicional en la PEA al Perú el cual es un crecimiento sustancial. Lima y Callao albergan más del $80 \%$ de los migrantes venezolanos, quienes harán uso de servicios de transporte público, salud, educación, vivienda, entre otros. Cabe mencionar que el estado peruano tiene un déficit al brindar estos servicios a sus propios ciudadanos (Reátegui, 2019).

Ante la llegada de una migración masiva venezolana hacia el Perú, el país empieza a tener un flujo muy amplio de nuevos habitantes los cuales arriban a nuestro país en busca de satisfacer sus necesidades básicas. Por tal motivo se crea una necesidad por parte de los migrantes de buscar empleo y vivienda mayormente en Lima Metropolitana y principales ciudades del resto del país. Gracias a este nuevo flujo migratorio aparecen en la ciudad de Lima nuevas costumbres traídas por los ciudadanos venezolanos. Estas nuevas costumbres traen consigo cambios que se empiezan a ver de manera progresiva en el país. 
Para ello se analiza cómo influye una migración en la oferta de productos de consumo masivo ofrecidos en bodegas y mercados, la cual tiene mayor proximidad con el consumidor y shopper. Por tal razón el mercado interno se ve comprometido con esta migración, por lo que empieza a sufrir una serie de variaciones de productos y servicios. El presente estudio se centrará en los productos de consumo masivo que satisfagan sus necesidades, mas no la adquisición de servicios por parte de los migrantes.

Ante esta problemática se busca analizar esta situación al mostrar el impacto y cómo repercute en el canal tradicional de bodegas y mercados en el mix de productos ofrecidos, las conclusiones que se brindarán sentarán la base a posibles nuevas industrias y mercados, sobre todo a un nuevo perfil de consumidor extranjero que reside en el país.

\section{Formulación del problema}

\section{Problema general}

¿Cuál es el impacto de la población migrante venezolana en la demanda de nuevos productos de consumo masivo dentro de Lima Norte?

\section{Problemas específicos}

¿Cuáles son los factores que motivaron a la población migrante venezolana en Lima Norte a elegir al Perú?

¿Cuáles son las diferencias de consumo entre peruanos y migrantes venezolanos?

¿Cuál es la nueva tendencia de productos demandados por la población migrante venezolana en Lima Norte en el canal tradicional?

¿Cuáles son las marcas de productos de consumo masivo que tienen potencial aceptación por los migrantes venezolanos? 


\section{MARCO REFERENCIAL}

\section{Antecedentes}

El plan de negocios para la implementación de una cadena de food trucks de comida fusión peruano - venezolana en la ciudad de Lima fue desarrollado por Araujo, Del Castillo, Flores, Reátegui \& Poma.

Objetivo: Realizar una investigación de mercado para conocer la viabilidad de un negocio de comida fusión peruana - venezolana, los atributos valorados por ellos y definir un plan estratégico para poner en marcha el negocio.

Herramientas: Análisis cualitativo y cuantitativo de estudio de mercado, análisis SEPTE, Fuerzas de Porter, modelo Canvas, cadena de valor, diagrama de bloques de proceso, análisis de punto crítico y análisis de sensibilidad.

Conclusión: La investigación desarrollada indica que la idea de negocio sí es viable económicamente con un costo de oportunidad del capital de $25 \%$, un VAN de 488,600 PEN y un TIR de $41 \%$ y tendría gran acogida en el mercado, pero su principal desventaja es la regulación que tiene los food trucks en distintos distritos de Lima moderna. Además, se indica que gracias a la migración venezolana la arepa cuyo ingrediente principal es la harina de maíz se hace cada vez más conocido dentro del país, poniendo énfasis en la marca de Harina P.A.N la cual es la más consumida, preferida y usada para la elaboración de estos productos debido a su textura y sabor. En el plan de negocios resaltan el uso de harina de maíz en el mix de productos ofrecidos que tienen rellenos tradicionales del Perú y de Venezuela (Araujo García, Del Castillo Rodríguez, Reátegui del Aguila, \& Poma Marroquín, 2017).

Blouin, Hurtado, Jave Pinado, Vargas Canales \& Jáuregui. (2019). Su investigación realizada es "Estudio sobre el perfil socio económico de la población venezolana y sus comunidades de acogida: una mirada hacia la inclusión". 
Objetivo: Se busca indagar los factores de la población migrante venezolana en el país y examinar el proceso de inserción de los migrantes venezolanos con un enfoque en 9 distritos de la capital conformados por Comas, San Martín de Porres, Independencia, Los Olivos, La Victoria, Cercado de Lima, Chorrillos, San Juan de Miraflores y San Juan Lurigancho en cuanto a las variables de trabajo, vivienda, salud y educación.

Herramientas: Análisis cuantitativo y cualitativo. Por el enfoque cuantitativo, se realizó 400 encuestas a migrantes, 250 encuestas a peruanos y 8 entrevistas semiestructuradas a organizaciones relacionadas al tema de la migración venezolana. En cuanto al enfoque cualitativo, se recogió las experiencias y percepciones cotidianas de los migrantes.

Conclusión: Una de las más interesantes conclusiones es que los ciudadanos venezolanos residen en las periferias de Lima por temas de cercanía y costos. Se encontró que las personas suelen vivir en cuartos compartidos en condiciones precarias y que en su mayoría laboran en el sector informal o ambulante, con jornadas extensas de trabajos y sueldo por debajo del mínimo establecido por el gobierno peruano. Se determina que en su mayoría son una población joven y en edad laboral. También da a conocer que los ciudadanos venezolanos tienen dificultades debido a vacíos en las políticas migratorias en temas de educación, trabajo, vivienda y salud en el Perú, lo cual dificulta su adaptación en la ciudad y son considerados una población altamente vulnerable debido a que alrededor del $40 \%$ de la migración es del sexo femenino. Todos estos factores afectan a la inclusión de la población venezolana al Perú (Blouin, Hurtado, Jave Pinedo, Vargas Canales, \& Jáuregui, 2019).

Tomás Castillo Castro y Mercedes Reguant Alvarez, 2017, docentes de la Universidad Pontificia Comillas ubicada en Madrid, España, presentaron el siguiente artículo: "Percepciones sobre la migración venezolana: causas, España como destino, expectativas de retorno" (Castillo Castro \& Reguant Álvarez, 2017).

Objetivo: Analizar la migración venezolana hacia España y dar a conocer las principales causas que obligan a un ciudadano venezolano salir de su país. 
Herramientas: Estudio exploratorio de orientación cualitativa hecho a través de un análisis bibliográfico de fuentes secundarias: publicaciones, artículos de revista, libros, para entender y profundizar el proceso migratorio venezolano y la situación socioeconómica en Venezuela.

Conclusión: Corroborar que la principal causa es la inseguridad personal y jurídica los cuales son los factores por las que gran porcentaje de la población joven de Venezuela busque otros países para poder vivir con dignidad. Detallan que tan nefasta es la situación económica y la escasez de productos básicos. Por lo que se indica que los venezolanos que escogen España como país de refugio lo hacen por distintos factores tales como proximidad idiomática, cercanía cultural y estatus legales. También indican que los venezolanos que residen en España ven que retornar a su país en el corto plazo es una posibilidad remota.

Human Rights Watch, 2016, es una organización internacional con representantes en más de 40 países, impreso en Estados Unidos, presentaron el siguiente estudio: "Crisis humanitaria en Venezuela La inadecuada y represiva respuesta del gobierno ante la grave escasez de medicinas, insumos y alimentos" (Human Rights Watch, 2016).

Objetivo: Dar a conocer factores como la escasez de medicamentos e insumos médicos en diferentes hospitales de Venezuela y en muchas farmacias los medicamentos estaban agotadas o tenían precio muy excesivo, debido a esto Venezuela sufre un aumento de la tasa de mortalidad infantil y materna.

Herramientas: La realización de más de 100 entrevistas a profesionales de atención de la salud, pacientes con distintas enfermedades, personas que hacían fila para comprar artículos sujetos a precios máximos fijados por el gobierno, miembros de diferentes comunidades, ex detenidos y defensores de derechos humanos.

Conclusión: El gobierno de Venezuela decreta iniciativas para poder afrontar la escasez, una de las iniciativas es la producción local de medicamentos e insumos básicos, pero hasta el momento las iniciativas no lograron aliviar la escasez. Otro punto importante del estudio son las respuestas del gobierno hacia los críticos, debido a que una gran mayoría de médicos en Venezuela se quejaba abiertamente sobre la escasez. El gobierno los amenazaba 
con destituirlos de sus puestos y abrirles investigaciones por actos políticos de desestabilización. En el estudio también nos explica sobre las grandes dificultades para la compra de alimentos subsidiados en centros comerciales con los precios máximos fijados por el gobierno como arroz, pasta y la harina. Los productos de higiene personal como pañales, dentífrico y papel higiénico estaban estrictamente racionados. Por lo que cada día era más difícil de encontrarlos.

Jose Koechlin y Joaquin Eguren, 2018, editores de la Universidad Antonio Ruiz de Montoya, ubicada en Lima, Peru, con apoyo de Konrad Adenauer Stiftung, la Organización Internacional para las Migraciones, Observatorio Iberoamericano sobre Movilidad Humana, Migraciones y Desarrollo, presentaron el siguiente libro: "El éxodo venezolano: entre el exilio y la emigración" (Koechlin \& Eguren, 2018).

Objetivo: Detallar el acontecimiento de la migración venezolana al Perú como perfiles de migrantes, razones de migración y busca de oportunidades.

Herramientas: Estudio exploratorio de orientación cualitativa hecho a través de un análisis bibliográfico de fuentes primarias y secundarias. Con estudios ya realizados por la ONU, Banco Mundial, entre otros.

Conclusión: La República del Perú jamás tuvo un flujo tan alto de migrantes. El estado brindó condiciones migratorias a los venezolanos en un primer momento tales como el PTP y estatus de refugiados. Para el año 2017 se calcularon cuatro olas de migración venezolanas de las cuales cada ola tiene distintos perfiles de migrantes. Dan a conocer que muchos venezolanos prefieren venir al Perú porque consideran que el costo de vida es más económico a comparación de otros países, en otros casos llegan al país por tener familiares o amigos. También se dio el caso de muchos migrantes que tenían como destinos países como Chile o Argentina, pero se quedaron en el Perú por falta de recursos. El estudio indica que los venezolanos salen del país por razones económicas, falta de alimentos, inseguridad y violencia, falta de trabajo. Otro punto importante es la condición de trabajo del emigrante venezolano, que llega al Perú y se auto emplean a través de trabajos informales impulsados por ellos mismos. Así como otro grupo pequeño quienes generan su empresa formal, desarrollando su profesión o trabajando en algo ajeno a lo que estudiaron. 
Maritza Landaeta-Jiménez, Marianella Herrera Cuenca, Guillermo Ramírez y Maura Vásquez, 2018, investigadores de la Fundación Bengoa, ubicada en Caracas, Venezuela, con apoyo coordinado por la Universidad Católica Andrés Bello en conjunto con la Universidad Central de Venezuela, Universidad Simón Bolívar, presentaron el siguiente artículo: "Las precarias condiciones de alimentación de los venezolanos: Encuesta Nacional de Condiciones de Vida 2017" (Landaeta-Jiménez, Herrera Cuenca, Ramírez, \& Vásquez, 2018).

Objetivo: Dibujar una radiografía del tipo de alimentación de los niveles de inseguridad alimentaria y de los hábitos alimentarios de los venezolanos, todo ello ambientado en el marco de una crisis social y económica sin precedentes.

Herramientas: El uso de encuestas con un tamaño de la muestra total de 6.168 hogares, el muestreo fue no probabilístico y por cuotas, restringido en dos etapas, en ciudades grandes, medianas, pequeñas y caseríos. Abarca la totalidad de la población residente en el país, se excluye población indígena, las dependencias, hogares colectivos y población en localidades con menos de 10 viviendas. La encuesta fue levantada entre los meses de julio a septiembre de 2017.

Conclusión: La composición de la canasta básica semanal de alimentos revela que un $78.8 \%$ de estos hogares adquiere arroz y sus derivados, ocupando el primer lugar. Con una cifra muy cercana se ubica el patrón de compra de la harina de maíz con un 73.6 \% en los hogares como segundo lugar. En tercer lugar, figura la preferencia del pan, harina de trigo y sus derivados con $73.2 \%$. Esta vez sería el primer año que el maíz no aparece en el primer lugar de la lista de compra de la canasta básica de los venezolanos. Existen 2 principales motivos que sustentan esta situación: la significativa reducción de la actividad agrícola en el país vs la demanda nacional del producto y la comercialización del maíz y sus derivados a precios inalcanzables para la población.

Carlos David Rojas Mora, César Antoni Monterroso Coronado, 2019, estudiantes de la Universidad Católica Sedes Sapientiae Perú, ubicada en Lima, Perú, con apoyo informativo Fundación Koinonia, presentaron el siguiente estudio: "Perfil de Competencias Profesionales de la Población Inmigrante Venezolana al Perú 2017-2018” (Rojas Mora \& Monterroso Coronado, 2019). 
Objetivo: Dar a conocer los cinco tipos de diáspora reconocidos por el autor, dos de ellas se orientan desde criterios eminentemente económicos, como es el caso de las diásporas de trabajo y de comercio.

Herramientas: Se planteó el desarrollo de una investigación de tipo descriptiva, de corte transversal, a través de la aplicación de un instrumento tipo cuestionario bajo un muestreo no probabilístico que incluyó 727 inmigrantes venezolanos llegados al Perú, entre los años 2017 y 2018. El vaciado de los datos de las encuestas se hizo a través del programa de computación Excel, en hojas de cálculo. El procesamiento de estos se hizo con la utilización del programa estadístico Stata en su Versión 13 y SPSS.

Conclusión: La diáspora venezolana planteada tiene enfoque en el mediano y largo plazo, que incluye la reunificación familiar en Perú. La mayor parte de los inmigrantes tienen la meta de traer a sus familiares al país. Por ello, el Perú tiene el potencial del aprovechamiento de los inmigrantes traducida en demanda de bienes y servicios ante un factor coyuntural en materia de crecimiento económico. La encuesta reveló datos demográficos, el $62.48 \%$ eran hombres y el $37.52 \%$ mujeres. En cuanto al rango de edades, el $24.15 \%$ de los venezolanos tenían edades inferiores a 25 años, el 39,97\% se encontraba entre los 25 y 35 años, el 21,75\% tenía entre 35 y 45 años, el 9,18\% se encontraba entre 45 y 55 años y el resto tenía más de 55 años. Con relación a los perfiles profesionales de la población inmigrante, el $35.98 \%$ de los venezolanos tenía estudios universitarios completos, $13.95 \%$ poseen títulos de Técnico Superior Universitario y un $7.53 \%$ tenía estudios de postgrados finalizados.

Zinnia Martínez, 2015, periodista especializada en gastronomía del Instituto de Estudios Superiores de Administración, ubicada en Caracas, Venezuela, presentó el siguiente artículo: "PANORÁMICA DE LA COCINA CALLEJERA VENEZOLANA" (Martínez, 2015).

Objetivo: Detallar como es la comida callejera de Caracas. 
Herramientas: Estudio exploratorio de orientación cualitativa con el uso de referencias bibliográficas y trabajo de investigación periodística con galería fotográfica y entrevistas a profundidad de los vendedores y consumidores.

Conclusión: Los productos clave que se usan en la preparación de los platillos son Harina PAN, aceite de pollo, azúcar, harina de trigo y leche. La venta está conformada por puestos de cachapas, arepas, perros calientes, dulces, jugo de naranja, chicha, hamburguesas y otros. Si la zona es densa que incluye trabajadores y oficinistas, el menú puede incluir shawarmas y almuerzos en envase aluminio, Sin embargo, la comida más demanda en este sector es el perro caliente.

Instituto Nacional de Estadística e Informática, 2012, preparado por la Dirección Técnica de Demografía e Indicadores Sociales: "Perú: Consumo per cápita de los principales alimentos 2008-2009" (INEI, 2012).

Objetivo: Dar a conocer los resultados de la Encuesta nacional de presupuestos familiares (ENAPREF).

Herramientas: Investigación de tipo descriptiva con una encuesta diseñada para inferir resultados a nivel nacional, área urbana, rural, regiones naturales, Lima Metropolitana y 25 ciudades capitales departamentales. Análisis de datos cuantitativos para expresar resultados basados en datos reales.

Conclusión: El consumo per cápita de alimentos en los peruanos muestra al arroz como el más preferido con 56 kilos 800 gramos al año, seguido de la gaseosa con 38 litros 300 mililitros. Con un tercer lugar está la azúcar refinada con 23 kilos y, en cuarto lugar, los fideos con 13 kilos 300 gramos. Si la persona tiene acceso a servicios básicos como el agua, se observa que el hogar consume más kilos de arroz con 48 kilos 400 gramos, seguido por la bebida gaseosa, pan, azúcar refinada, pollo, cebolla y leche evaporada. Por otro lado, el hogar que no tiene acceso al agua por red pública, el mayor consumo está en la papa con 86 kilos 700 gramos, seguida por el plátano con 35 kilos 200 gramos y los fideos con 12 kilos 700 gramos por año. 
La Cámara de Comercio de Lima (CCL) elaboró el informe de importaciones de harina de maíz de enero a julio 2019.

Objetivo: Analizar el histórico de importaciones de harina de país en los primeros 7 meses de 2019 en cuanto a volúmenes de compra y valor CIF.

Herramientas: MS-SQL de datos del área de Inteligencia Comercial.

Conclusión: Las importaciones de harina de maíz en Perú alcanzaron una cifra récord entre enero y julio de dicho año al registrar US\$ 7,2 millones, lo que significa un crecimiento más de cuatro veces de los valores registrados en comparación al año pasado (US\$1.6 millones en harina de maíz) e inclusive muchísimo mayor si se compara con toda la importación del 2018 por dicho producto (US $\$ 4.8$ millones en harina de maíz). Se señala que el incremento en las importaciones de maíz es resultado del aumento de demanda tras la migración venezolana a nuestro país, quienes traen su cultura en cuanto a platillos. La CCL indica que el principal país que abastece al Perú de harina de maíz es Colombia, de donde se importa el $85 \%$ del total importado del mundo, seguido por Estados Unidos (7\%), México (5\%) y Costa Rica 1\%. Las marcas más demandadas son: P.A.N, Arepasan, La Nieve, Del Sol y Maseca (CCL, 2019). 


\section{Estado del arte}

Koechlin, J., Vega, E., \& Solórzano (2018), junto con el apoyo de la Universidad Antonio Ruiz de Montoya realizaron un estudio que se titula "Migración venezolana al Perú: proyectos migratorios y respuesta del Estado", publicado en diciembre del 2018, donde el estudio realizado tiene como objetivo de investigación describir el contexto venezolano como una variable que promueve la migración, conocer las causas de la migración y describir el perfil del migrante venezolano identificar el proyecto migratorio que buscan implementar en Perú y dar a conocer las acciones tomadas por el Estado frente a esta migración.

Para detallar los mencionados objetivos los investigadores realizaron entrevistas, focus group y entrevistas en profundidad, así como el uso de fuentes segundarias de información. Brinda como conclusiones que la migración venezolana en el Perú es una situación que nunca se había dado, que no solo por las condiciones económicas venezolanas el migrante sale de su país, una atracción para elegir al Perú como país receptor es el TPT brindado por el estado y por último indica una respuesta tardía por parte del gobierno peruano en políticas de migración.

Los autores nos dan a conocer que hasta el momento no hay soluciones reales para afrontar la migración venezolana al país. Las acciones tomadas por el estado hasta el momento son tardías e ineficientes, en temas laborales ya se mencionó anteriormente que la gran mayoría trabaja en el sector informal.

Tomando la publicación realizada por el Banco Mundial, este organismo hizo un cálculo del costo fiscal, en la que se demuestra que la población venezolana no solo demanda servicios públicos, sino que también generan ingresos fiscales. Este potencial ingreso neto sería un 0,23\% del PBI en promedio entre 2019 y 2025 (Banco Mundial, 2019).

Se considera que los refugiados venezolanos se irán asimilando paulatinamente a la estructura económica y social del país. Este acceso se produciría por tres frentes. Primero, con un gradual acceso de los venezolanos a empleos más afines con el nivel educativo. Segundo, a partir de los vínculos sociales que se comenzarán a generar con la población 
local. Tercero, a través de una flexibilización de regulaciones que faciliten su desempeño en la economía.

Para el cálculo del impacto sobre la recaudación fiscal en IGV, se trabajó con el supuesto que el trabajador venezolano gasta todo su ingreso laboral, es decir, el neto de remesas.

Se asume que, para el caso del pago de impuesto a la renta, los migrantes y refugiados irán accediendo paulatinamente a empleos formales, así en el largo plazo los niveles de formalidad serán similares a los peruanos.

Para el caso de los servicios de la salud, en la actualidad las visitas a consultorios atendidos por el MINSA son menos de 0.25 veces por una persona venezolana, mientras que los ciudadanos peruanos son de cuatro veces por habitante.

Para protección social, se asume que el gasto en los programas sociales de relevancia urbana se mantiene constante en relación al PBI. Además, se cree que se va flexibilizando el acceso de esta población a programas sociales tales como Pensión 65 u otros subsidios.

En cuanto a la proyección de venezolanos en el Perú, se asumió que serán alrededor de un millón en el 2019 y alcanzarían casi el millón y medio hacia el 2025. 


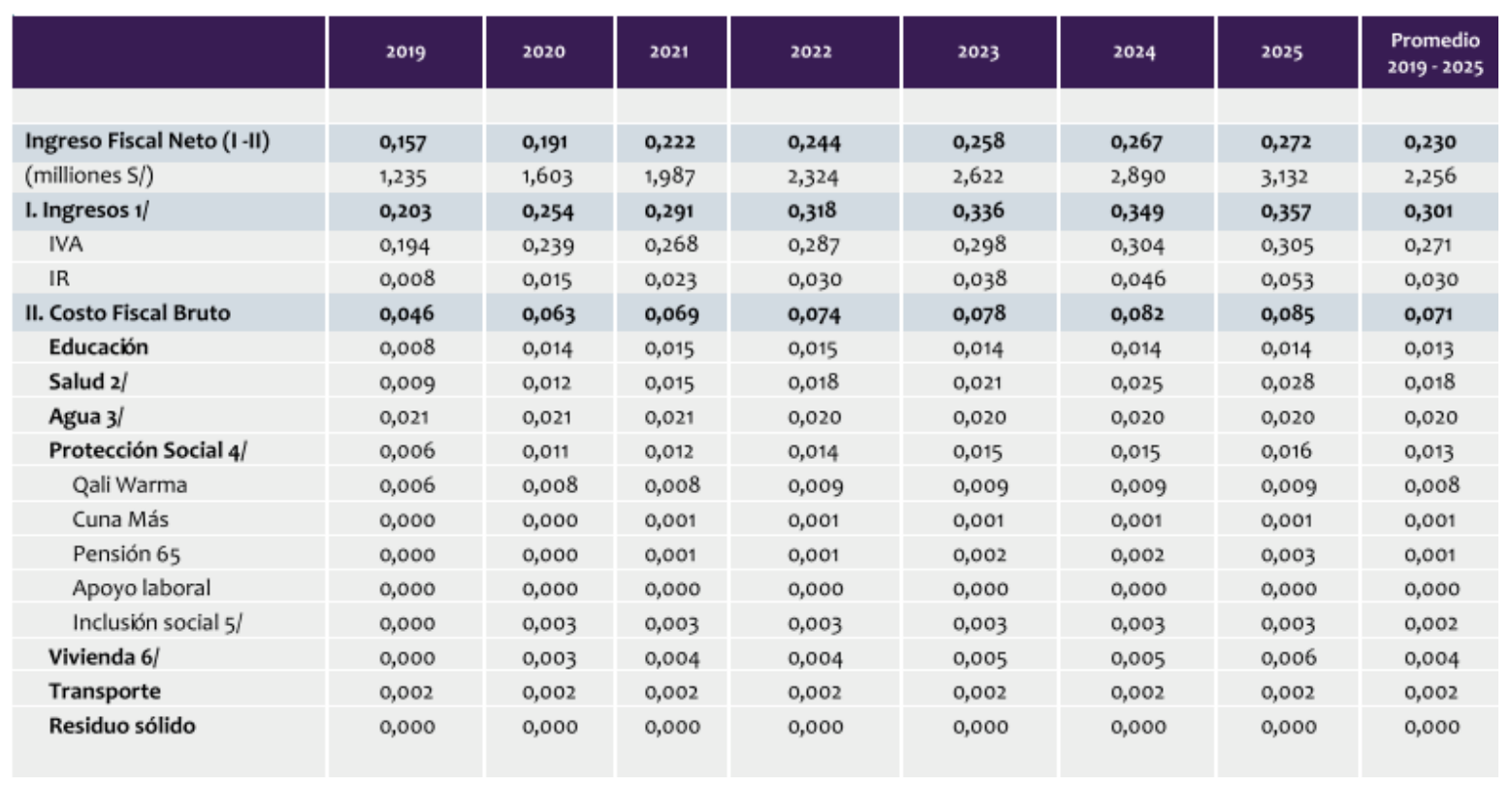

Figura 1. Proyección de venezolanos 2019-2025. Adaptado de "Una oportunidad para todos", por el Banco Mundial, 2019.

La población que migró de Venezuela al Perú proviene de zonas predominantemente urbanas. Un $15 \%$ de los encuestados vienen del distrito capital, y casi un $20 \%$ del área metropolitana de Caracas. La población proveniente de los estados Carabobo, Lara, Aragua y Zulia, que en su conjunto conforma alrededor del $40 \%$ de los venezolanos en Perú, está constituida en casi su totalidad por personas de Valencia, Barquisimeto, Maracay y Maracaibo. Lo que se resalta es que todas son ciudades capitales de dichos estados y/o las más importantes en el país después de Caracas.

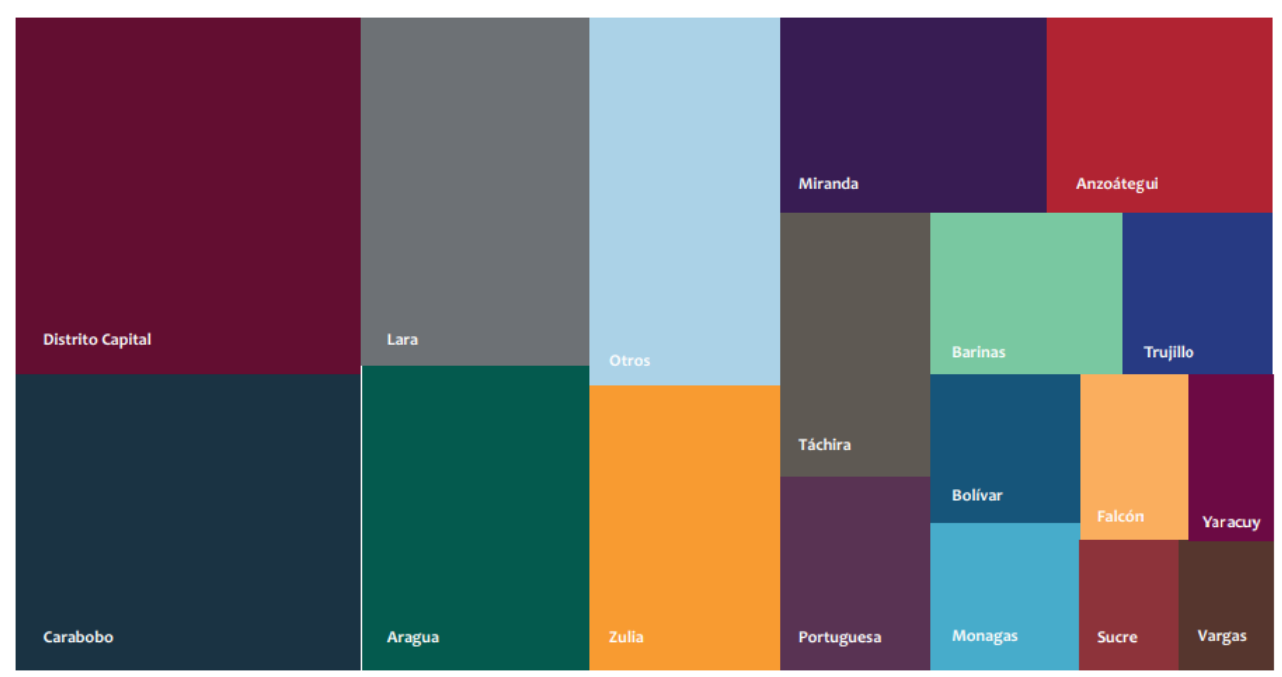

Figura 2. Estados provenientes de los migrantes venezolanos. Adaptado de "Una oportunidad para todos", por el Banco Mundial, 2019. 
El flujo de población venezolana hacia el Perú es un fenómeno relativamente reciente, sostenido desde mediados de 2017 , debido a los cambios de política en el país de origen y en los de destino.

Según los datos de la Superintendencia de Migraciones, a inicios del 2017 entre 8 mil y 10 mil ciudadanos venezolanos llegaban al Perú por mes, mientras que entre 6 mil y 7 mil personas salían del país, lo cual nos conduce a un aumento promedio en el número de población venezolana en el Perú de unos 2 mil a 3 mil personas mensualmente. Desde mayo de 2017 se evidencia un aumento sostenido del flujo migratorio, alcanzando su cifra pico en agosto de 2018, cuando unos 79 mil migrantes ingresaron al país. A partir de agosto de 2018 , mes en el que se introduce una serie de regulaciones por parte de Perú el cual incluye la solicitud de pasaportes y el cambio en la fecha límite para la expedición del PTP, originó fluctuaciones en las entradas y salidas. Luego de la introducción de la visa humanitaria en junio de 2019, se registra una reducción significativa en los ingresos y salidas de población venezolana.

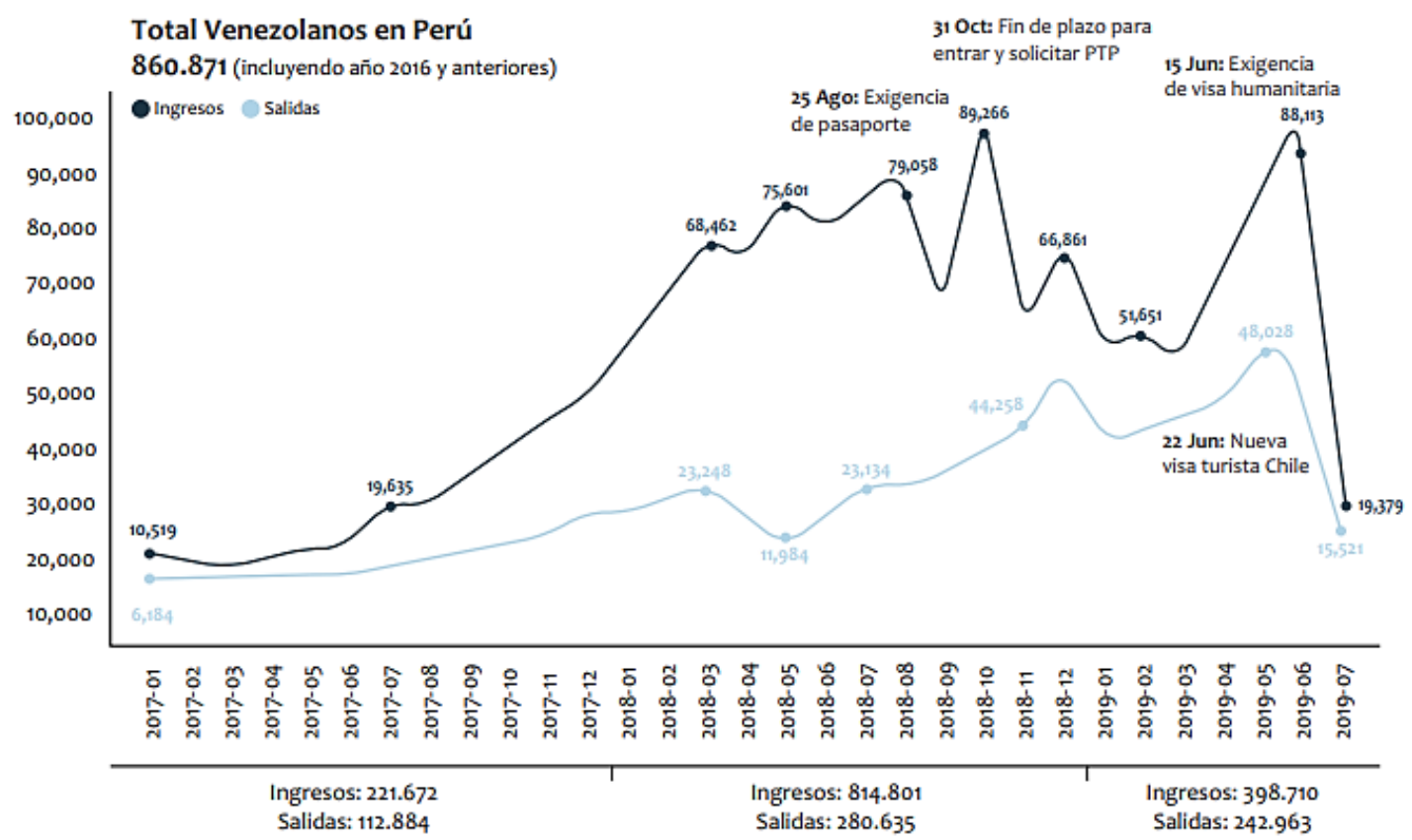

Figura 3. Venezolanos en Perú 2017-2019. Adaptado de "Una oportunidad para todos", por el Banco Mundial, 2019. 
También se obtuvo nueva información extraída del portal Mercado Negro que es especialista en marketing, nos brinda el siguiente detalle: Productos venezolanos que ya se venden en el Perú (Suito, 2019)

Tabla 1

Productos venezolanos que ya se venden en Perú

\begin{tabular}{cl}
\hline NUMERO & PRODUCTO \\
\hline 1 & Harina Pan \\
2 & Cerveza Polar (Pilsen) \\
3 & Queso de mano \\
4 & Malta \\
5 & Frescolita \\
6 & Ron Santa Teresa \\
7 & Ron Diplomático \\
8 & Cocosete \\
9 & Samba \\
10 & Pirulin \\
11 & Diablitos \\
12 & Cheese whiz \\
13 & Chicha en polvo \\
14 & Belmont \\
15 & Susy \\
16 & Leche la campiña
\end{tabular}

Fuente: Elaboración propia basada en Productos venezolanos que ya se venden en Perú (Suito, 2019)

También se considera en el estado del arte los últimos estudios realizados por la firma The Nielsen Company, en la cual trata sobre el impacto del Covid 19 en la conducta del consumidor para Perú durante el periodo de la segunda semana del mes de marzo hasta el día 19 de abril, en donde dan a conocer la nueva tendencia de consumo que tuvo grandes cambios en tan poco tiempo. 


\begin{tabular}{|c|c|c|c|c|}
\hline & CRECEN & & CAEN & \\
\hline & POLVOS PARA HORNEAR & $198 \%$ & CONSERVAS DE CARNE & $-57 \%$ \\
\hline & VINAGRES & $181 \%$ & BARRAS & $-34 \%$ \\
\hline ALIMENTOS & ACETUNAS & $174 \%$ & HELADOS IMPULSNOS & $-28 \%$ \\
\hline & COMIDAS PREP.CONGELADAS & $2338 \%$ & HËO & $-84 \%$ \\
\hline & CONGELADOS DE PESCADO & $182 \%$ & & \\
\hline $\begin{array}{l}\text { FRESCOS Y } \\
\text { CONGELADOS }\end{array}$ & HAMBURGUESAS & $140 \%$ & & \\
\hline & LECHE CONDENSADA & $143 \%$ & LECHES CHOCOLATADAS & $-16 \%$ \\
\hline 三 & LECHE EVAPORADA & $55 \%$ & LECHES EN POLVO ENTERAS & $-8 \%$ \\
\hline LACTEOS & LECHES VEGETALES & $45 \%$ & & \\
\hline & GALLEITIAS & $48 \%$ & CHOCOLATES & $-60 \%$ \\
\hline & CHUPETINES & $17 \%$ & GOMAS DE MASCAR & $-52 \%$ \\
\hline CONFIERIA & PASTELITOS & $9 \%$ & CARAMEOS & $-22 \%$ \\
\hline & ANTISEPTICOS & $1770 \%$ & BRONCEADORES & $-90 \%$ \\
\hline & ANALGESICOS Y ANTIGRIPALES & $96 \%$ & MAQUILLAJE & $-87 \%$ \\
\hline TOCADOR & TALCOS Y DESODORANTES & $63 \%$ & FUADORES Y BRILLANTINAS & $-60 \%$ \\
\hline & & & AGUARDENTE & $-95 \%$ \\
\hline 红肖 & & & GN & $-81 \%$ \\
\hline $\begin{array}{l}\text { BEBIDAS CON } \\
\text { ALCOHOL }\end{array}$ & & & CERVEZAS & $-71 \%$ \\
\hline & JUGOS EN POLVO & $67 \%$ & BEBDAS DE MALTA & $-60 \%$ \\
\hline & & & TE LISTO PIBEBER & $-48 \%$ \\
\hline $\begin{array}{l}\text { BEBIDAS SIN } \\
\text { ALCOHOL }\end{array}$ & & & JUGOS ISOTONICOS & $-41 \%$ \\
\hline & GUANTES DE LATEX & $277 \%$ & BETUN & $-62 \%$ \\
\hline & LAVANDINAS & $163 \%$ & CERAS PARA PISOS & $-20 \%$ \\
\hline LIMPIEZA & LIMPIADORES DE HORNO & $121 \%$ & & \\
\hline
\end{tabular}

Figura 4. Ranking categorías con mayor crecimiento/caída. Adaptado de "Covid 19 Perú Tracking the impact on FMCG and retail”, por The Nielsen Company, 2020.

Como podemos analizar en la figura 4 para la categoría alimentos hubo un incremento sustancial del $198 \%$ en polvos para hornear, mientras las conservas de carnes bajaron un $57 \%$. Otro dato interesante sucede en la categoría Frescos y Congelados se incrementó en un $2338 \%$ de comidas preparadas congeladas, mientras que el consumo de hielo bajo en un $-84 \%$. También los congelados se pescado como las hamburguesas preparadas tuvieron incrementos considerables en un lapso pequeño de tiempo. Otro dato interesante sobre el comportamiento del mercado se da en la categoría tocador el cual tiene un incremento del 
$1770 \%$ en antisépticos y una caída de $90 \%$ en bronceadores como un $87 \%$ en maquillajes. El estudio también indica la gran caída de la categoría bebidas con alcohol en un $-82.3 \%$ en promedio (The Nielsen Company, 2020).

El estudio realizado por Nielsen indica que se viene un nuevo periodo para el consumidor que lo llaman "Vivir una nueva normalidad".

Tomando al estudio Inmigración venezolana a Perú realizado por el BBVA (2019) que brinda datos interesantes sobre la migración para el tercer trimestre del año 2019. Se indica que entre el año 2016 a octubre de 2019 ingresaron al país alrededor de 810 mil ciudadanos venezolanos, donde la mayoría solo ingresó con pasaporte.

\section{INGRESO NETO MENSUAL DE VENEZOLANOS A PERÚ (MILES DE PERSONAS)}

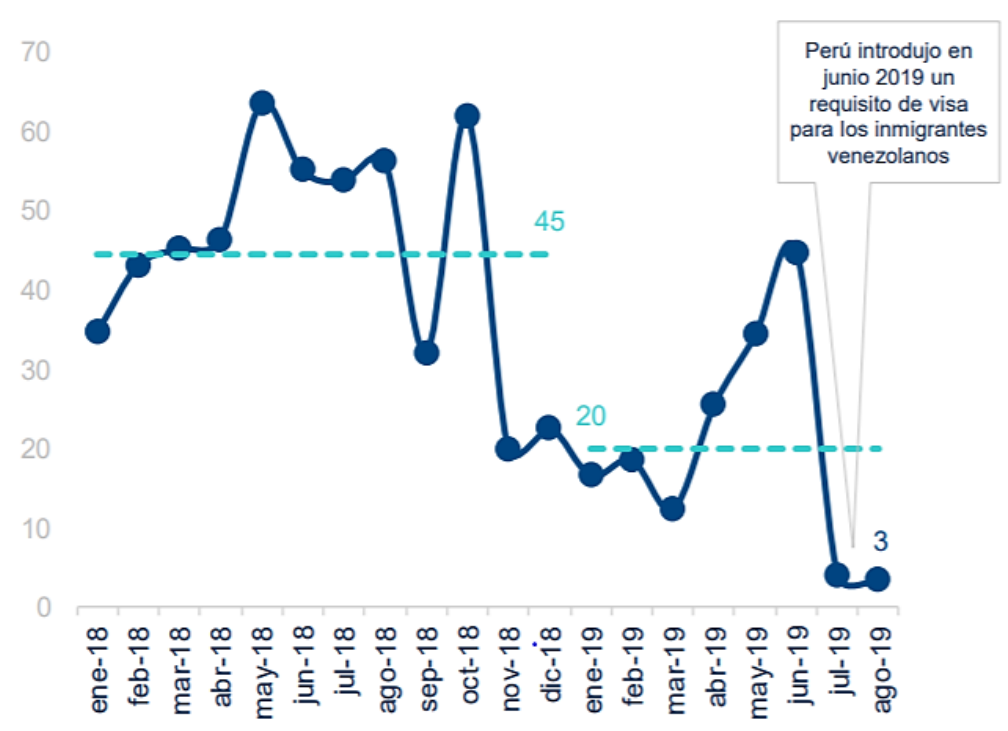

Figura 5. Ingreso Neto mensual de venezolanos a Perú 2018-2019. Adaptado de "Inmigración venezolana a Perú: características e impactos macroeconómicos", por BBVA Research, 2019.

Otros datos interesantes del estudio del BBVA son los siguientes: 
$89 \%$ de los trabajadores dependientes no tiene contrato.

$76 \%$ trabaja en empresas muy pequeñas (de 1 a 10 trabajadores), que tienden a ser menos productivas y más informales ( $91 \%$ de informalidad).

97\% no tiene seguro de salud otorgado por el empleador" (BBVA Research, 2019).

Se menciona que los migrantes venezolanos se integraron al mercado, pero no en las mejores condiciones, tienen un promedio mayor en horas de trabajo a comparación de un ciudadano peruano y un promedio de ingreso mensual de 1116 soles.

\begin{tabular}{|lrr|}
\hline PET & 531.956 & $100 \%$ \\
\hline Inactiva & 45.216 & $8 \%$ \\
PEA & 486.740 & $92 \%$ \\
\hline PEA ocupada & 455.102 & $86 \%$ \\
PEA desocupada & 31.638 & $6 \%$ \\
\hline
\end{tabular}

PET: Población en edad de trabajar (entre 14 y 65 años). Inactiva: PET, pero que no está trabajando ni busca empleo.

PEA: PET que está laborando o está buscando empleo.

PEA ocupada: PET que trabaja.

PEA desocupada: PET que no está trabajando,

pero sí buscando empleo.

Figura 6. Inmigrantes venezolanos en el Perú. Adaptado de "Inmigración venezolana a Perú: características e impactos macroeconómicos”, por BBVA Research, 2019.

Otro factor interesante del estudio es sobre el envío de remesas desde el Perú hacia Venezuela. Donde según el estudio, más del 66\% de personas encuestadas indica que sí realizan remesas de dinero de manera semanal, quincenal y mensual y un monto promedio entre 240 y 280 soles. 
Otro factor interesante es la necesidad de condiciones básicas de vida de los migrantes venezolanos. Según el estudio del BBVA con los análisis realizados por el INEI indica que para el 2018 alrededor de 33 mil venezolanos se encuentran en edad formativa (3 a 18 años) de los cuales el $70 \%$ asistieron a escuelas públicas y un $30 \%$ a escuelas privadas.

El estudio realizado también habla sobre el impacto fiscal que tiene la migración venezolana en el Perú, el cual se encuentra representado en la figura 7.

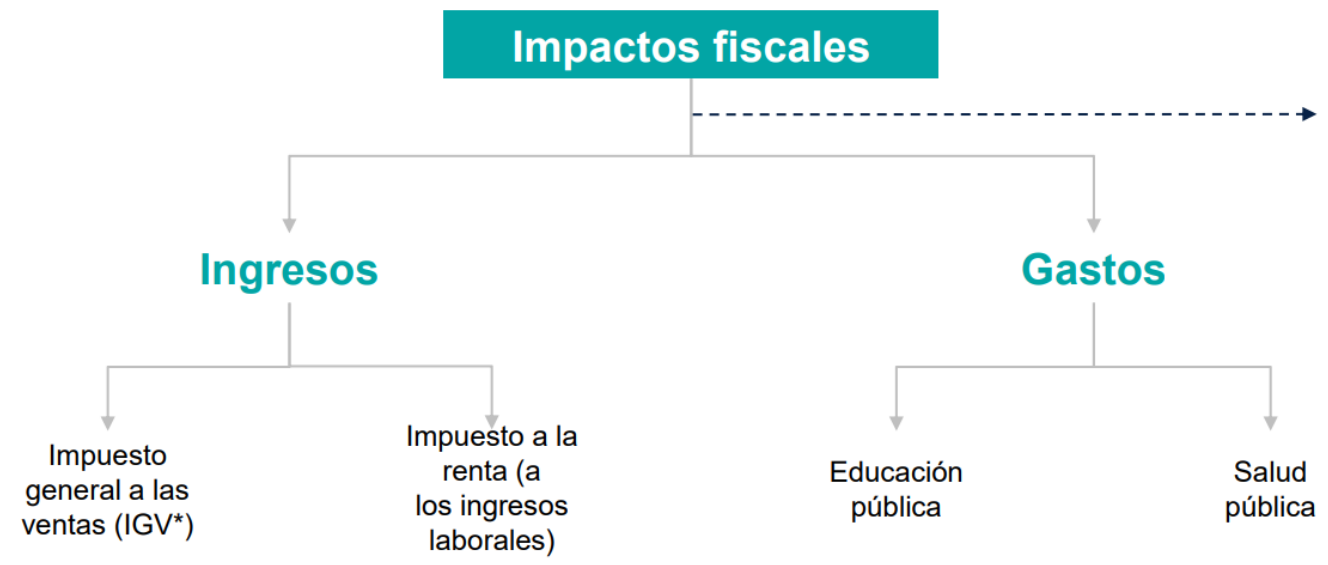

Figura 7. Mapa de impactos fiscales. Adaptado de "Inmigración venezolana a Perú: características e impactos macroeconómicos”, por BBVA Research, 2019.

Se ilustra cómo impacta fiscalmente al gobierno, por un lado, los gastos y por otro lado los ingresos.

El estudio da a conocer una estimación de la recaudación fiscal por IGV, con lo cual aplica la siguiente fórmula:

((Ingreso laboral promedio anual de inmigrante -

Envio de remesas promedio anual del inmigrante $) *$ tasa del IGV 18\% * (1tasa de evasión tributaria del IGV (36\%))) * Número de inmigrantes venezolanos que trabajan. 


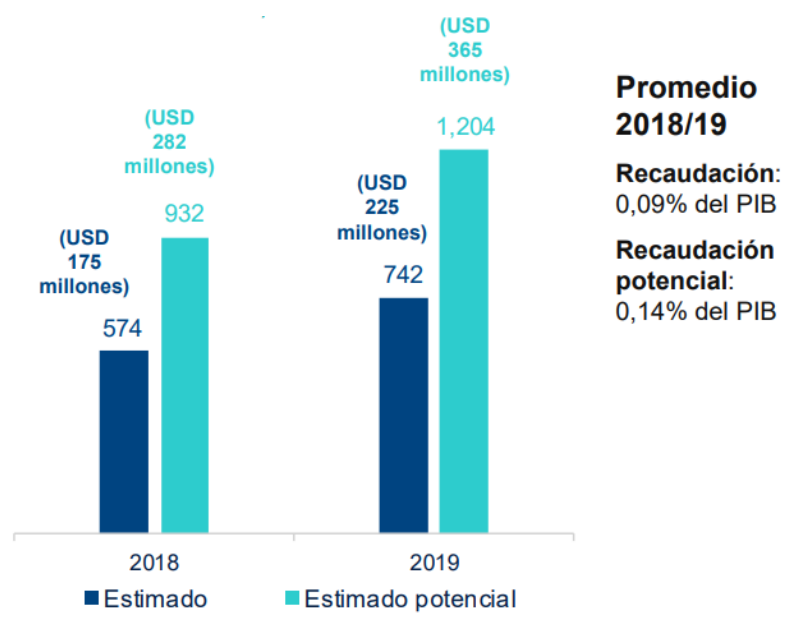

Figura 8. Recaudación fiscal por IGV de inmigrantes venezolanos. Adaptado de "Inmigración venezolana a Perú: características e impactos macroeconómicos", por BBVA Research, 2019.

También da a conocer el impacto por la recaudación fiscal por impuesto a la renta, al aplicar la siguiente fórmula.

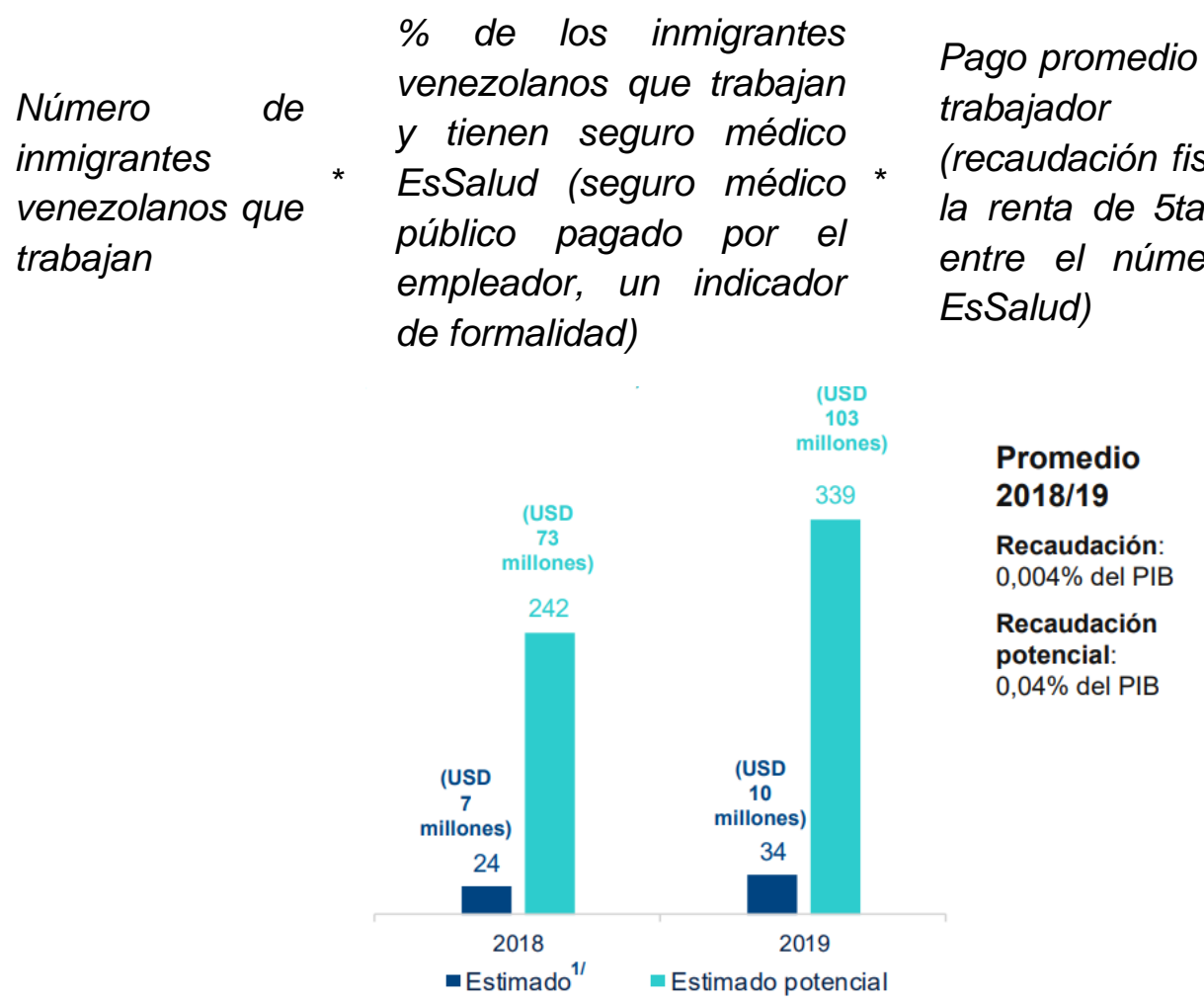

Figura 9. Recaudación fiscal por Impuesto a la Renta de inmigrantes venezolanos. Adaptado de "Inmigración venezolana a Perú: características e impactos macroeconómicos", por BBVA Research, 2019. 
Se resalta que la recaudación estimada es 10 veces menor a la potencial que podría lograr el estado.

El estudio da a conocer el gasto fiscal en educación pública donde aplica la siguiente fórmula en el cual sacan los resultados en la siguiente figura 10.

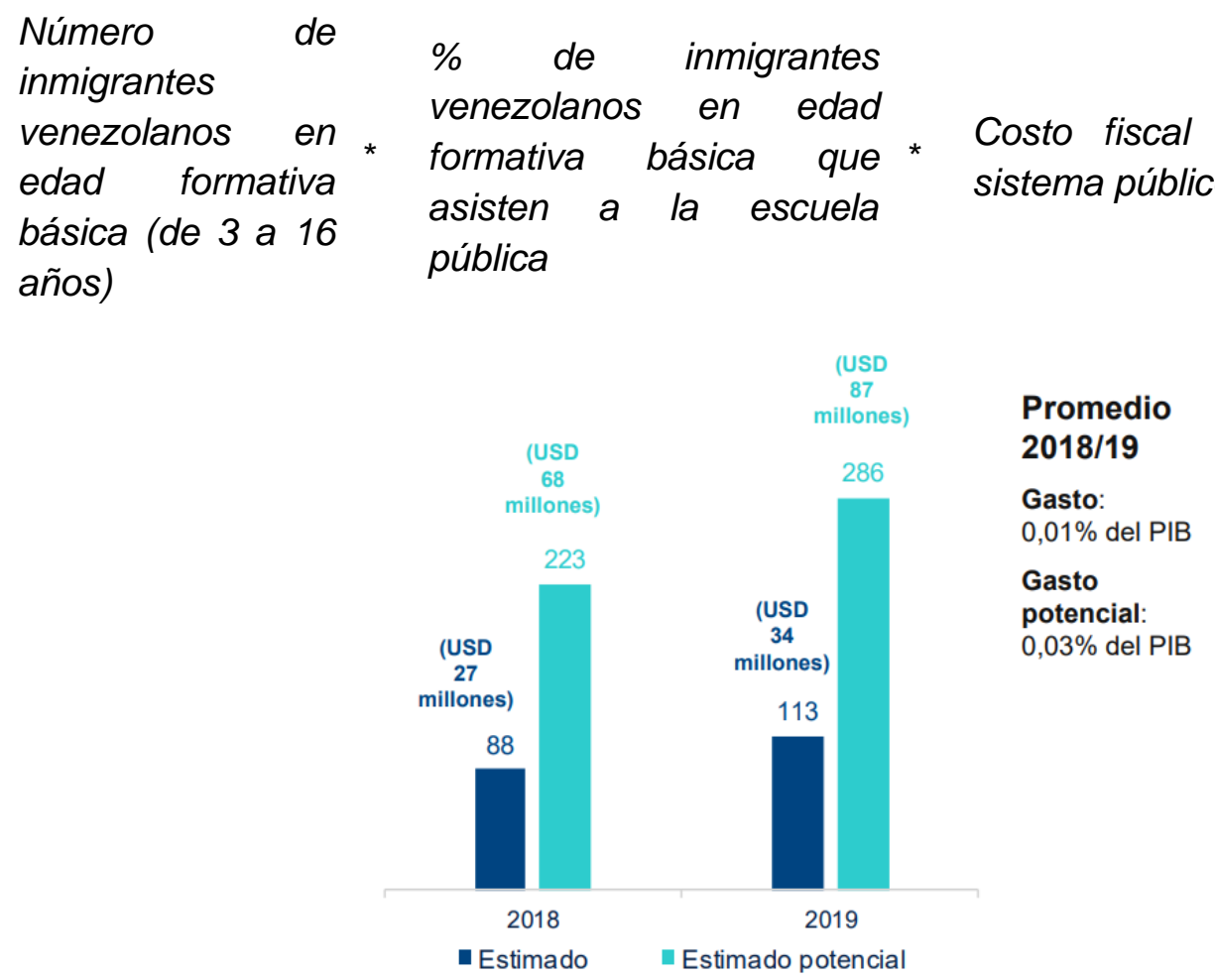

Figura 10. Gasto fiscal por educación pública de inmigrantes venezolanos. Adaptado de "Inmigración venezolana a Perú: características e impactos macroeconómicos", por BBVA Research, 2019.

El último análisis sobre el impacto fiscal es la salud pública donde se realiza la siguiente fórmula para analizar el gasto estimado y potencial gasto en salud. Para eso se debe analizar la figura 11.

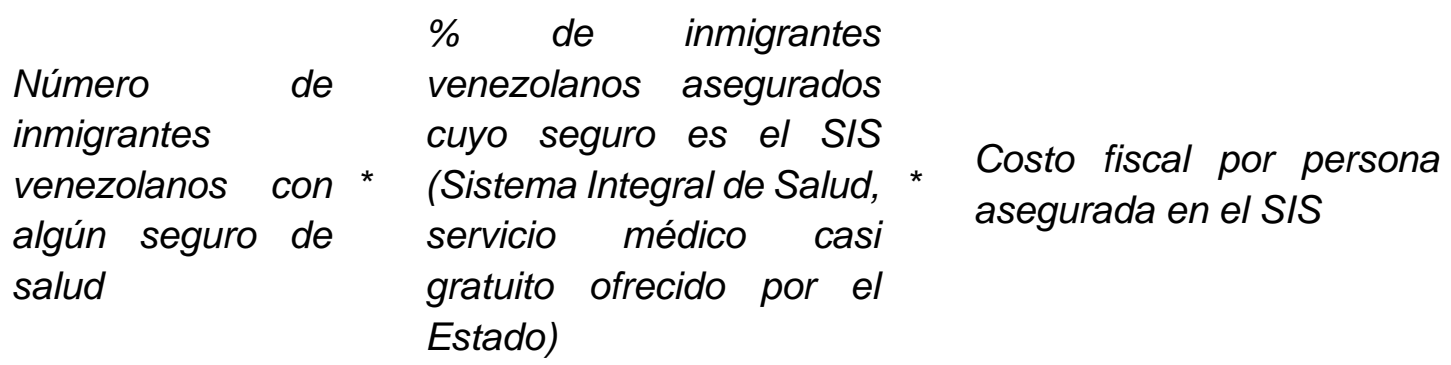




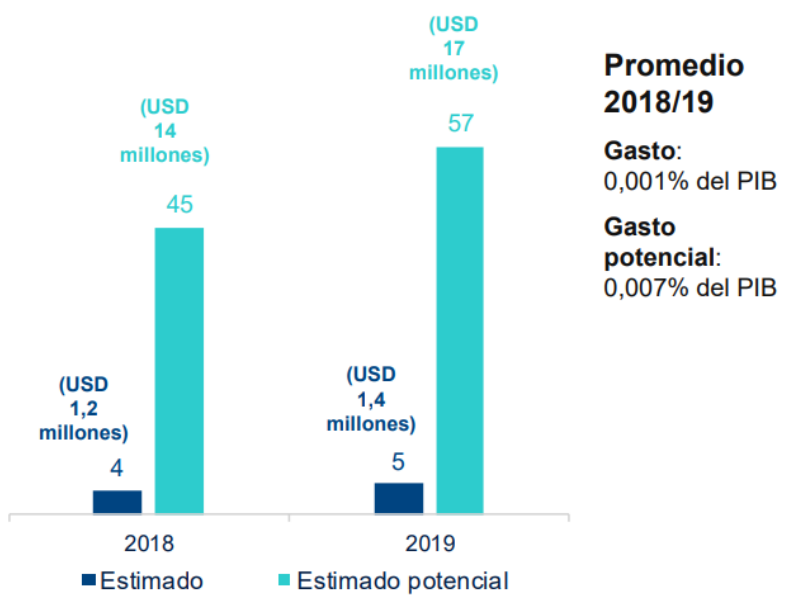

Figura 11. Gasto fiscal por salud pública en inmigrantes venezolanos. Adaptado de "Inmigración venezolana a Perú: características e impactos macroeconómicos", por BBVA Research, 2019.

Según las estimaciones realizadas por el BBVA indica que el gasto promedio en salud para inmigrantes venezolanos es del $0.001 \%$ del $\mathrm{PBI}$, a lo cual el estimado potencial podría extenderse hasta el $0.007 \%$ del $\mathrm{PBI}$, donde se consideraría esto si todos los inmigrantes estarían afiliados al Sistema de salud integral (SIS).

Ya con todos los impactos fiscales explicados anteriormente el BBVA da a conocer los resultados obtenidos según sus estudios, el cual se presenta la siguiente figura 12. Los resultados indican que la recaudación fiscal es ampliamente más grande que el gasto fiscal, sobre todo, en la recaudación del IGV en la población de inmigrantes venezolanos.

Aunque también se debe de considerar que el gasto fiscal en educación y salud del Perú es uno de los más bajos de la región, situación que se ve reflejada en la actual crisis del Covid-19. Así como que la situación laboral de los inmigrantes en el país no es la mejor, por lo que la recaudación del impuesto a la renta se vería seriamente afectada por el número pequeño de inmigrantes en el sector formal. 


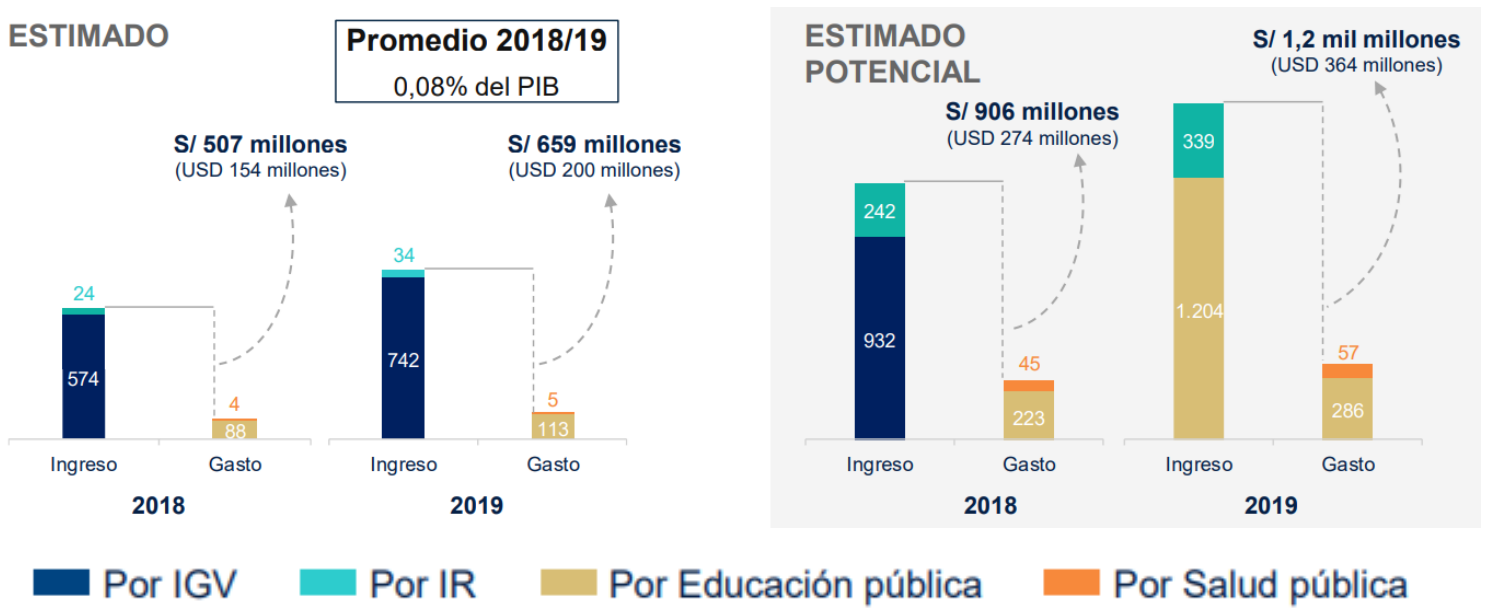

Figura 12. Impacto fiscal de la población migrante venezolana a Perú. Adaptado de "Inmigración venezolana a Perú: características e impactos macroeconómicos", por BBVA Research, 2019.

A continuación, se muestra el cuadro de resumen donde se muestra el análisis realizado en el estado de arte: 
Tabla 2

Análisis del estado de arte

\begin{tabular}{|c|c|c|c|c|c|}
\hline Paper & Título & Autor & Objetivo & $\begin{array}{c}\text { Año de } \\
\text { publicación }\end{array}$ & Metodología empleada \\
\hline 1 & $\begin{array}{l}\text { Migración } \\
\text { venezolana al Perú: } \\
\text { proyectos } \\
\text { migratorios } \quad \text { y } \\
\text { respuesta del } \\
\text { Estado }\end{array}$ & $\begin{array}{l}\text { José Koechlin } \\
\text { Eduardo Vega } \\
\text { Ximena Solórzano }\end{array}$ & $\begin{array}{l}\text { Describir el contexto venezolano como } \\
\text { una variable que promueve la migración, } \\
\text { conocer las causas de la migración y } \\
\text { describir el perfil del migrante venezolano. }\end{array}$ & 2018 & $\begin{array}{l}\text { Entrevistas } \\
\text { Focus Group } \\
\text { Entrevistas en } \\
\text { profundidad } \\
\text { Fuentes segundarias de } \\
\text { información }\end{array}$ \\
\hline 2 & $\begin{array}{l}\text { Una oportunidad } \\
\text { para todos }\end{array}$ & Banco Mundial & $\begin{array}{l}\text { Demostrar que la población venezolana } \\
\text { no solo demanda servicios públicos, sino } \\
\text { que también generan ingresos fiscales. }\end{array}$ & 2019 & $\begin{array}{l}\text { Encuestas: } \\
\text { ENPOVE, INEI } \\
\text { Encuesta por el Banco } \\
\text { Mundial con la técnica de } \\
\text { mapa de empatía } \\
\text { Entrevistas con } \\
\text { autoridades y actores } \\
\text { claves relevantes } \\
\text { Modelo de Crecimiento a } \\
\text { Largo Plazo (MCLP) }\end{array}$ \\
\hline 3 & $\begin{array}{l}\text { Estos son los } \\
\text { productos }\end{array}$ & Juan Suito & $\begin{array}{l}\text { Explicar los productos de marcas } \\
\text { venezolanas que están ingresando al }\end{array}$ & 2019 & $\begin{array}{l}\text { Comportamiento del } \\
\text { consumidor } \\
\text { Trade marketing }\end{array}$ \\
\hline
\end{tabular}




\begin{tabular}{|c|c|c|c|c|c|}
\hline & $\begin{array}{l}\text { venezolanos que ya } \\
\text { se venden en Perú }\end{array}$ & & $\begin{array}{l}\text { Perú con procedencia de Estados Unidos } \\
\text { o Colombia }\end{array}$ & & \\
\hline 4 & $\begin{array}{l}\text { Covid } 19 \text { Perú } \\
\text { Tracking the impact } \\
\text { on FMCG and retail. }\end{array}$ & $\begin{array}{l}\text { The Nielsen } \\
\text { company }\end{array}$ & $\begin{array}{l}\text { Determinar el impacto del Covid } 19 \text { en la } \\
\text { conducta del consumidor peruano durante } \\
\text { el periodo de la segunda semana del mes } \\
\text { de marzo hasta el día } 19 \text { de abril } 2020 \text {, en } \\
\text { donde indican la nueva tendencia de } \\
\text { consumo. }\end{array}$ & 2020 & $\begin{array}{l}\text { Insights } \\
\text { Comportamiento del } \\
\text { consumidor } \\
\text { Trade marketing } \\
\text { Retail management }\end{array}$ \\
\hline 5 & $\begin{array}{l}\text { Inmigración } \\
\text { venezolana a Perú: } \\
\text { características e } \\
\text { impactos } \\
\text { macroeconómicos }\end{array}$ & BBVA Research & $\begin{array}{l}\text { Demostrar que la migración venezolana } \\
\text { modifica la oferta de factores productivos } \\
\text { en la economía peruana y favorece el PIB } \\
\text { potencial de Perú en } 2018 \text {. }\end{array}$ & 2019 & $\begin{array}{l}\text { Métodos estadísticos } \\
\text { Métodos económicos } \\
\text { Método de la función de } \\
\text { producción - Cobb } \\
\text { Douglass } \\
\text { Método de la tasa natural } \\
\text { - Laubach y Williams }\end{array}$ \\
\hline
\end{tabular}




\section{Marco teórico}

Para el estudio del Impacto de la migración venezolana en la oferta de productos masivos para satisfacer la nueva demanda, se tiene que comprender primero el significado de los conceptos claves referidas en el estudio a desarrollar, entre tenemos las siguientes:

\section{Migración}

Para definir la palabra "Migración" se basará en conceptos desarrollados por la Organización de las Naciones Unidas, debido a que es una organización mundial que monitorea alrededor del mundo el cumplimiento del derecho internacional, derechos humanos, mantenimiento de la paz mundial, entre otros asuntos de alta importancia. Una de sus oficinas y áreas competentes en el presente tema es la OIM (Organización Internacional para las Migraciones) la cual nos brinda la siguiente información.

"Migración es el movimiento de personas fuera de su lugar de residencia habitual, ya sea a través de una frontera internacional o dentro de un país" (Organización Internacional para las Migraciones, 2020).

Al respecto, la ONU sostiene:

Migración internacional se define como toda persona que cambia de país de residencia habitual. El país de residencia habitual es el país en el que vive la persona, es decir, el país en que la persona tiene una vivienda donde normalmente pasa los periodos diarios de descanso. Los viajes temporales al exterior con fines de ocio, vacaciones, negocios, tratamiento médico o peregrinación religiosa no cambian el país de residencia habitual (ONU, 1999).

Lo que se da a entender con el término de migración es toda aquella persona que sale de su país de origen y residencia para establecerse en otro. El término indica que no se considera migración a las personas que salen por un periodo corto, a esto se le considera viaje temporal. 


\section{Oferta}

Se analizará el término "Oferta"; el cual representa una palabra clave en el estudio a realizar, el Libro Principios de economía lo define como:

"La cantidad ofrecida de cualquier bien o servicio es la cantidad que los vendedores quieren y pueden vender" (Mankiw, 2012).

$\mathrm{Da}$ a conocer que el término Oferta es la cantidad óptima que se vende y saben que pueden vender de un cierto producto o servicio que pueden ofrecer al público en general.

Otro dato interesante de esta palabra es que proviene del término offerre que es una palabra en latín que quiere decir cosas que se ofrecen.

\section{Demanda}

El Libro Principios de economía lo define como:

"La cantidad demandada de un bien determinado es la cantidad que de ese bien están dispuestos a adquirir los compradores" (Mankiw, 2012).

El término Demanda da a conocer que es la cantidad que los compradores están dispuestos a adquirir de un cierto producto o servicio que se le puede ser brindado.

\section{Productos masivos}

Para la palabra clave productos masivos, encontramos la siguiente definición brindada por IEBS SCHOOL, escuela de negocios online española.

"Productos de alta demanda son aquellos productos requeridos por todos los estratos de la sociedad” (Roca Martínez, 2016). 
Un producto masivo tiene que tener ciertas características como ser un de consumo inmediato, compra cotidiana y fácil de adquirirlo en el mercado.

\section{Shopper}

EL portal Perú Retail brinda el siguiente extracto referente al término shopper: "El shopper no siempre es el consumidor, es decir, si un señor compra pañales o comida para mascota no consume precisamente esos productos" (Perú Retail, 2018).

Nos indica que el shopper es quien compra un producto, pero no necesariamente sería para su consumo.

\section{Canasta básica}

Para analizar el término canasta básica, al estar nosotros en el Perú usaremos los datos brindados por el mismo gobierno.

"Canasta Básica de Consumo 1/ (CBC) que incluye alimentos y otros bienes y servicios en los cuales las familias de las regiones naturales del país en los ámbitos rural y urbano gastan sus ingresos. Aquellos cuyo ingreso no permite cubrir la CBC son considerados pobres" (INEI, 2000).

Para empezar, hablar de la canasta básica familiar peruano se deberá recoger los últimos datos brindados por los especialistas del tema, esto debido a que la entidad nacional que se encarga del estudio es el Instituto Nacional De Estadística y Probabilidades. Según la información leída se está desarrollando actualmente los estudios de la canasta básica familiar para el año 2020 con su último estudio de campo realizado en el año 2019, pero la información aún no está publicada.

El columnista Alfredo Palacios del diario Expreso nos da el siguiente alcance sobre la situación estudiada hasta ese momento por el INEI. 
"Actualmente la canasta tiene un valor mensual de S/ 1,376 para una familia de 4 miembros (S/ $344 \mathrm{c} / \mathrm{u})$, si su gasto per cápita es menor son consideradas pobres, para pobreza extrema es S/ 732 (S/ 183 c/u)" (Palacios Dongo, 2019).

Como dato histórico se adjunta la siguiente imagen de los estudios realizados años anteriores por el INEI.

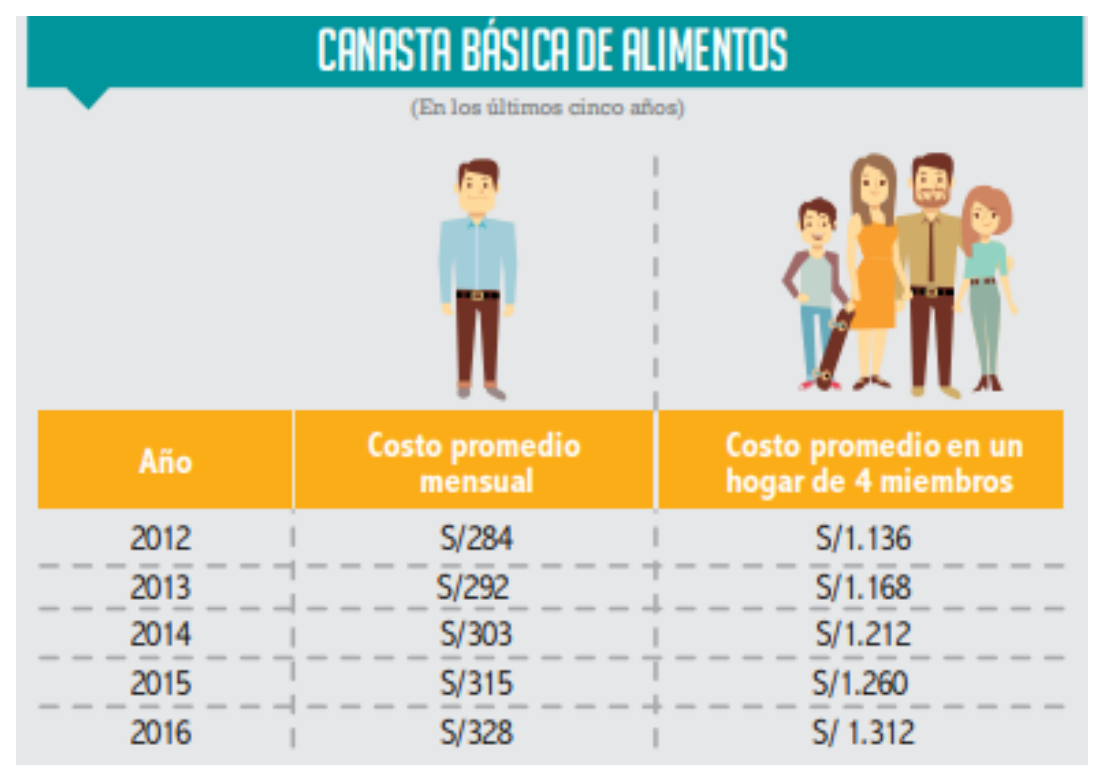

Figura 13. Canasta básica de alimentos. Adaptado de "La canasta básica en Perú representa el 34.8\% del sueldo mínimo", por Peru Retail, 2020.

Mientras que para enero del 2020 el Portal Peru Retail realiza la siguiente publicación sobre la canasta básica familiar.

"Los gastos en la canasta básica representan el 34,8\% del sueldo mínimo neto este año, mientras que la misma canasta en 2019 constituía el 33,3\% del salario mínimo" (Peru Retail, 2020). 

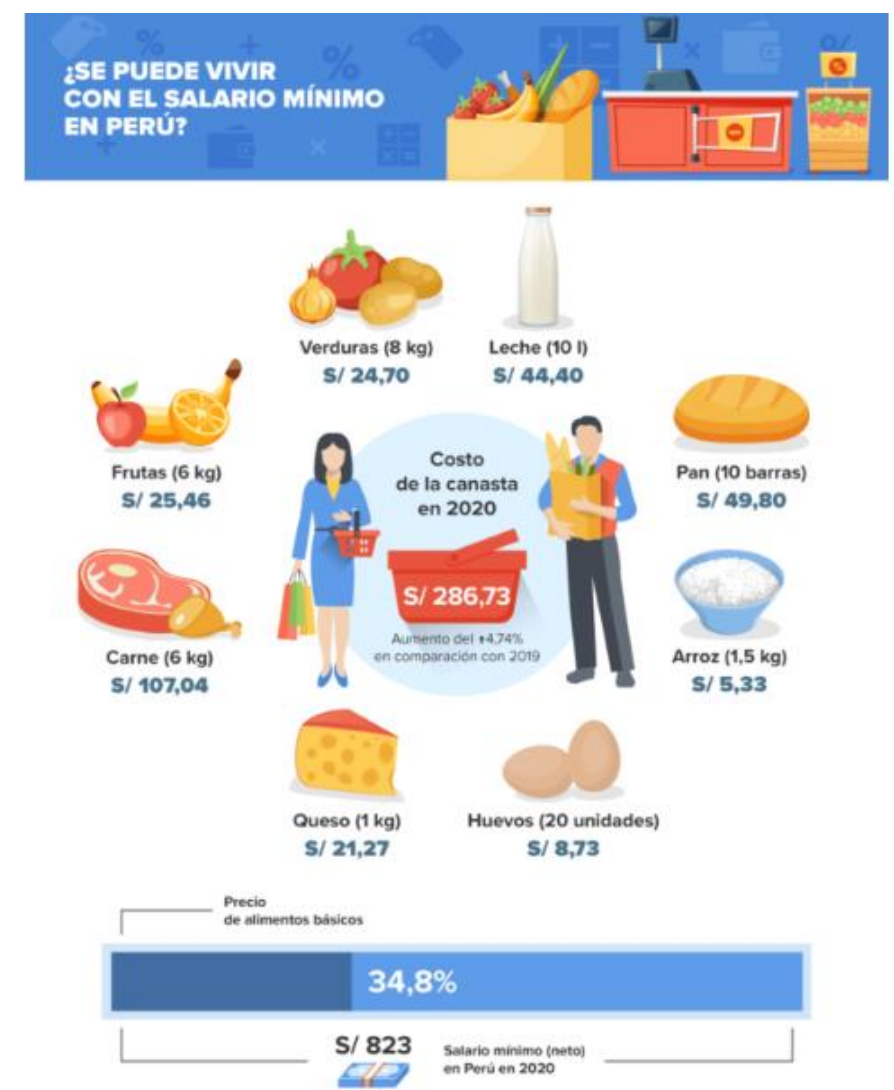

Figura 14. Productos de la canasta básica familiar. Adaptado de "La canasta básica en Perú representa el 34.8\% del sueldo mínimo", por Peru Retail, 2020.

Para analizar a profundidad los alimentos que están dentro de la canasta básica familiar y más consumidos por el peruano, se adjunta la tabla 3 en la cual podemos ver la cantidad de kilos consumos por un peruano en Lima Metropolitana para el año 2012 según el INEI el cual había realizado un estudio de consumo para los años 2008-2009. Los consumos en $\mathrm{Kg}$ deben haber variado para el presente año, pero no debe haber un mayor cambio en los productos consumidos por ser considerados para el peruano como alimentos de primera necesidad de primera necesidad.

El siguiente párrafo nos explica mejor porque se debe realizar este tipo de estudios en el país en ciertos periodos de tiempo es de alta importancia.

"El conocimiento del consumo alimentario también es de importancia para desarrollar la canasta de alimentos con sus múltiples aplicaciones para determinar los niveles y 
estructura del gasto familiar, índices de precio al consumidor, ajustes de salarios, e índices de marginalidad social" (INEI, 2012).

\section{Tabla 3}

Consumo per cápita de los principales alimentos 2009

\begin{tabular}{|c|c|}
\hline \multicolumn{2}{|c|}{$\begin{array}{c}\text { CONSUMO PER CAPITA } 2009 \\
\text { (EN KG) }\end{array}$} \\
\hline ARROZ & 46.6 \\
\hline PAPA & 43.4 \\
\hline POLLO & 26.1 \\
\hline PAN & 23.6 \\
\hline LECHE EVAPORADA & 16.4 \\
\hline PLATANO & 14.7 \\
\hline CEBOLLA & 12.2 \\
\hline HUEVOS & 8.1 \\
\hline MANDARINA & 7.4 \\
\hline PESCADO DE MAR & 7 \\
\hline NARANJA & 6.7 \\
\hline TOMATE & 6.7 \\
\hline ZANAHORIA & 6.6 \\
\hline MANZANA & 6.5 \\
\hline YOGURT & 5.5 \\
\hline CARNE VACUNO & 5.3 \\
\hline PAPAYA & 5.3 \\
\hline LIMON & 4.8 \\
\hline ALVERJA & 3.9 \\
\hline CAMOTE & 3.6 \\
\hline LECHE PASTEURIZADA & 3.3 \\
\hline QUESO FRESO & 2.3 \\
\hline LENTEJA & 2 \\
\hline FREJOL & 1.9 \\
\hline AVENA Y SIMILARES & 1.7 \\
\hline MAIZ & 1.5 \\
\hline HARINA DE TRIGO & 0.5 \\
\hline
\end{tabular}

Fuente: Consumo per cápita de los principales alimentos, 2008- 2009 (INEI, 2012)

El diario Gestión realizó una entrevista a la Asociación Peruana de Avicultura a mediados del año 2019, en lo cual se encuentra un extracto muy interesante el cual vamos a presentar. 
“El año pasado alcanzamos los 46.6 kilogramos per cápita. Esto supera ampliamente a los 20 kilogramos consumidos por habitante, de pescado; 8 kilogramos para el caso del cerdo; y 8 kilogramos de carne roja" (Gestión, 2019).

Como podemos analizar el consumo de pollo creció de $26.1 \mathrm{Kg}$ para el año 2009 a $46.6 \mathrm{Kg}$ en el año 2018, esto representa un crecimiento de $178 \%$ en casi 10 años. Otro dato interesante es que el consumo de cerdo también sufrió un incremento esto debido a que era menor a $1 \mathrm{~kg}$ en el año 2009 pasando a $8 \mathrm{Kg}$ para el año 2018.

En el mismo artículo también se habla sobre otro producto que tuvo un incremento considerable.

"237 huevos es el consumo anual per cápita" (Gestión, 2019).

Al realizar un breve análisis se considera que aproximadamente 1 kilo de huevo regular contiene 16 huevos medianos, a lo cual con la cifra de 237 huevos se crea un aproximado de $14.8 \mathrm{~kg}$ de huevos para el año 2018-2019, esto desplaza a las cifras medidas por el INEI durante el año 2009 que fue de $8.1 \mathrm{Kg}$, así llega a tener un crecimiento de 182.7 $\%$.

El estudio realizado por Kantar en el ranking anual Brand Footprint dio a conocer las marcas más elegidas por los peruanos. Este resultado se obtiene a través de la penetración de la marca en los hogares y la frecuencia de compra lo que conlleva al índice CRP, llamado el Consumer Reach Point. Esto refleja el número de veces en la que una marca fue elegida por los consumidores en todo el año (Kantar Worldpanel, 2019).

Esta investigación dividió la canasta en 5 categorías:

En la categoría de alimentos, lidera Ajinomoto. 
En la categoría de bebidas, lidera Inca Kola.

En la categoría de lácteos, lidera Gloria.

En la categoría hogar, lidera Elite

En la categoría personal, lidera Huggies.

Top 5 marcas por sectores - Total Perú

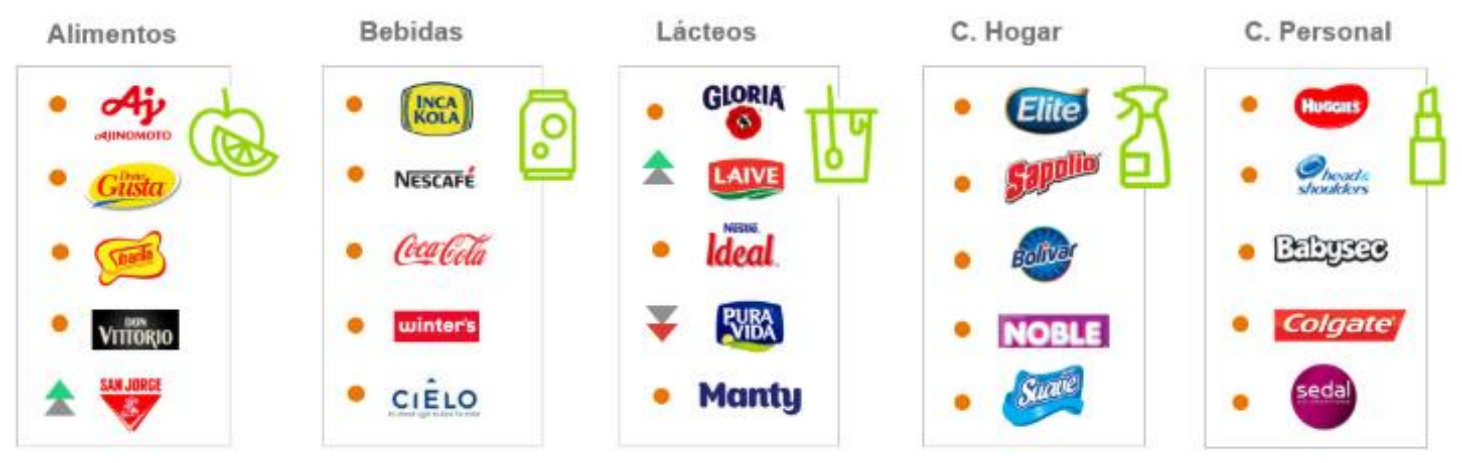

Figura 15. Top 5 marcas por sectores Perú. Adaptado de "Brand Footprint", por Kantar Worldpanel, 2019.

Según un estudio reciente de Kantar, se analizó seis factores al momento de elegir el canal de compra. El nivel socioeconómico (NSE) influye a la hora de valorar estos factores (Kantar Worldpanel, 2020).

En el caso del nivel socioeconómico A/B, el 79\% de los encuestados valora la cercanía a su hogar, seguido de que el establecimiento cumpla las medidas sanitarias con un $73 \%$, los precios accesibles con $61 \%$, la poca cantidad de personas con $52 \%$ y el surtido de productos con un $42 \%$.

En el caso del nivel socioeconómico $\mathrm{C}$, el cumplimiento de las medidas sanitarias corresponde al $72 \%$, precios accesibles con un $67 \%$ y cercanía a su hogar con $65 \%$. 
En el caso del nivel socioeconómico D, el cumplimiento de las medidas sanitarias corresponde al $64 \%$ y precios accesibles con un $62 \%$.

En el caso del nivel socioeconómico E, los precios accesibles son lo más importante con un $79 \%$.

\section{Canal tradicional}

Para el Portal Peru Retail en una de sus publicaciones nos brinda la siguiente definición.

"El canal tradicional en el Perú es aquel que permite vender un producto al consumidor a través de mercados, bodegas y kioscos" (Peru Retail, 2018).

\section{Canal Moderno}

El canal moderno en el Perú está representado por las grandes cadenas de supermercados e hipermercados tales como Plaza Vea, Cencosud, Tottus. También en este sector ingresa las categorías de tiendas por departamento como Saga Falabella y Ripley. Otro nuevo segmento que apareció en el país hace poco tiempo son las tiendas de conveniencias tales como Oxxo, Tambo, Listo y otras más. Todas estas tiendas se consideran canal moderno en el país.

\section{Los Estilos de Vida (EdV)}

De acuerdo con el estudio realizado por Rolando Arellano, existen 6 estilos de vida en el Perú y Latinoamérica (Arellano Cueva, 2020).

\section{Los sofisticados}

Pertenecen a un segmento mixto, pero con un nivel de ingreso más alto que el promedio.

Mayormente, son los más jóvenes que el promedio de la población. 
Son liberales, cosmopolitas, abiertos a la globalización, optimistas, valoran la imagen personal, con interés en ascender socialmente e innovadores en el consumo.

\section{Actividades en tiempo libre}

Descansan en casa, escuchan música, ver TV o navegan en internet.

Salen a reunirse con amigos o familiares.

Tienen la costumbre de salir a comer fuera de casa como mínimo 3 veces al mes.

Leen periódicos, revistas o páginas de internet para estar actualizados.

Van al cine. Es el segmento que más acude.

Frecuentan bares y discotecas los fines de semana.

Salen de compras a centros comerciales. Tienden a comprar y mostrar moda hacia los demás.

Comportamiento en el trabajo

Aspiran a importantes posiciones.

Consideran que crecer profesionalmente es la llave para el éxito y liderazgo anhelado.

Se esfuerzan para conseguir dinero, pero no es una obsesión.

Intereses

Mucha expectativa por viajar al extranjero para estudiar y retornar para poner una empresa. 
Viven consiguiendo símbolos de estatus como productos exclusivos, anécdotas y otros.

\section{Estilos de compra}

Les atraen los productos innovadores y las nuevas plataformas de compra y de marketing.

Se relacionan y valoran con las marcas.

Ponen interés en la información nutricional de los alimentos.

\section{Progresistas}

Pertenecen al segmento hombres y en su mayoría son obreros y empresarios formales e informales.

Tienen carácter pujante, proactivos, sacrificados, realistas, pero con poco interés en su imagen.

Toman turnos para cuidar a los hijos y los quehaceres básicos de la casa.

Actividades en tiempo libre

Descansan y ven televisión.

Tienen preferencia por divertirse con amigos, en discotecas o jugar fulbito en las losas deportivas del barrio.

Comportamiento en el trabajo 
Se buscan el trabajo en la calle, no dejan de estar de hacer algo productivo.

Son muy sociables.

Intereses

Estudian carreras cortas para empezar a trabajar rápidamente.

Se trazan metas desafiantes para lograrlas a través del ingenio.

Estilos de compra

Consumen productos tradicionales y modernos, pero sin pagar un extra por la novedad.

Aprovechan las ofertas para adquirir productos tecnológicos.

Buscan el costo-beneficio en el momento de la compra al economizar.

\section{Las Modernas}

Pertenecen al segmento mujeres quienes buscan su realización personal.

Están en contra del machismo.

Se encuentran en todos los NSE

Actividades en el tiempo libre

Gran parte está trabajando el cual le permite darse un lugar en el hogar. 
Valoran los estudios porque les da independencia económica.

Hacen manualidades y escuchan música.

Intereses

Las autorrealizaciones para ser reconocida dentro de su familia.

Involucrarse en actividades para mantenerse activas.

Estilos de compra

Les gusta proyecta una imagen profesional y cuidar su estética.

Consideran el hecho de comprar como un placer y valoran las marcas.

Les interesa los productos que les haga sentir menos ama de casa.

\section{Los Formalistas}

Pertenecen al segmento hombres.

Llegan un poco tarde a la moda.

Tienden al machismo.

Actividades en el tiempo libre

Descansan en casa viendo televisión. 
Se informan de la actualidad a través del internet y periódicos.

Comparten tareas del hogar.

Comportamiento en el trabajo

Son reacios al cambio.

Son poco ambiciosos e innovadores en sus actividades.

Estilos de compra

Son los segundos en adoptar productos de moda.

Prefieren vestir ropa deportiva o casual.

Son los que menos compran artículos de hogar.

\section{Las Conservadoras}

Pertenecen al segmento mujeres de tendencia religiosa y tradicional como las típicas mamás gallina y se encuentran en todos los NSE.

Son las responsables de casi todos los gastos del hogar.

Sus hijos son lo más importante.

Procuran conservar las buenas costumbres. 
Actividades en el tiempo libre

Visitan con frecuencia a sus familiares

Les gusta ver telenovelas, pasear en parques y centros comerciales.

La decoración de su vivienda es lo más importante.

Tienden poco interés en la moda.

Intereses

Consideran que el jefe de hogar es el esposo.

Desean ser buenas amas de casa y sentirse queridas por su familia.

Consideran importante la educación de sus hijos.

Estilos de compra

Son ahorrativas.

Las marcas no son lo más importante sino los beneficios nutricionales y la cantidad recibida.

La compra es vista como una necesidad y no como un placer. 


\section{Los Austeros}

Pertenecen al segmento mixto con pocos recursos económicos.

Son reacios a los cambios.

Su principal preocupación es conseguir dinero para subsistir.

Actividades en el tiempo libre

Les agrada ver televisión y escuchar música.

Pasean dentro de la ciudad.

Prefieren la diversión dentro de la familia.

Intereses

La educación es valorada, pero tienen poco acceso a ella.

Perciben lo novedoso como un riesgo.

El legado más importante que le dejan a sus hijos es la educación.

Estilos de compra

El precio es un factor determinante en el proceso de compra. 
Economizar es una actividad del día a día.

Las compras y objetos personales tienen un sentido pragmático.

\section{Covid 19}

COVID-19 es la enfermedad infecciosa causada por el coronavirus que se ha descubierto más recientemente. Actualmente la COVID-19 es una pandemia que afecta a muchos países de todo el mundo (Organizacion Mundial de la Salud, 2019). 


\section{Herramientas}

\section{PEST}

El Instituto Profesional Esucomex de Chile nos brinda la siguiente descripción del análisis:

"El análisis PEST es una herramienta de gran utilidad para comprender el crecimiento o declive de un mercado y, en consecuencia, la posición, potencial y dirección de un negocio. Es una herramienta de medición de negocios" (Instituto Profesional Esucomex, 2016).

EI PEST incluye los factores políticos, económicos, sociales y tecnológicos.

\section{IBM SPSS Statistics}

Este programa es una de las plataformas de software estadístico más reconocido en el mundo que permite extraer y gestionar información de manera práctica de datos de gran tamaño y complejidad.

Este software es capaz de reducir el tiempo de preparación de los datos, logra identificar valores no válidos, resume las distribuciones de variables y garantiza una toma de decisiones de alta precisión y calidad (IBM, 2020).

\section{Pronóstico}

Es una estimación informada de lo que ocurrirá en el futuro a través de una técnica estadística de análisis de datos del pasado y del presente. Sin importar la técnica empleada, no se puede elaborar pronósticos perfectos (Anderson, Sweeney, Williams, Camm, \& Martin, 2011). 


\section{Pronóstico con promedio móvil ponderado}

Es un método de proyección de las series de tiempo que implica escoger una posible ponderación diferente para cada valor de datos y luego se calcula un promedio ponderado de los valores $\mathrm{n}$ más recientes como valor uniformizado. De tal forma que se emplea un valor uniformizado como una proyección al futuro.

Entonces, al dato más reciente se le da una mayor ponderación, la cual disminuye con valores de datos más antiguos. La suma de las ponderaciones tiene que ser igual a 1 (Lind, Marchal, \& Wathen, 2012).

\section{Pronóstico con suavizamiento exponencial simple}

Es el método ideal para patrones de demanda aleatorios donde se desea reducir el impacto de los elementos irregulares. Se realiza el ajuste de los pronósticos en dirección opuesta a las desviaciones históricas mediante una autocorrección del coeficiente de suavización.

Si se requiere predecir el valor siguiente de una serie de tiempo $Y_{t}$, su pronóstico se denota por $F_{t}$. Cuando la observación $Y_{t}$ se vuelve disponible, el error de pronóstico se calcula como $\left(Y_{t}-F_{t}\right)$. Este pronóstico toma el periodo anterior y lo ajusta utilizando el error de pronóstico. Por lo tanto, el pronóstico para el siguiente periodo será: $F_{t+1}=F_{t}+\alpha\left(Y_{t}-F_{t}\right)$ (Hyndman, Makridakis, \& Wheelwright, 2008).

Donde a toma un valor entre 0 y 1 .

\section{Pronóstico con el modelo Holt}

Este método adicional al suavizamiento exponencial el elemento de tendencia, por lo que también se le conoce como suavizamiento exponencial doble.

Además de la constante de suavizamiento $\alpha$, se toma en cuenta la tendencia $\beta$. Ambas constantes oscilan entre 0 a 1 (Izar, 2019). 
La variable pronosticada para el periodo de tiempo t se calcula con la siguiente fórmula: $\hat{y}_{t}=L_{t}+p T_{t}$

Donde $\hat{y}_{t}$ es el valor pronosticado, $L_{t}$ es el valor estimado para el periodo $\mathrm{t}, \mathrm{p}$ es el periodo a pronosticar en el futuro y $T_{t}$ es el valor de tendencia en el periodo t.

Por otro lado, se tiene la ecuación $L_{t}=\alpha Y_{t-1}+(1-\alpha)\left(L_{t-1}+T_{t-1}\right)$

Asimismo, la tendencia T se obtiene de la ecuación $T_{t}=\beta\left(L_{t}-L_{t-1}\right)+(1-\beta)\left(T_{t-1}\right)$.

\section{Pronóstico con aditivo de Winters}

Este método mezcla un componente de nivel, un componente de tendencia y un componente estacional en cada periodo para poder generar los pronósticos. Los valores iniciales para los componentes de nivel y de tendencia son obtenidos de una regresión lineal, mientras que los valores iniciales para el componente estacional son obtenidos de una regresión de variables simulada utilizando datos sin tendencia.

El pronóstico para m periodos en el periodo de tiempo t se obtiene de ecuación $L_{t}+m T_{t}+S_{t}+m-p$.

Donde Lt es el nivel, Tt es la tendencia en el tiempo t y $\mathrm{St}+\mathrm{m}-\mathrm{p}$ es el componente estacional para el mismo período del año anterior (IBM, 2020).

\section{Error porcentual absoluto medio}

Este término es conocido como MAPE (Mean Absolute percent error) en inglés. 
Se calcula a partir del promedio de las diferencias absolutas halladas de los valores pronosticados y los reales. Se expresa en valor de porcentaje (Heizer \& Render, 2014).

\section{Prueba de normalidad de Shapiro-Wilk}

Se utiliza para contrastar la normalidad cuando la muestra tiene como máximo 50 observaciones. Primero, se calcula la media y la varianza muestral y se ordenan los datos de manera creciente. Luego, se determina las diferencias entre el primero y el último, el segundo y el penúltimo, el tercero y el antepenúltimo. Así sucesivamente y se corrige con unos coeficientes tabulados por Shapiro y Wilk.

Se rechazará la hipótesis nula de que la muestra proviene de una distribución normal si el estadístico W es menor que el valor crítico proporcionado por la tabla propuesta por los autores de acuerdo al tamaño muestral y el nivel de significancia (Díaz, 2009).

\section{Coeficiente de correlación de Spearman}

Es una medida de correlación de asociación o interdependencia no paramétrica. Se usa cuando las variables cuantitativas no cumplen con el supuesto de normalidad o son variables de tipo cualitativo ordinal.

Se obtiene del cálculo $r_{R}=1-\frac{6 \sum_{i} d_{i}^{2}}{n\left(n^{2}-1\right)}$

Donde $\mathrm{n}$ es el número de datos y $d_{i}$ es la diferencia de rango del elemento $\mathrm{n}$.

Sus valores van de -1 a 1 , siendo 0 el valor que indica no correlación y los signos indican correlación directa e inversa (Bravo, Rodríguez, \& Salazar, 2001). 


\section{OBJETIVOS}

\section{Objetivo General}

Determinar el impacto de la población migrante venezolana en la demanda de nuevos productos de consumo masivo dentro de Lima Norte.

\section{Objetivos Específicos}

Establecer los factores que motivaron a la población migrante venezolana en Lima Norte a elegir al Perú.

Diferenciar el consumo entre peruanos y migrantes venezolanos.

Establecer la nueva tendencia de productos demandados por la población migrante venezolana en Lima Norte en el canal tradicional.

Determinar las marcas de productos de consumo masivo que tienen potencial aceptación por los migrantes venezolanos. 


\section{JUSTIFICACIÓN}

\section{Teórica}

La presente tesis surge en el marco de una fuerte migración masiva venezolana la cual habilita el escenario de posibles ingresos de nuevos productos de consumo masivo, en las bodegas y mercados, que hasta el momento es el más preferido por los shoppers y consumidores.

Entonces el Perú empieza a adquirir un nuevo nicho de mercado que se encuentra actualmente en desarrollo al tener necesidades que antes no existían. La investigación busca definir el perfil de un nuevo consumidor cuyas preferencias de consumo tendrán ciertas diferencias al del consumidor peruano, por lo cual se brindará detalles de los posibles productos para su distribución y comercialización en este canal, apoyándonos de un pronóstico de la demanda.

Por lo tanto, se podrá indicar las empresas que entrarían al país o aquellas que prefieren importar los productos. Asimismo, valiéndonos de las tendencias comerciales, se busca identificar el top of mind de marcas peruanas que los venezolanos prefieren como parte de su canasta básica. También se analizará los factores que influyen para que los venezolanos opten por el canal de venta tradicional para su consumo y la recomendación que se brindará al punto de venta tradicional aplicando el trade marketing para los productos a ingresar al mercado.

\section{Práctica}

Esta tesis tiene la finalidad de ser un aporte para los bodegueros y mercados, en cuanto a maximizar el escenario positivo que surge ante la migración de los venezolanos y la prevalencia de sus preferencias en el momento de compra. Entonces, el canal tradicional tiene que adaptarse para incluir los nuevos productos que son solicitados por la nueva población que llega y/o llegó al Perú. 
Para ello, a través del perfil que se obtendrá de estos nuevos consumidores se podrá sugerir al canal tradicional cómo enfocarse en el mix de los productos ofrecidos en el punto de venta.

Además, que con un pronóstico de la demanda de los posibles productos requeridos podría ser muy útil para la industria que puede estar interesada en producirlo o importarlo. Asimismo, se podrá entender los factores por las que el canal tradicional es preferido por los venezolanos para su canasta básica y con ello, el punto de venta poder potenciarlo con el trade marketing para exhibir los nuevos productos de la mejor forma.

\section{Social}

La presente investigación se dará en Lima Norte. Cabe mencionar que Perú se considera aún un país centralizado, por ende, Lima alberga la mayor parte de la población e industria.

La presente investigación se enfoca en el análisis en la oferta de productos de consumo masivo en las bodegas y mercados, debido a que estas sufrirán un cambio por la migración venezolana en el país, cuyos migrantes llegan con otra cultura y otros tipos de consumo.

También el presente trabajo dará las pautas para que las bodegas y mercados puedan aprovechar la migración y ofertar nuevos productos, la mayoría bodegas y mercados se ubican en las periferias de Lima. Un dato interesante es el gran apego del consumidor al consumo canal tradicional en comparación del canal moderno.

Asimismo, tendrá impacto al desarrollo de nuevas empresas e industrias de que podrán desarrollar o importar productos para satisfacer las nuevas necesidades de los migrantes. 


\section{HIPÓTESIS}

\section{Hipótesis General}

La población migrante venezolana en Lima Norte tiene un impacto significativo en la demanda de nuevos productos de consumo masivo.

\section{Hipótesis Específicas}

La población migrante venezolana en Lima Norte eligió al Perú por condiciones socioeconómicas.

La demanda de nuevos productos de consumo masivo corresponde a ser símbolo de identidad, cultura y tradición, pero a la vez adaptando su patrón de consumo.

A mayor población migrante venezolana, mayor demanda de nuevos productos de consumo masivo insertados al canal tradicional por el nuevo perfil de consumo en Lima Norte.

Las marcas de productos de consumo masivo que tienen potencial aceptación por los migrantes venezolanos son Maltín Polar, Diablitos y Cerelac. 


\begin{abstract}
Alcance
El límite territorial de la tesis se dará dentro del territorio de Lima Norte, siendo el canal de ventas tradicional el escogido donde encontramos bodegueros y mercados. Se da en el presente contexto social peruano, que en la actualidad tiene un gran flujo de migrantes venezolanos que residen y trabajan en el país. Los migrantes venezolanos en el Perú tienen ciertas características de consumo y cuentan con una cultura totalmente distinta a la peruana.
\end{abstract}

\title{
Limitaciones
}

Una de las limitaciones del presente trabajo de investigación es depender de la disponibilidad de la comunidad venezolana que reside en Lima Norte. Ellos son una pieza clave para el análisis debido a que nos aportarán información. Otra de las limitantes es el presupuesto que se manejará para realizar las encuestas, porque muchas personas buscarán responder las preguntas a cambio de un beneficio para ellos.

También se debe tener en cuenta la limitación de información, debido a que los entes reguladores de la migración venezolana es el estado y sus flujos de información son lentos.

Otro caso es que se tiene información de periódicos realizadas por periodistas y especialistas, pero no cuentan con un estudio a profundidad para poder tomarlo como fuente fidedigna, mientras que la información confiable que se maneja por parte del estado no es del presente año, si no de años anteriores, pero cuentan con un gran respaldo al ser emitidos por el gobierno peruano.

Un factor importante para considerar es la coyuntura del Covid-19 que desfavoreció el levantamiento de información con encuestas presenciales ante las restricciones de movilidad y el miedo de contagio. 
MATRIZ DE CONSISTENCIA 
Tabla 4

Matriz de consistencia

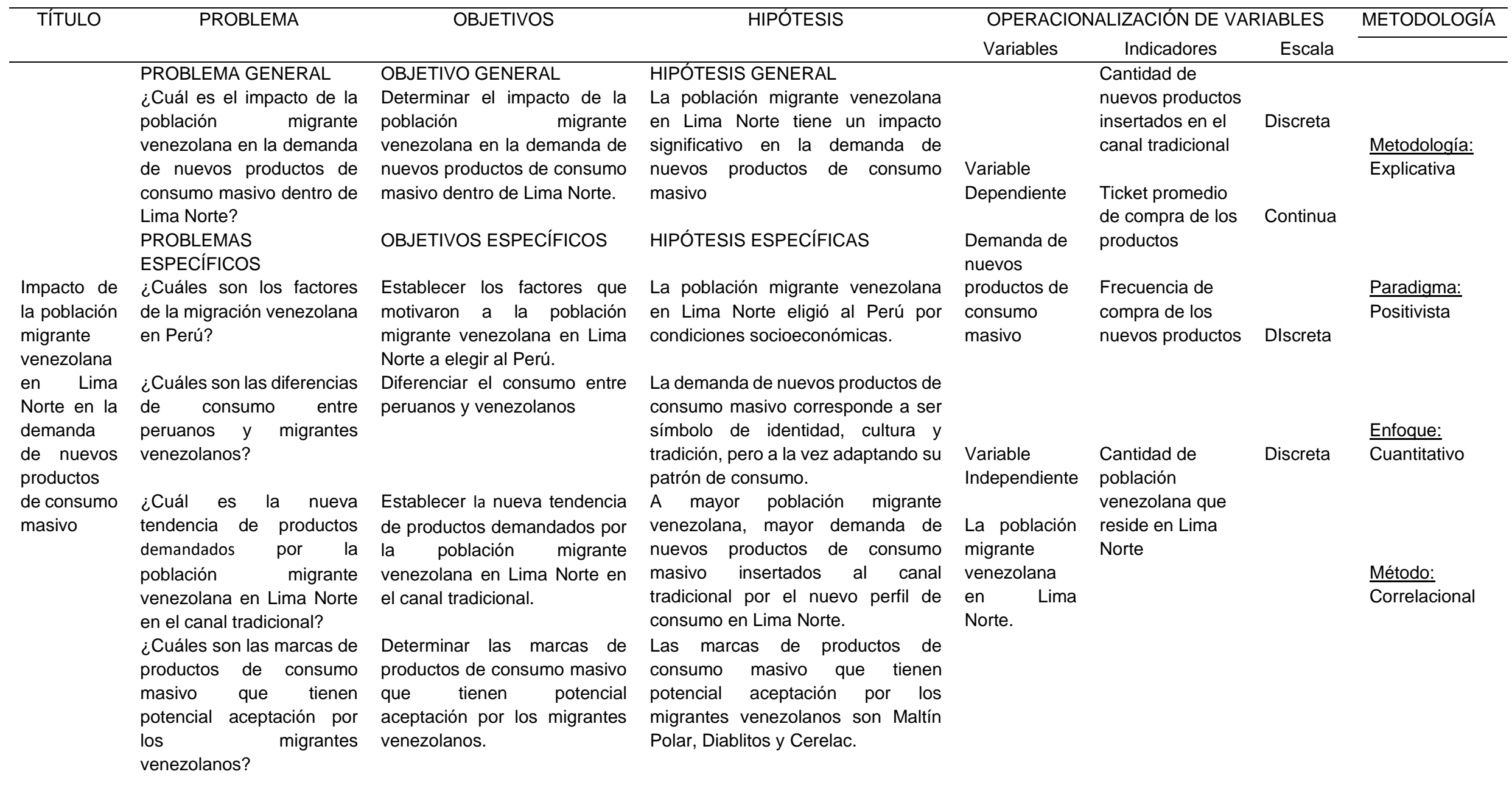

Fuente: Elaboración propia 


\section{MARCO METODOLÓGICO}

\section{Paradigma}

La presente investigación se basa en el paradigma positivista. Tendrá datos medibles, de los cuales se requiere recopilar información actual por parte de la población observada.

El estudio se dará en la población de Lima Norte, donde alberga la realidad social de la migración venezolana. De los datos recabados se dará una discusión para ver la veracidad de la información y se presentará luego los resultados obtenidos de la misma. Nuestra principal técnica de medición en este caso será las encuestas.

\section{Enfoque}

Para realizar nuestro enfoque cuantitativo vamos a usar la recolección de datos por medio de las encuestas a los ciudadanos venezolanos residentes en Lima norte y así recabar la información estadística para sacar distintos resultados de las hipótesis que estamos tratando de establecer, los datos recabados nos ayudaran a entender los patrones de compra y su comportamiento como consumidor.

La información que se buscara está delimitada por zona, los participantes son los ciudadanos venezolanos. Con todos los datos que obtengamos vamos a explicar cómo afecta y se podrá predecir qué productos nuevos tendrán gran acogida en Lima Norte. Toda la información será lógica y tendrá razonamiento deductivo para poder 


\section{Método}

La investigación consistirá en el método correlacional.

Con el método explicativo, se describirá el perfil del consumidor venezolano migrante: nivel de ingresos, productos de canasta básica, preferencia de marcas peruanas, frecuencia de compra, canal de preferencia y otros aspectos relevantes para la recopilación de datos.

Con el método correlacional, se conocerá el vínculo entre la migración venezolana y la oferta de nuevos productos en las bodegas y mercados que han ingresado en los últimos meses en Lima. Con ello, será de gran utilidad para definir los nuevos sectores beneficiados por las nuevas empresas que ofrecen los productos de consumo masivo que son solicitados por la comunidad venezolana. 
VARIABLES

Se define las siguientes variables:

\section{Variable Independiente}

Tabla 5

Variable independiente

\begin{tabular}{lll}
\hline Variable Independiente & Indicadores & Escala \\
\hline & Género & Nominal
\end{tabular}

Rango de edad

Continua

La población migrante venezolana en Lima Norte.

Estado civil Nominal

Grado de instrucción

Ordinal

Ocupación

Nominal 


\section{Variable Dependiente}

Tabla 6

Variable dependiente

\begin{tabular}{lll}
\hline Variable Dependiente & Indicadores & Escala \\
\hline & Cantidad de nuevos productos & Discreta \\
insertados en el canal tradicional
\end{tabular}

$\begin{array}{lrrr}\text { Demanda } & \text { de } & \text { nuevos } & \begin{array}{l}\text { Ticket promedio de compra de los Continua } \\ \text { productos }\end{array} \\ \text { productos de } & \text { consumo } & \\ \text { masivo } & & & \end{array}$

Frecuencia de compra de los nuevos

Discreta

productos 


\section{POBLACIÓN Y MUESTRA}

\section{Población}

Basado en el Monitoreo de flujo de la población venezolana en el Perú, en el 2019 se albergó alrededor de 860 mil ciudadanos venezolanos en nuestro país, ubicándolo como el segundo país después de Colombia que acoge a estos migrantes a nivel global (Organización Internacional para las Migraciones Perú, 2020).

Los niños y adolescentes representan el 18,7\% de la población venezolana en Perú, un $42 \%$ de venezolanos son jóvenes entre 18 a 29 años, un $29,8 \%$ tienen 30 a 44 años, un $8 \%$ son adultos entre 45 y 60 años (Reuters, 2019).

Se elabora la estratificación por edades, donde 686280 migrantes venezolanos están entre 18 a 60 años.

Tabla 7

Grupo Etario - población venezolana

\begin{tabular}{lrr}
\hline Grupo etario & Porcentaje & Población \\
\hline Niños y adolescentes & 18.7 & 160,820 \\
$18-29$ años & 42.0 & 361,200 \\
30 - 44 años & 29.8 & 256,280 \\
$45-60$ años & 8.0 & 68,800 \\
+60 años & 1.5 & 12,900 \\
Total & 100.0 & 860,000
\end{tabular}

Fuente: Elaboración propia basada en Radiografía de los venezolanos en Perú

Según el informe de la Superintendencia Nacional de Migraciones, Lima Metropolitana y Callao albergan el $92 \%$ de ciudadanos venezolanos, siendo Lima Norte donde se concentra el 28\% de los ciudadanos venezolanos (Superintendencia Nacional de Migraciones, 2018). 
Se elabora la estratificación por zonas de residencia:

Tabla 8

Zonas de residencia - migrantes venezolanos

\begin{tabular}{lrr}
\hline Zonas de residencia & Porcentaje & Población \\
\hline Otra región & $8 \%$ & 54,902 \\
Lima Norte & $28 \%$ & 192,158 \\
Lima Centro & $26 \%$ & 178,433 \\
Lima Este & $20 \%$ & 137,256 \\
Lima Sur & $18 \%$ & 123,530
\end{tabular}

Total migrantes venezolanos residentes en

Lima Metropolitana y Callao 631,378

Fuente: Elaboración propia basada en el Informe Migratorio de características sociodemográficas de ciudadanos venezolanos

Por lo tanto, realizando la delimitación de la población, se obtiene 192158 migrantes venezolanos en Lima Norte en un rango de edad de 18 a 60 años.

\section{Muestra}

La fórmula utilizada para obtener la muestra fue la siguiente:

$$
n=\frac{\left(Z^{2}\right) *(P * Q * N)}{\left.\left(\left(E^{2}\right)(N-1)\right)+\left(Z^{2}\right)(P * Q)\right)}
$$

Donde:

- $\mathrm{n}=$ tamaño de muestra

- $\quad Z$ = Nivel de confiabilidad

- $\mathrm{P}=$ probabilidad positiva

- $Q=$ probabilidad negativa

- $E=$ margen de error

- $\mathrm{N}=$ población 


$$
n=\frac{\left(1.96^{2}\right) *(0.5 * 0.5 * 192158)}{\left.\left(\left(0.05^{2}\right)(192158-1)\right)+\left(1.96^{2}\right)(0.5 * 0.5)\right)}
$$

$\mathrm{n} \cong 384$ personas

Según la muestra obtenida, se obtuvo la cantidad de personas en los ocho distritos de Lima Norte que se presentan en la tabla 9:

Tabla 9

Muestreo estratificado

\begin{tabular}{lcc}
\hline Distritos & Muestra & Porcentaje \\
\hline San Martín de Porres & 151 & $39.06 \%$ \\
Los Olivos & 119 & $30.99 \%$ \\
Comas & 57 & $14.84 \%$ \\
Independencia & 28 & $7.29 \%$ \\
Puente Piedra & 16 & $4.17 \%$ \\
Carabayllo & 12 & $3.13 \%$ \\
Ancón & 1 & $0.26 \%$ \\
Santa Rosa & 1 & $0.26 \%$ \\
Total & 384 &
\end{tabular}

Fuente: Elaboración propia basada en el informe Migratorio de la Superintendencia Nacional de Migraciones.

\section{UNIDAD DE ANÁLISIS}

1 migrante venezolano que reside en Lima Norte con un rango de edad dentro de los 18 a 60 años. 


\section{INSTRUMENTOS Y TÉCNICAS}

\section{Instrumentos}

Uno de los instrumentos para realizar esta investigación son las fichas bibliográficas de distintos trabajos y estudios realizados, reseñas brindadas por varios autores, resúmenes e interpretaciones. Así como el desarrollo de un análisis PEST y el cuestionario a través de la estadística como parte de interpretación. Describiremos la relación que tienen nuestras hipótesis con las técnicas e instrumentos que se usará.

Hipótesis 1: La población migrante venezolana en Lima Norte eligió al Perú por condiciones socioeconómicas.

Para el desarrollo de mencionada hipótesis se tendrá que aplicar el cuestionario y se profundizará con el análisis PESTEL en el cual ingresan las siguientes partes: POLITICOECONÓMICO-SOCIAL-TECNOLÓGICO. Mayormente los análisis un país PEST se utiliza para examinar una empresa, el análisis a realizar será enfocado al país en el 2018 donde hubo un flujo excepcional de migrantes.

Hipótesis 2: La demanda de nuevos productos de consumo masivo corresponde a ser símbolo de identidad, cultura y tradición, pero a la vez adaptando su patrón de consumo.

Para la validación de la hipótesis mencionada se aplicará el cuestionario junto con un análisis documental de la diferenciación de productos de consumo para peruanos y venezolanos.

Hipótesis 3: A mayor población migrante venezolana, mayor demanda de nuevos productos de consumo masivo insertados al canal tradicional por el nuevo perfil de consumo en Lima Norte. 
Se validará con ciertas preguntas del cuestionario. A la vez, se procesará el histórico de importaciones de harina de maíz que nos permiten mapear si hubo crecimiento exponencial desde que se dio la migración. Sin duda, el coeficiente de correlación tendrá mucho valor para esta tesis.

Hipótesis 4: Las marcas de productos de consumo masivo que tienen potencial aceptación por los migrantes venezolanos son Maltín Polar, Diablitos y Cerelac.

Se validará con ciertas preguntas del cuestionario.

\section{Confiabilidad del instrumento}

Se optó por calcular el alfa de Cronbach como el estadígrafo para probar la confiabilidad.

En la medición de constructos a través de escalas, donde no existen respuestas correctas ni incorrectas, sino que cada persona elige el valor que representa mejor su respuesta (Cronbach, 1951).

La fórmula es:

$\alpha=\frac{n}{n-1} \frac{\sum_{k=1}^{n} \sum_{h=1}^{n} \sigma_{k, h}}{\sigma_{x}^{2}} ; \forall \mathrm{h} \neq \mathrm{k}$

Donde:

$\alpha=$ coeficiente de confiabilidad

n = número de ítems

$\mathrm{k}$ y $\mathrm{h}=$ partes sobre las que se calcula el estadístico

$\sigma_{x}^{2}=$ es la suma de las varianzas individuales de los ítems. 
En base a la recomendación, George y Mallery (2003, p. 231) sugieren las siguientes referencias para evaluar los coeficientes de alfa de Cronbach:

Coeficiente alfa $>.9$ es excelente

Coeficiente alfa $>.8$ es bueno

Coeficiente alfa $>.7$ es aceptable

Coeficiente alfa $>.6$ es cuestionable

Coeficiente alfa $>.5$ es pobre

Coeficiente alfa $<.5$ es inaceptable

En la tabla 10 se observa los resultados obtenidos, a través del SPSS versión 21 , del estadístico de fiabilidad alfa de Cronbach.

\section{Tabla 10}

Alfa de Cronbach

\begin{tabular}{ccc}
\hline \multicolumn{3}{c}{ Estadísticos de fiabilidad } \\
\hline \multirow{2}{*}{ Alfa de Cronbach } & Alfa de Cronbach basada en & $\mathrm{N}$ de \\
& los elementos tipificados & elementos \\
,802 &, 785 & 21 \\
\hline
\end{tabular}

Fuente: Software SPSS

De acuerdo con el resultado del análisis de fiabilidad de ,802, se determina que el instrumento de medición se aproxima a ser de consistencia interna "buena".

\section{Validez del instrumento}


El instrumento fue validado a través del juicio de expertos. Se utilizó el método de validez de contenido a través del criterio de dos jueces para que manifiesten su opinión sobre la claridad en la redacción, coherencia interna, inducción al sesgo, lenguaje adecuado y medir lo que se pretende.

El instrumento fue presentado a los expertos, con la finalidad de hacer reajustes y verificación de la claridad, así como mejorar la comprensión de algunos ítems.

\section{Tabla 11}

Registro de expertos en la validación del instrumento

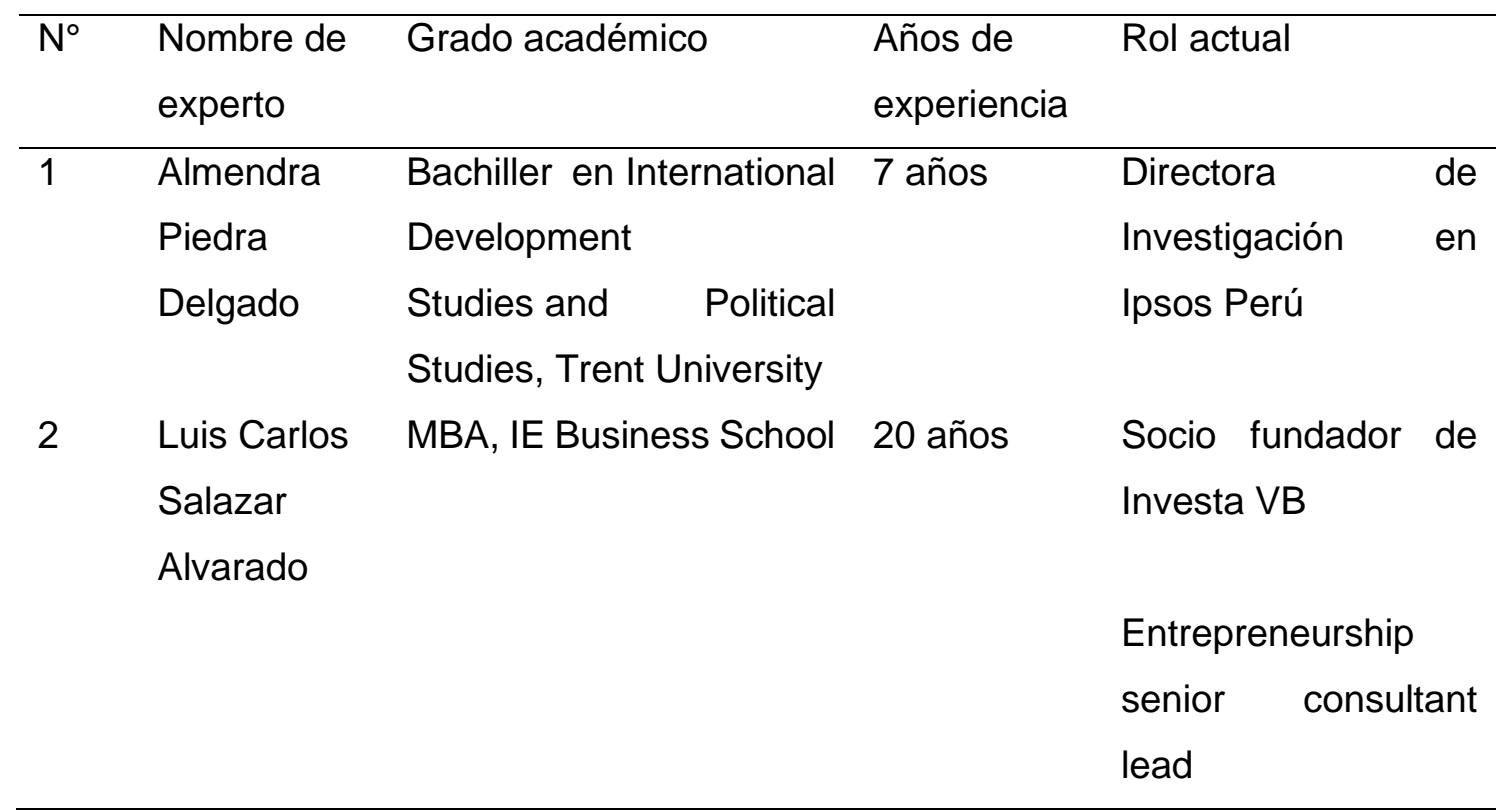

Fuente: Elaboración propia

\section{Técnicas}

Se realizará con el análisis de información de manera cuantitativa debido a todos los datos que se manejarán son extraídos de distintos estudios ya realizadas reforzándola con el propio análisis de datos que se obtendrán a través de distintas herramientas de recolección de datos y procesamiento. 
Para poder obtener datos se utilizará las técnicas documentales porque se analizarán distintas fuentes, informes realizados por entidades, libros de investigación histórica y diversos ensayos ya realizados.

Para complementar lo mencionado un estudio de la Universidad Autónoma de México nos indica lo siguiente:

"Ejemplos de estas técnicas son el aparato crítico (conjunto de apoyos al texto principal de un documento científico, según normas internacionales), las técnicas de lectura (aproximación al documento) y la reseña, el resumen, etc. (recuperación de la información)" (Universidad Autónoma del Estado de México, 2011).

Otra técnica importante será la investigación con la encuesta online que se realizará con migrantes residentes de Lima Norte, con las cuales se medirán los indicadores que interpretaremos para dar solución a la presente tesis. 


\section{PROCEDIMIENTO Y MÉTODO DE ANÁLISIS}

\section{Procedimiento}

Para realizar el análisis de la información y encontrar una solución a nuestros problemas específicos se optó por realizar una encuesta a los migrantes venezolanos que radican en Lima Norte durante el 22 al 30 de junio del 2020. Debido a la coyuntura Covid 19 no podemos realizar de manera presencial el levantamiento de información vía encuesta presencial porque debemos respetar las normas sanitarias dadas por el gobierno. Según las restricciones del Decreto supremo № 057-2020-PCM detalla en el siguiente Párrafo lo siguiente:

"Se dispone la restricción del ejercicio de los derechos constitucionales relativos a la libertad y la seguridad personales, la inviolabilidad del domicilio, y la libertad de reunión y de tránsito en el territorio, estableciendo una serie de medidas para el ejercicio del derecho a la libertad de tránsito durante la vigencia del Estado de Emergencia Nacional" (La Nación, 2020).

Debido a estas medidas restrictivas decretadas por el Gobierno Peruano, nos vimos en la obligación de buscar un nuevo método a estos nuevos tiempos.

Después de analizar varias opciones, se decidió por usar las redes sociales. En nuestra búsqueda de información buscamos grupos de venezolanos en Facebook y en Instagram con gran cantidad de miembros o followers. Se contactó al administrador de dicho grupo de Facebook y al dueño de un emprendimiento venezolano. Así se pudo postear la encuesta online. A cambio de la realización de la encuesta, el encuestado ingresaba a un sorteo de una canasta con productos exclusivamente venezolanos. Esto nos permitió hacer el filtro de obtener una respuesta de un venezolano y no de un peruano.

\section{Método de análisis}

Luego de la recolección de datos se procedió a procesar los datos con IBM SPSS STATISTICS versión 21. 


\section{RESULTADOS}

En primera instancia, se presenta los resultados obtenidos de la encuesta, los cuales fueron procesados con el programa SPSS:

Tabla 12

Sexo

\begin{tabular}{cccccc}
\hline & & $\begin{array}{c}\text { Frecuenci } \\
\text { a }\end{array}$ & $\begin{array}{c}\text { Porcentaj } \\
\text { e }\end{array}$ & $\begin{array}{c}\text { Porcentaje } \\
\text { válido }\end{array}$ & $\begin{array}{c}\text { Porcentaje } \\
\text { acumulado }\end{array}$ \\
\hline \multirow{4}{*}{ Válidos } & Femenino & 207 & 53,9 & 53,9 & 53,9 \\
& Masculino & 177 & 46,1 & 46,1 & 100,0 \\
& Total & 384 & 100,0 & 100,0 & \\
\hline
\end{tabular}

Fuente: Software SPSS

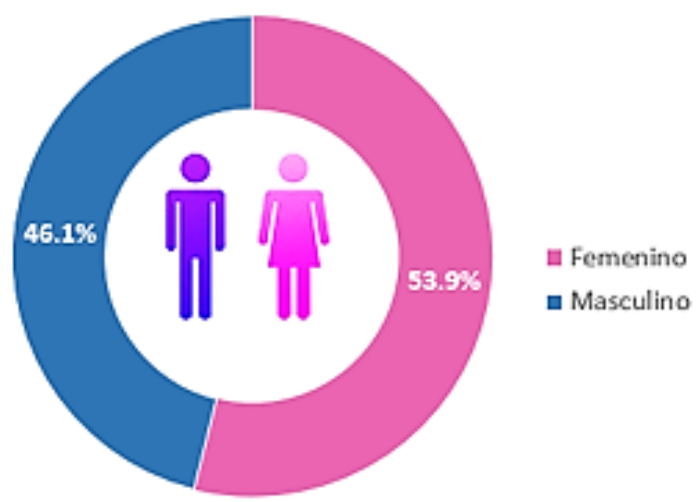

Figura 16. Sexo en encuestados

Fuente: Elaboración propia

Interpretación: En la figura 16 podemos visualizar que el predominio de encuestadas son mujeres con un $53.9 \%$, el restante son varones.

Tabla 13

Estado civil

\begin{tabular}{llcccc}
\hline & $\begin{array}{c}\text { Frecuenci } \\
\text { a }\end{array}$ & Porcentaje & $\begin{array}{c}\text { Porcentaje } \\
\text { válido }\end{array}$ & $\begin{array}{c}\text { Porcentaje } \\
\text { acumulado }\end{array}$ \\
\hline \multirow{6}{*}{ Válidos } & Soltero(a) & 261 & 68,0 & 68,0 & 68,0 \\
& Casado(a) & 52 & 13,5 & 13,5 & 81,5 \\
& Conviviente & 64 & 16,7 & 16,7 & 98,2 \\
& Divorciado(a & 7 & 1,8 & 1,8 & 100,0 \\
) & & & & \\
Total & 384 & 100,0 & 100,0 & \\
\hline
\end{tabular}

Fuente: Software SPSS 


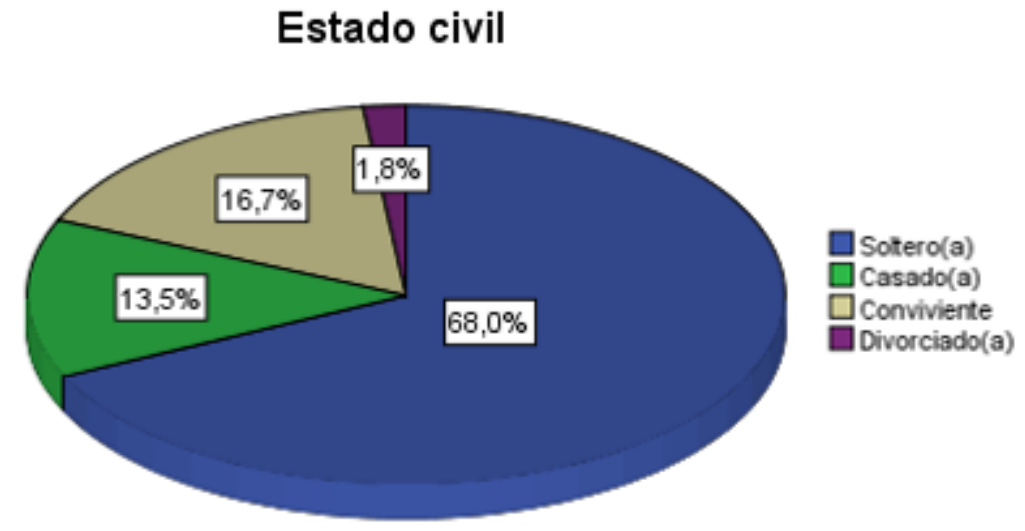

Figura 17. Estado civil

Fuente: Elaboración propia

Interpretación: De acuerdo con la figura 17 podemos visualizar que un $68 \%$ de los encuestados son solteros, seguido por un $16.7 \%$ son convivientes, los casados con un $13,5 \%$ y finalmente los divorciados con un 1,6\%.

Tabla 14

Edad

\begin{tabular}{|c|c|c|c|c|c|}
\hline & & $\mathrm{Se}$ & xo & Total & Porcentaje \\
\hline & & Femenino & Masculino & & \\
\hline & 18 a 24 & 45 & 24 & 69 & 18.0 \\
\hline & años & & & & \\
\hline & 25 a 29 & 64 & 62 & 126 & 32.8 \\
\hline & años & & & & \\
\hline & 30 a 34 & 45 & 42 & 87 & 22.7 \\
\hline Edad & años & & & & \\
\hline & 35 a 39 & 38 & 33 & 71 & 18.5 \\
\hline & años & & & & \\
\hline & 40 a 59 & 12 & 15 & 27 & 7.0 \\
\hline & años & & & & \\
\hline & 60 a más & 3 & 3 & 6 & 1.6 \\
\hline Total & & 207 & 177 & 384 & 100 \\
\hline
\end{tabular}




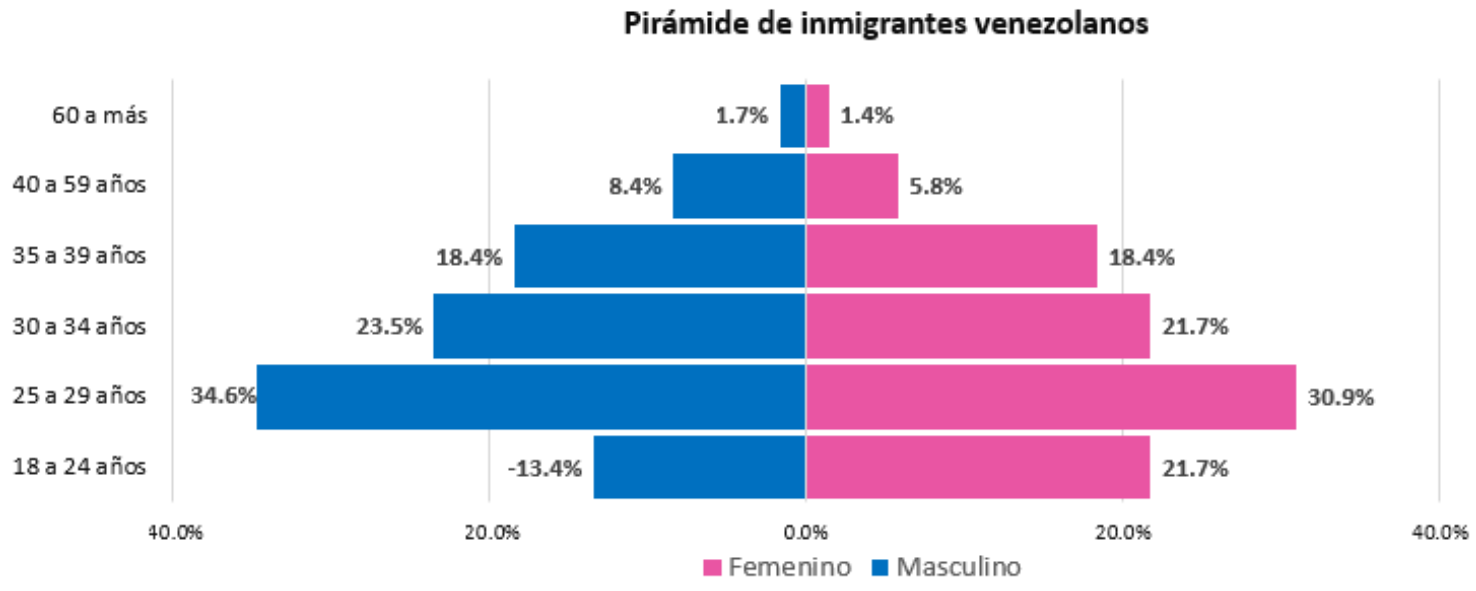

Figura 18. Edad

Fuente: Elaboración propia

Interpretación: En la figura 18 podemos visualizar que el porcentaje más fuerte son personas de 25 a 29 años con un $32.8 \%$, seguido de 30 a 34 años con $22.7 \%$. Por lo cual, nos hace pensar que es una migración de gente joven al tener un grupo etario con mayor presencia de los jóvenes entre 25 a 34 años, quienes son parte de la PEA

Tabla 15

Grado de instrucción

\begin{tabular}{llrrrr}
\hline & $\begin{array}{c}\text { Frecuenci } \\
\text { a }\end{array}$ & Porcentaje & $\begin{array}{c}\text { Porcentaje } \\
\text { válido }\end{array}$ & $\begin{array}{c}\text { Porcentaje } \\
\text { acumulado }\end{array}$ \\
\hline Primaria & 3 &, 8 &, 8 &, 8 \\
Secundaria & 132 & 34,4 & 34,4 & 35,2 \\
Universitari & 98 & 25,5 & 25,5 & 60,7 \\
Válidos & & & & \\
& Técnico & 137 & 35,7 & 35,7 & 96,4 \\
Postgrado & 14 & 3,6 & 3,6 & 100,0 \\
Total & 384 & 100,0 & 100,0 & \\
\hline
\end{tabular}

Fuente: Software SPSS 


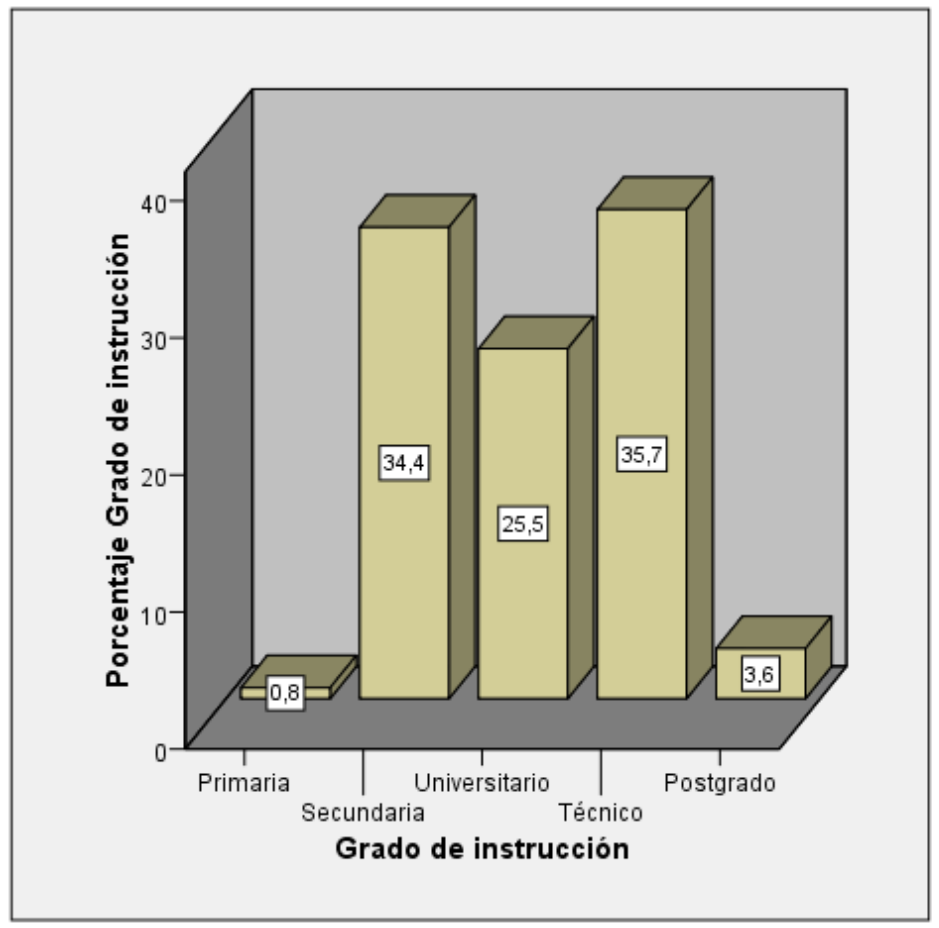

Figura 19. Grado de instrucción

Fuente: Elaboración propia

Interpretación: De acuerdo con la figura 19 podemos visualizar que un $35.7 \%$ de los encuestados tienen educación técnica, seguido de un $34.4 \%$ con educación secundaria y finalmente un $25.5 \%$ con educación universitaria. Por lo que, si agrupamos los de grado técnico, universitario y postgrado da el $64.8 \%$

Tabla 16

En el Perú, ¿con quién está viviendo?

\begin{tabular}{llcccc}
\hline & $\begin{array}{c}\text { Frecuenci } \\
\text { a }\end{array}$ & Porcentaje & $\begin{array}{c}\text { Porcentaje } \\
\text { válido }\end{array}$ & $\begin{array}{c}\text { Porcentaje } \\
\text { acumulado }\end{array}$ \\
\hline Con su familia & 214 & 55,7 & 55,7 & 55,7 \\
Con amigos/as & 66 & 17,2 & 17,2 & 72,9 \\
Válidos & Con su familia y & 23 & 6,0 & 6,0 & 78,9 \\
& amigos/as & & & & \\
Solo/a & 81 & 21,1 & 21,1 & 100,0 \\
& Total & 384 & 100,0 & 100,0 & \\
\hline \multicolumn{1}{c}{ Fuente: Software SPSS } & & & &
\end{tabular}


En el Perú, ¿con quién está viviendo?

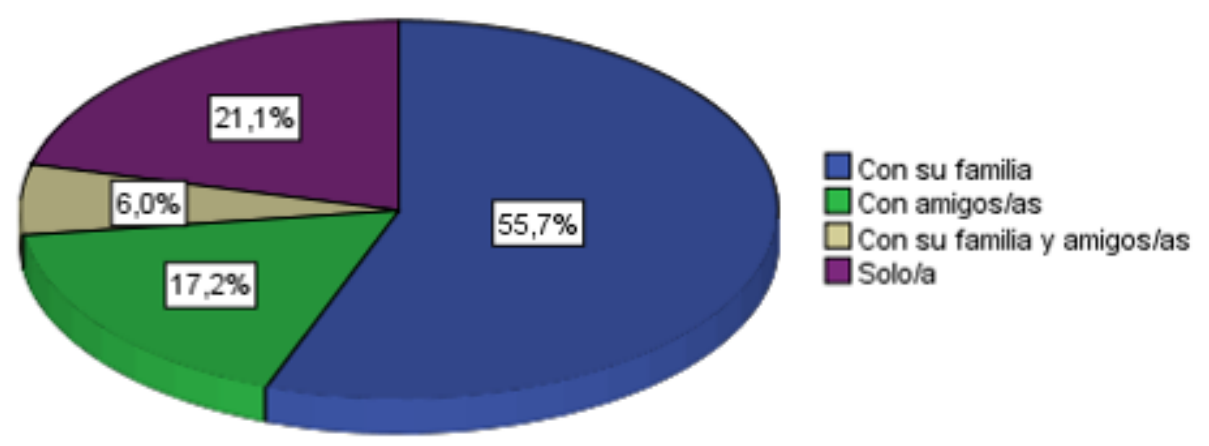

Figura 20. Personas con quienes viven

Fuente: Elaboración propia

Interpretación: En la figura 20 podemos visualizar que el $55.7 \%$ de los encuestados viven con sus familiares en el Perú. Mientras que un 21.1\% se encuentran viviendo solos y un $17.2 \%$ que vive con sus amigos. Un porcentaje muy bajo vive con su familia y amigos pues solo representa el $6 \%$.

Tabla 17

Año de residencia en el Perú

\begin{tabular}{llcccc}
\hline & & $\begin{array}{c}\text { Frecuenci } \\
\text { a }\end{array}$ & $\begin{array}{c}\text { Porcenta } \\
\text { je }\end{array}$ & $\begin{array}{c}\text { Porcentaje } \\
\text { válido }\end{array}$ & $\begin{array}{c}\text { Porcentaje } \\
\text { acumulado }\end{array}$ \\
\hline Antes del & 25 & 6,5 & 6,5 & 6,5 \\
2017 & & & & \\
2017 & 103 & 26,8 & 26,8 & 33,3 \\
Válidos & 2018 & 208 & 54,2 & 54,2 & 87,5 \\
& 2019 & 39 & 10,2 & 10,2 & 97,7 \\
& 2020 & 9 & 2,3 & 2,3 & 100,0 \\
& Total & 384 & 100,0 & 100,0 & \\
\hline
\end{tabular}

Fuente: Software SPSS 


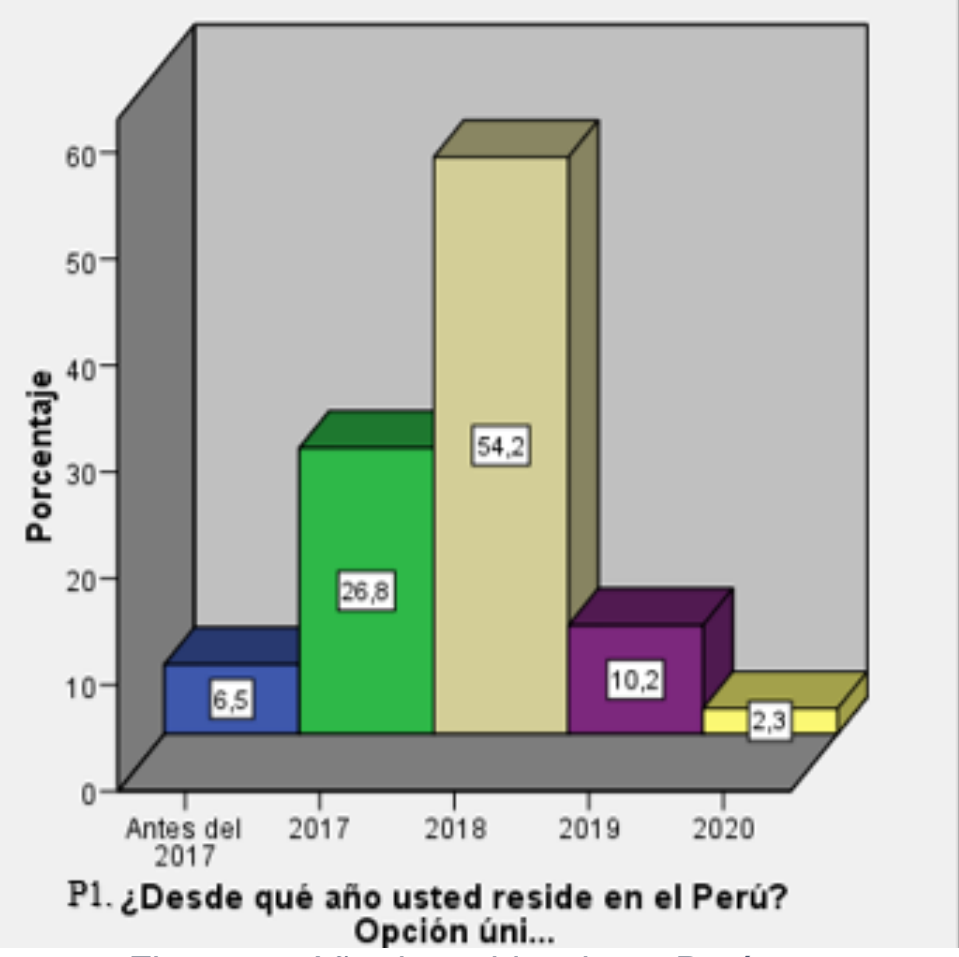

Figura 21. Año de residencia en Perú

Fuente: Elaboración propia

Interpretación: Según la figura 21, se deduce con un acumulado de porcentaje que alcanza al $81 \%$ de los encuestados que el boom migratorio se dio entre los años 2017 y 2018 , con un ingreso masivo de migrantes venezolanos al Perú. Posterior al año 2019 la cantidad que ingresa va en descenso considerable. 


\begin{tabular}{lcccc}
\hline & $\begin{array}{c}\text { Frecuenci } \\
\text { a }\end{array}$ & Porcentaje & $\begin{array}{c}\text { Porcentaje } \\
\text { válido }\end{array}$ & $\begin{array}{c}\text { Porcentaje } \\
\text { acumulado }\end{array}$ \\
\hline $\begin{array}{l}\text { Inseguridad social en } \\
\text { Venezuela }\end{array}$ & 34 & 8,9 & 8,9 & 8,9 \\
$\begin{array}{l}\text { Falta de trabajo en } \\
\text { Venezuela }\end{array}$ & 48 & 12,5 & 12,5 & 21,4 \\
$\begin{array}{l}\text { La cercanía del país y } \\
\text { mismo idioma }\end{array}$ & 3 &, 8 &, 8 & 22,1 \\
$\begin{array}{l}\text { Facilidad en el trámite } \\
\text { migratorio en Perú }\end{array}$ & 77 & 20,1 & 20,1 & 42,2 \\
$\begin{array}{l}\text { Desabastecimiento de } \\
\text { alimentos y medicinas }\end{array}$ & 122 & 31,8 & 31,8 & 74,0 \\
$\begin{array}{l}\text { Elevados precios de } \\
\text { alimentos y medicinas } \\
\text { Persecución política }\end{array}$ & 74 & 19,3 & 19,3 & 93,2 \\
$\quad$ & 3 &, 8 &, 8 & 94,0 \\
Otros & 23 & 6,0 & 6,0 & 100,0 \\
Total & 384 & 100,0 & 100,0 & \\
\hline
\end{tabular}

Fuente: Software SPSS

P2. ¿La principal razón por la que decidió migrar a Perú? Opción única

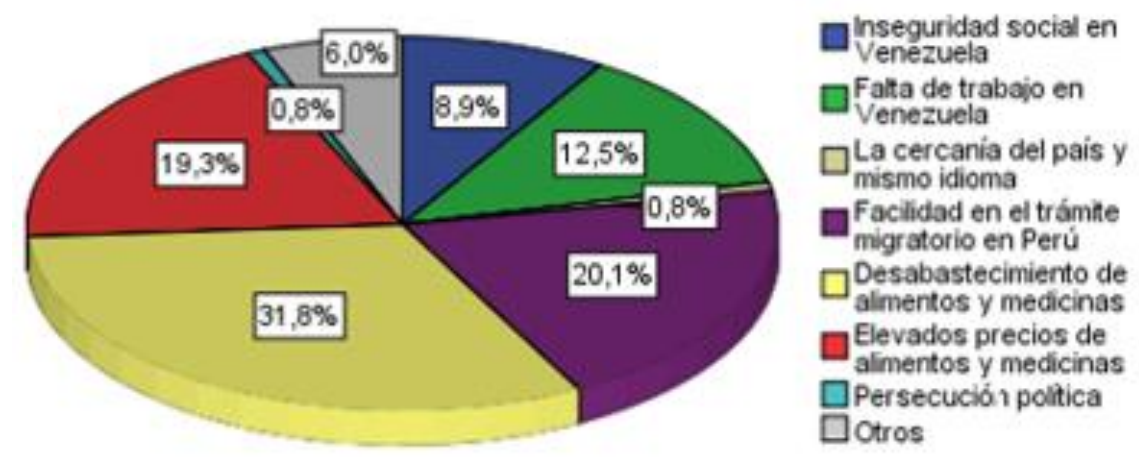

Figura 22. Las razones de migración de venezolanos

Fuente: Elaboración propia

Interpretación: Como se puede observar en la figura 22, podemos deducir que alrededor de $63.6 \%$ de los encuestados migró principalmente por factores relacionados con alimentación. Dentro de este porcentaje se está considerando el desabastecimiento y elevados precios a alimentos y medicinas. Además de la falta de empleo, debido a que, ante 
la escasez de puestos de trabajos y salarios menores al costo de vida, les imposibilita la adquisición de bienes de consumo para satisfacer sus necesidades básicas alimenticias.

Tabla 19

Personas que influenciaron en la decisión de migrar al Perú

\begin{tabular}{cccccc}
\hline & $\begin{array}{c}\text { Frecuenci } \\
\text { a }\end{array}$ & Porcentaje & $\begin{array}{c}\text { Porcentaje } \\
\text { válido }\end{array}$ & $\begin{array}{c}\text { Porcentaje } \\
\text { acumulado }\end{array}$ \\
\hline \multirow{4}{*}{ Válidos } & Pareja & 43 & 11,2 & 11,2 & 11,2 \\
& Familia & 115 & 29,9 & 29,9 & 41,1 \\
& Amigos & 25 & 6,5 & 6,5 & 47,7 \\
& Iniciativa & 201 & 52,3 & 52,3 & 100,0 \\
& propia & & & & \\
& Total & 384 & 100,0 & 100,0 & \\
\hline
\end{tabular}

Fuente: Software SPSS

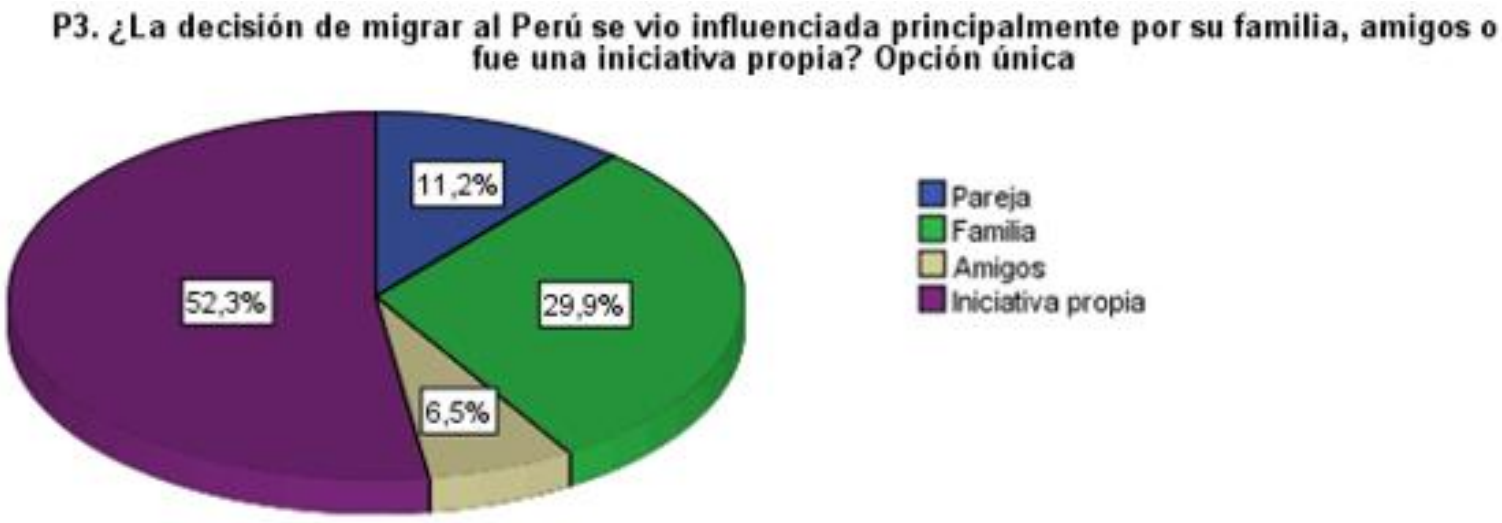

Figura 23. La influencia de migrar al Perú

Fuente: Elaboración propia

Interpretación: En la figura 23 podemos visualizar que el $52.3 \%$ de los encuestados migraron al Perú por iniciativa propia, mientras que un $41.1 \%$ de los encuestados se vieron influenciados a migrar por lazos familiares y pareja. Podríamos deducir que es la segunda razón fuerte por la cual migrar son los lazos de confianza. 
Tabla 20

Ocupación principal

\begin{tabular}{lcccc}
\hline & $\begin{array}{c}\text { Frecuenci } \\
\text { a }\end{array}$ & Porcentaje & $\begin{array}{c}\text { Porcentaje } \\
\text { válido }\end{array}$ & $\begin{array}{c}\text { Porcentaje } \\
\text { acumulado }\end{array}$ \\
\hline $\begin{array}{l}\text { Trabajo para un } \\
\text { empleador con } \\
\text { beneficios de ley }\end{array}$ & 71 & 18,5 & 18,5 & 18,5 \\
Trabajo para un & 120 & 31,3 & 31,3 & 49,7 \\
empleador pero sin & & & & \\
todos los beneficios de & & & & \\
Válidos & & & & \\
ley & 94 & 24,5 & 24,5 & 74,2 \\
Trabajo & 15 & 3,9 & 3,9 & 78,1 \\
independientemente & 84 & 21,9 & 21,9 & 100,0 \\
Ama de casa & 384 & 100,0 & 100,0 & \\
Estoy sin trabajo & & & & \\
Total & & & & \\
\hline
\end{tabular}

Fuente: Software SPSS

P4. ¿Cuál es su ocupación principal? Opción única

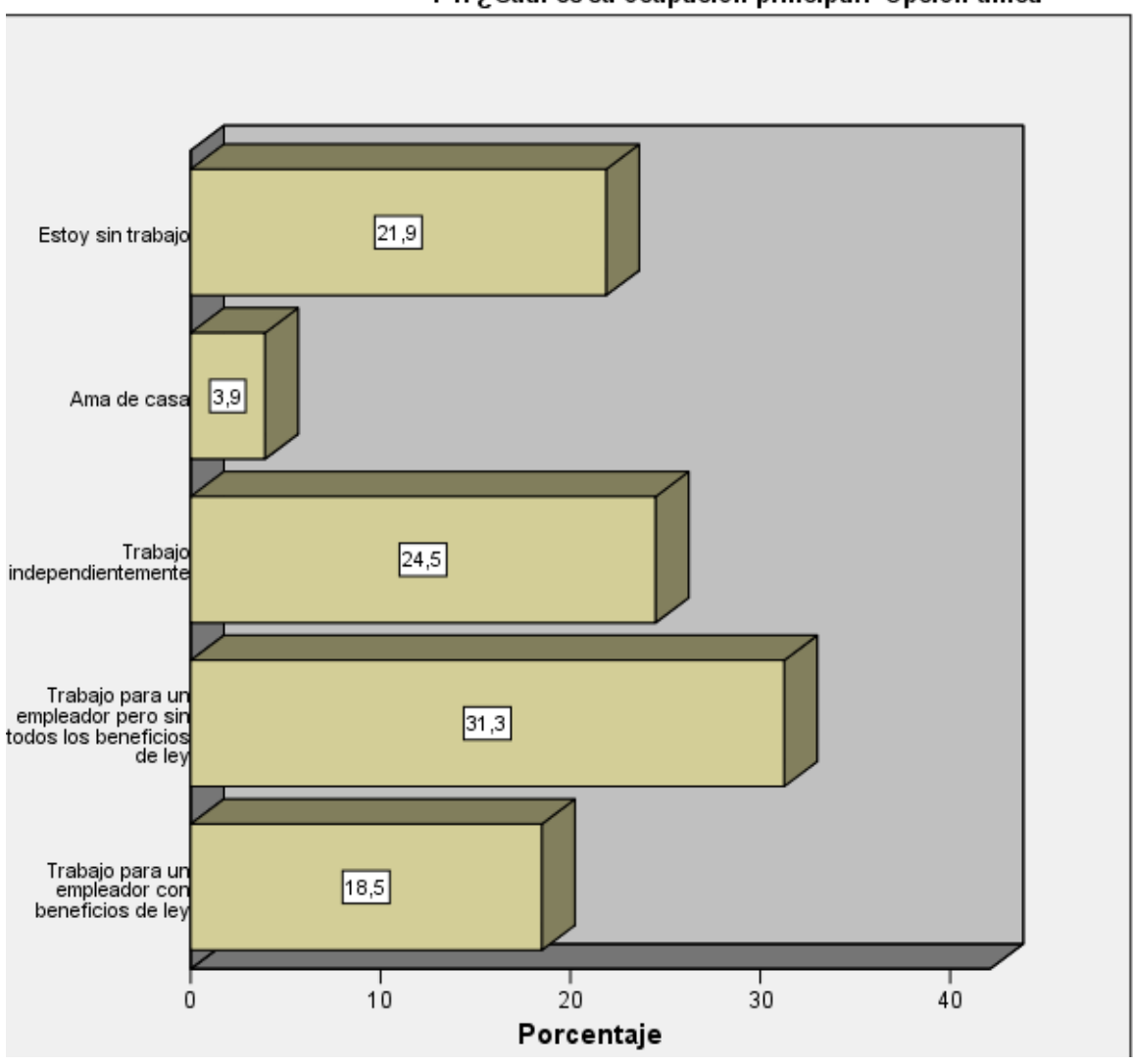

Figura 24. Ocupación principal

Fuente: Elaboración propia 
Interpretación: De acuerdo con la figura 24 , un alto porcentaje de $55.8 \%$ de los encuestados se encuentra en precariedad laboral, esto debido a que si bien cuentan con empleo este no genera ningún beneficio de ley o estarían trabajando en el sector informal como independientes. Otro dato interesante es que el $21.9 \%$ que en este momento no encuentra trabajo tendrá una tendencia a trabajar en el sector informal para poder cubrir sus gastos en el menor tiempo posible. Ante esto ya tenemos un escenario con un $77.7 \%$ que podría acumularse en un sector laboral informal para nuestra economía y un pequeño 3.9\% que es considerado ama de casa. Quedando solo $18.5 \%$ de encuestados que trabajan en el sector formal.

\section{Tabla 21}

\section{Situación actual del migrante venezolano}

\begin{tabular}{|c|c|c|c|c|c|}
\hline & & $\begin{array}{c}\text { Frecuenci } \\
\text { a }\end{array}$ & Porcentaje & $\begin{array}{l}\text { Porcentaje } \\
\text { válido }\end{array}$ & $\begin{array}{l}\text { Porcentaje } \\
\text { acumulado }\end{array}$ \\
\hline & $\begin{array}{l}\text { Estoy en mi casa } \\
\text { trabajando por } \\
\text { teletrabajo (trabajo } \\
\text { remoto) }\end{array}$ & 57 & 14,8 & 20,0 & 20,0 \\
\hline & $\begin{array}{l}\text { Estoy saliendo a } \\
\text { trabajar porque lo } \\
\text { necesito y me las }\end{array}$ & 135 & 35,2 & 47,4 & 67,4 \\
\hline \multirow[t]{3}{*}{ Válidos } & $\begin{array}{l}\text { ingenio, pero no estoy } \\
\text { autorizado por el } \\
\text { gobierno. }\end{array}$ & & & & \\
\hline & $\begin{array}{l}\text { Estoy saliendo a } \\
\text { trabajar porque estoy } \\
\text { autorizado por el } \\
\text { gobierno }\end{array}$ & 93 & 24,2 & 32,6 & 100,0 \\
\hline & Total & 285 & 74,2 & 100,0 & \\
\hline Perdidos & Sistema & 99 & 25,8 & & \\
\hline Total & & 384 & 100,0 & & \\
\hline
\end{tabular}

Fuente: Software SPSS 


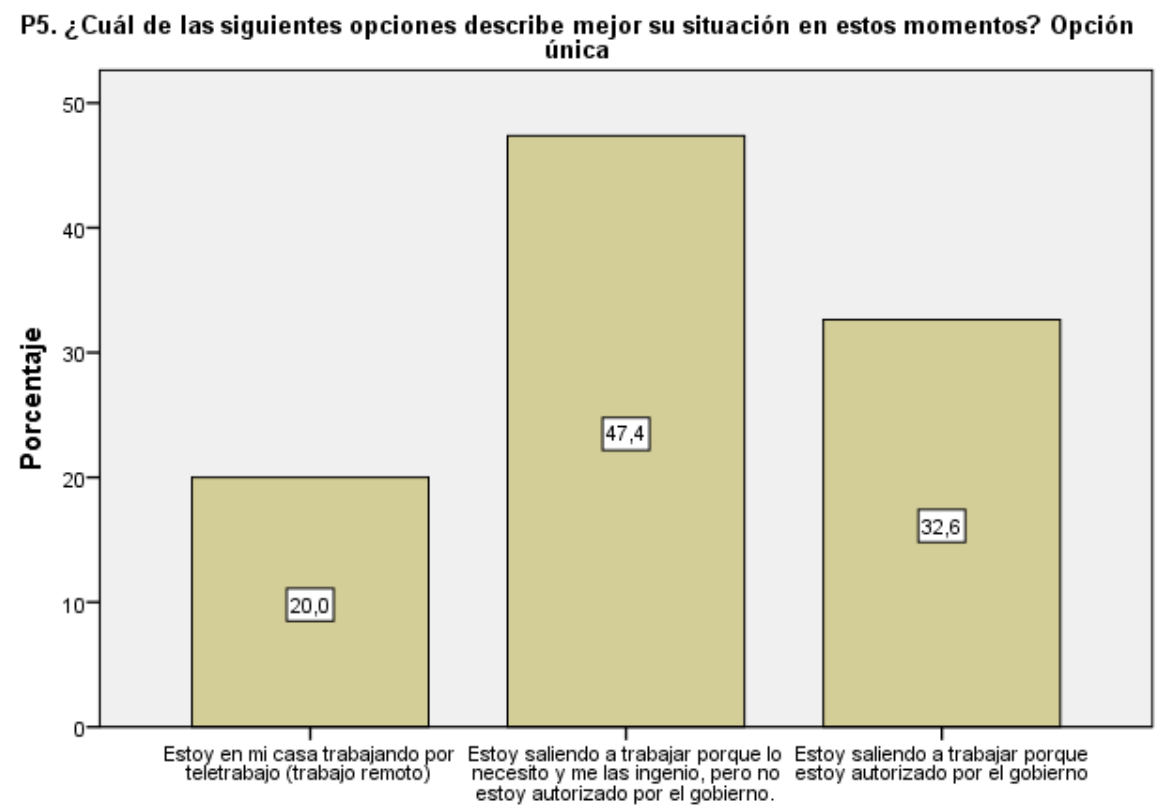

Figura 25. Situación actual de los migrantes en coyuntura Covid-19

Fuente: Elaboración propia

Interpretación: En la figura 25 podemos visualizar que el $47.4 \%$ indica que está saliendo a trabajar porque lo necesita y se las ingenia, pero no están autorizados por el gobierno. Otro $32.6 \%$ indica que sale a trabajar porque está autorizada por el gobierno y un $20 \%$ está trabajando de manera remota desde su hogar. Teniendo en cuenta que esta encuesta se realizó durante el confinamiento, refleja que casi el $47.4 \%$ de los venezolanos se expusieron a laborar a pesar de no estar autorizados.

\section{Tabla 22}

\section{Opciones de migrar a causa de Covid-19}

\begin{tabular}{llcccc}
\hline & Frecuencia & Porcentaje & $\begin{array}{c}\text { Porcentaje } \\
\text { válido }\end{array}$ & $\begin{array}{c}\text { Porcentaje } \\
\text { acumulado }\end{array}$ \\
\hline $\begin{array}{l}\text { Migrar a otro país de la } \\
\text { región }\end{array}$ & 12 & 3,1 & 3,1 & 3,1 \\
Migrar a otro país en & 34 & 8,9 & 8,9 & 12,0 \\
$\begin{array}{l}\text { otra región (América } \\
\text { del Norte, Europa, }\end{array}$ & & & & \\
$\begin{array}{l}\text { Asia, etc) } \\
\text { Retornar a Venezuela } \\
\text { Continuar viviendo en }\end{array}$ & 51 & 13,3 & 13,3 & 25,3 \\
$\quad \begin{array}{l}\text { Perú } \\
\text { Total }\end{array}$ & 287 & 74,7 & 74,7 & 100,0 \\
\hline Fuente: Software SPSS & 384 & 100,0 & 100,0 & \\
\hline
\end{tabular}


P6. Dada la coyuntura actual a causa del Covid-19 en el Perú, ¿usted considera...? Opción única

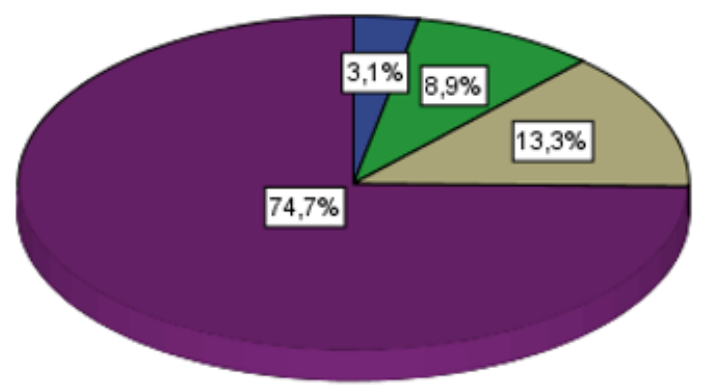

Migrar a otro país de la región

Migrar a otro pais en otra región

(América del Norte, Europa,

Asia, etc)

$\square$ Retornar a Venezuela

Continuar viviendo en Perú

Figura 26. Opciones de migrar a causa de Covid-19

Fuente: Elaboración propia, encuesta, junio 2020

Interpretación: En la figura 26 podemos visualizar que un $74.7 \%$ indica que seguirá viviendo en el Perú pasado la emergencia sanitaria, mientras que un $13.3 \%$ considera retornar a Venezuela. Esto nos hace concluir que los migrantes venezolanos siguen mirando con optimismo nuestra economía.

\section{Tabla 23}

Salario mensual de inmigrantes venezolanos

\begin{tabular}{|c|c|c|c|c|c|}
\hline & & $\begin{array}{c}\text { Frecuenci } \\
\mathrm{a} \\
\end{array}$ & Porcentaje & $\begin{array}{c}\text { Porcentaje } \\
\text { válido }\end{array}$ & $\begin{array}{l}\text { Porcentaje } \\
\text { acumulado }\end{array}$ \\
\hline \multirow{5}{*}{ Válidos } & $\begin{array}{l}\text { Por debajo del salario } \\
\text { básico }\end{array}$ & 132 & 34,4 & 34,4 & 34,4 \\
\hline & Igual al salario básico & 104 & 27,1 & 27,1 & 61,5 \\
\hline & $\begin{array}{l}\text { Mayor que el salario } \\
\text { básico }\end{array}$ & 64 & 16,7 & 16,7 & 78,1 \\
\hline & Prefiero no responder & 84 & 21,9 & 21,9 & 100,0 \\
\hline & Total & 384 & 100,0 & 100,0 & \\
\hline
\end{tabular}

Fuente: Software SPSS 
P7. Considerando que el salario básico en el Perú es S/930. ¿Usted diría que su ingreso personal mensual es de ...? Opción única

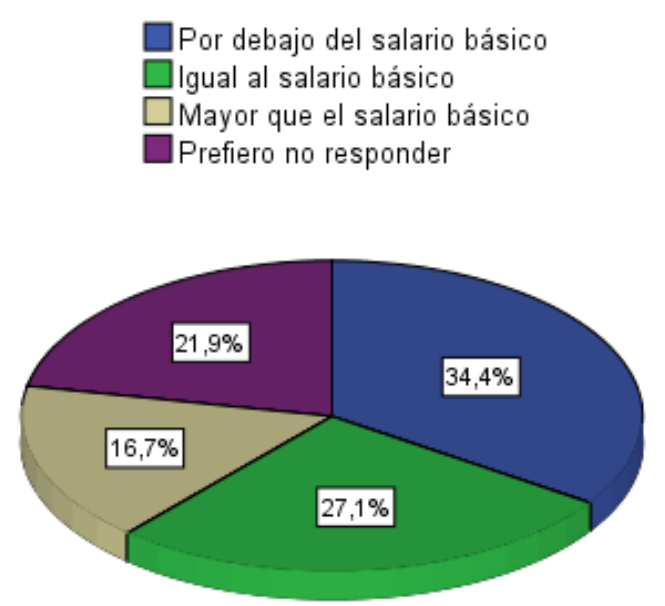

Figura 27. Salario de inmigrantes venezolanos

Fuente: Elaboración propia

Interpretación: De acuerdo con la figura 27 podemos visualizar que el 34.4\% tiene ingresos menores al salario básico, mientras otro $27.1 \%$ tiene un salario igual al básico y un porcentaje de $21.9 \%$ prefiere no responder.

Tabla 24

Monto mensual enviado en remesas a Venezuela

\begin{tabular}{|c|c|c|c|c|c|}
\hline & & $\begin{array}{c}\text { Frecuenci } \\
\mathrm{a}\end{array}$ & Porcentaje & $\begin{array}{c}\text { Porcentaje } \\
\text { válido }\end{array}$ & $\begin{array}{l}\text { Porcentaje } \\
\text { acumulado }\end{array}$ \\
\hline \multirow{5}{*}{ Válidos } & $\begin{array}{l}\text { Menos de } 100 \\
\text { soles }\end{array}$ & 110 & 28,6 & 28,6 & 28,6 \\
\hline & $\begin{array}{l}\text { De } 100 \text { a } 200 \\
\text { soles }\end{array}$ & 139 & 36,2 & 36,2 & 64,8 \\
\hline & Más de 200 soles & 63 & 16,4 & 16,4 & 81,3 \\
\hline & No envío remesas & 72 & 18,8 & 18,8 & 100,0 \\
\hline & Total & 384 & 100,0 & 100,0 & \\
\hline
\end{tabular}

Fuente: Software SPSS 
P8. ¿Cuál es el monto mensual enviado en remesas a Venezuela? Opción única

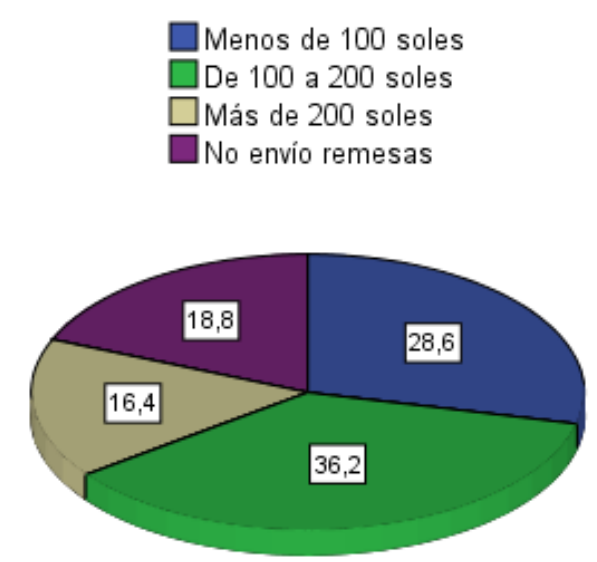

Figura 28. Monto mensual de remesas enviadas

Fuente: Elaboración propia

Interpretación: Con referencia a la figura 28 podemos visualizar que el $36.2 \%$ envía remesas a Venezuela entre el rango de 100 a 200 soles, mientras que un $28.6 \%$ envía menos de 100 soles al mes. Otros encuestados con un $18.8 \%$ indican que no envía remesas a Venezuela.

\section{Tabla 25}

Canales de compra

\begin{tabular}{|c|c|c|c|c|c|}
\hline & & $\begin{array}{c}\text { Frecuenci } \\
\text { a }\end{array}$ & Porcentaje & $\begin{array}{l}\text { Porcentaje } \\
\text { válido }\end{array}$ & $\begin{array}{l}\text { Porcentaje } \\
\text { acumulado }\end{array}$ \\
\hline \multirow{8}{*}{ Válidos } & Supermercados & 63 & 16,4 & 16,4 & 16,4 \\
\hline & Mercados & 245 & 63,8 & 63,8 & 80,2 \\
\hline & Bodegas de barrio & 46 & 12,0 & 12,0 & 92,2 \\
\hline & Tiendas de & 3 & ,8 & ,8 & 93,0 \\
\hline & conveniencia: Tambo, & & & & \\
\hline & Repsol y Listo & & & & \\
\hline & Discounter: Mass & 27 & 7,0 & 7,0 & 100,0 \\
\hline & Total & 384 & 100,0 & 100,0 & \\
\hline
\end{tabular}

Fuente: Software SPSS 
P9. ¿Dónde adquiere los alimentos para su hogar con mayor frecuencia? Opción única

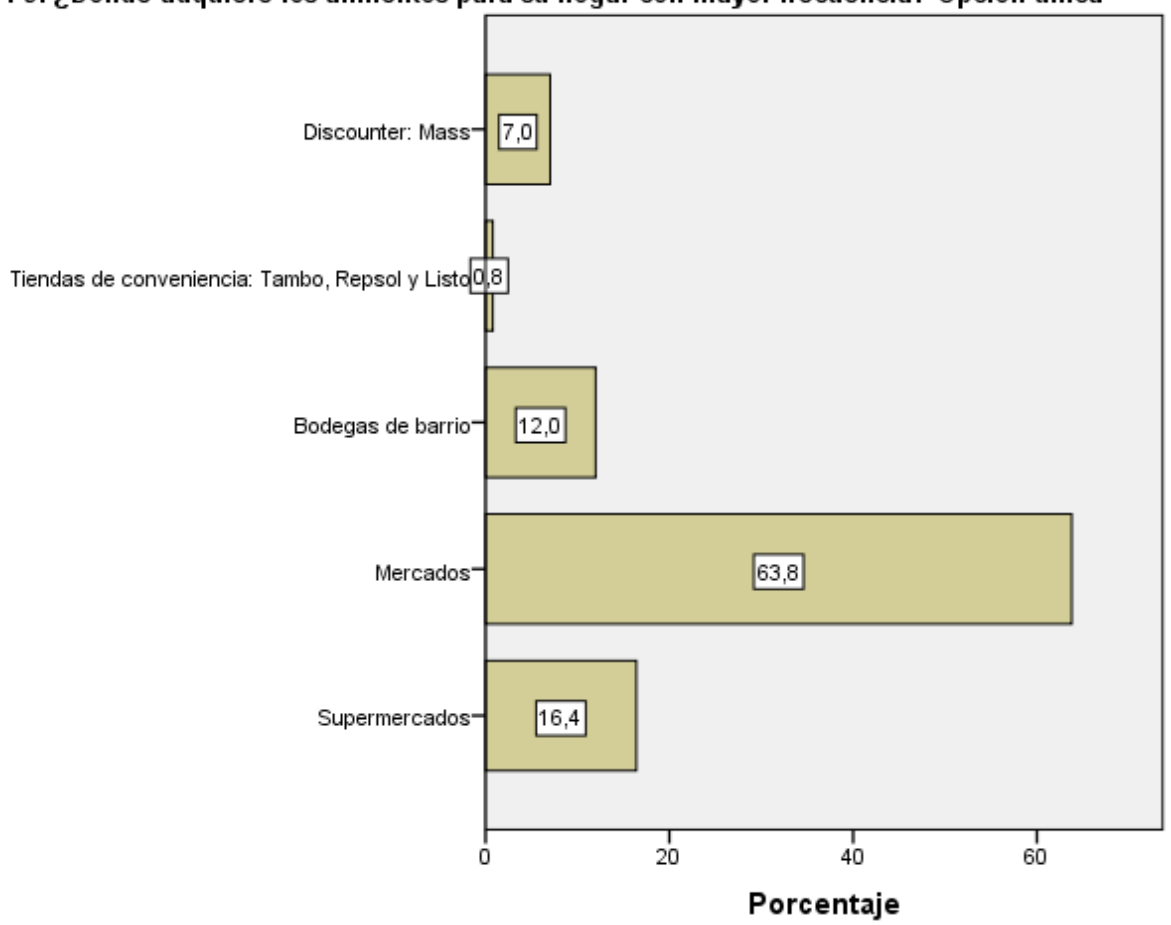

Figura 29. Lugares donde se adquiere los alimentos para el hogar

Fuente: Elaboración propia

Interpretación: Un $63.8 \%$ de los encuestados indica que prefiere realizar sus compras en los mercados, mientras que un $16.4 \%$ prefiere ir a los supermercados. Tan solo un $12 \%$ acude a una bodega de barrio y finalmente un $7 \%$ acude a discounters tales como Mass. Aquí prevalece el canal tradicional como punto de venta favorito.

Tabla 26

\section{Alimentos}

\begin{tabular}{lrrr}
\hline & \multicolumn{2}{c}{ Respuestas } & Porcentaje \\
& N & Porcentaje & de casos \\
\hline Arroz & 375 & $9,6 \%$ & $97,7 \%$ \\
Batata & 40 & $1,0 \%$ & $10,4 \%$ \\
Cambur & 90 & $2,3 \%$ & $23,4 \%$ \\
Caraotas & 182 & $4,7 \%$ & $47,4 \%$ \\
Carnes rojas & 138 & $3,5 \%$ & $35,9 \%$ \\
Cebolla & 226 & $5,8 \%$ & $58,9 \%$ \\
Cerdo & 79 & $2,0 \%$ & $20,6 \%$ \\
Ensalada & 211 & $5,4 \%$ & $54,9 \%$ \\
Frutas & 143 & $3,7 \%$ & $37,2 \%$ \\
Harina de & 242 & $6,2 \%$ & $63,0 \%$ \\
maíz & & &
\end{tabular}




\begin{tabular}{lrrr} 
Huevo & 262 & $6,7 \%$ & $68,2 \%$ \\
Mariscos & 29 & $0,7 \%$ & $7,6 \%$ \\
Name & 31 & $0,8 \%$ & $8,1 \%$ \\
Pan de trigo & 98 & $2,5 \%$ & $25,5 \%$ \\
Papa & 246 & $6,3 \%$ & $64,1 \%$ \\
Pastas & 256 & $6,6 \%$ & $66,7 \%$ \\
Pescado & 145 & $3,7 \%$ & $37,8 \%$ \\
Pollo & 348 & $8,9 \%$ & $90,6 \%$ \\
Queso & 204 & $5,2 \%$ & $53,1 \%$ \\
Tomate & 219 & $5,6 \%$ & $57,0 \%$ \\
Verduras & 247 & $6,3 \%$ & $64,3 \%$ \\
varios & & & \\
Otros & 81 & $2,1 \%$ & $21,1 \%$ \\
Total & 3892 & $100,0 \%$ & $1013,5 \%$ \\
\hline
\end{tabular}

Fuente: Software SPSS

Interpretación: En la tabla 22 se muestra que hay 7 productos básicos en su alimentación como el arroz con un $97.7 \%$, el pollo con un $90.6 \%$, el huevo con un $68.2 \%$, las pastas con un $66.7 \%$, las verduras con un $64.3 \%$, la papa con un $64.1 \%$ y la harina de maíz, $63 \%$.

Tabla 27

Productos con mayor volumen debido al confinamiento Covid-19

\begin{tabular}{|c|c|c|c|c|}
\hline & & \multicolumn{2}{|c|}{ Respuestas } & \multirow{2}{*}{$\begin{array}{l}\text { Porcentaje } \\
\text { de casos }\end{array}$} \\
\hline & & № & Porcentaje & \\
\hline \multirow{7}{*}{.$^{a}$} & $\begin{array}{l}\text { Hamburguesas } \\
\text { precocidas }\end{array}$ & 71 & $14,3 \%$ & $18,5 \%$ \\
\hline & Nuggets & 41 & $8,2 \%$ & $10,7 \%$ \\
\hline & Conservas de pescado & 53 & $10,6 \%$ & $13,8 \%$ \\
\hline & Polvos para hornear & 39 & $7,8 \%$ & $10,2 \%$ \\
\hline & Harina de trigo & 194 & $39,0 \%$ & $50,5 \%$ \\
\hline & Otros & 67 & $13,5 \%$ & $17,4 \%$ \\
\hline & Ninguno & 33 & $6,6 \%$ & $8,6 \%$ \\
\hline Total & & 498 & $100,0 \%$ & $129,7 \%$ \\
\hline
\end{tabular}




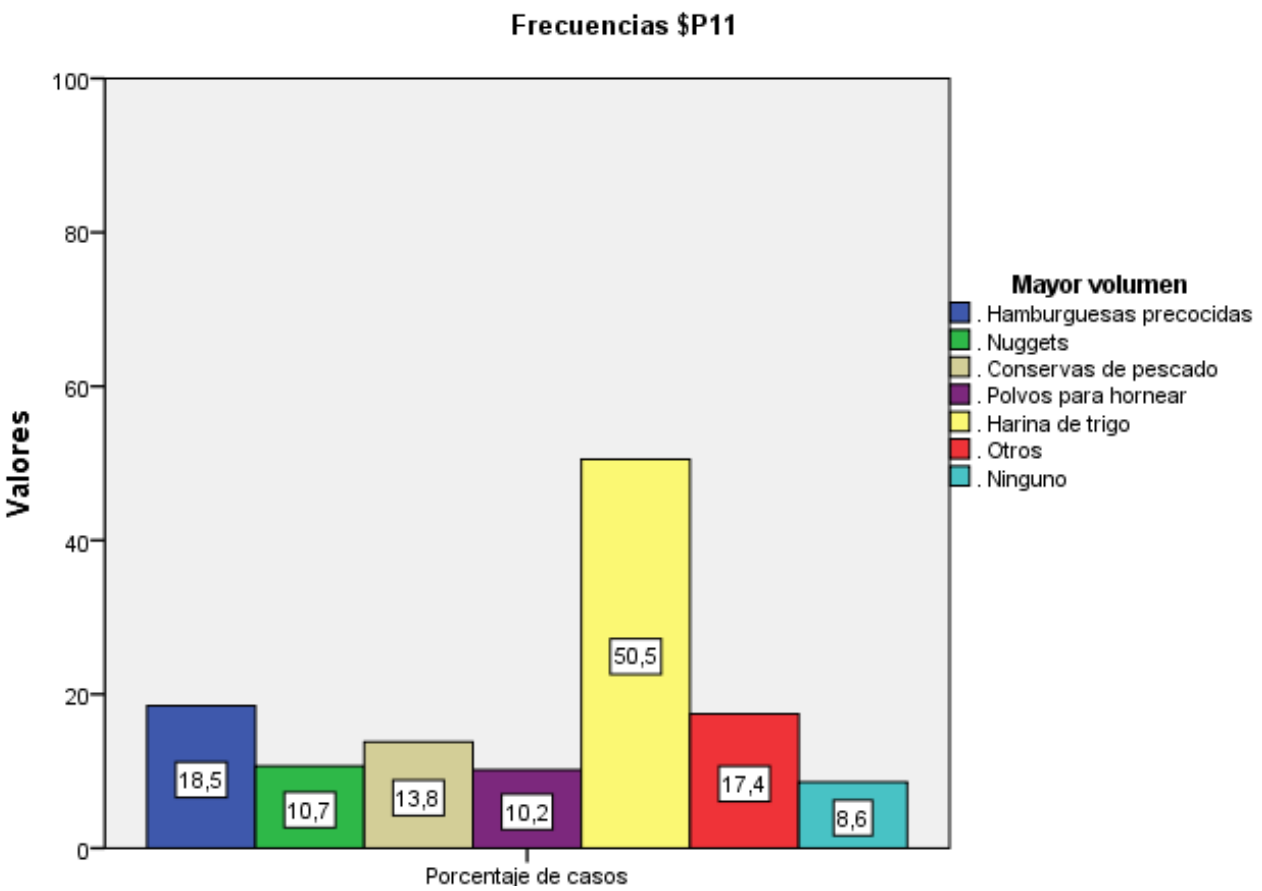

Figura 30. Alimentos con mayor volumen de compra durante el confinamiento Fuente: Elaboración propia, encuesta, junio 2020

Interpretación: En la figura 30 donde vemos como resultado que un 50.5\% compró harina de trigo durante el confinamiento y un 18.5\% compró hamburguesas pre cocidas, mientras que otro porcentaje considerable del $17.4 \%$ indica que consumió otros productos durante este periodo de Covid-19.

Tabla 28

Productos con menor volumen debido al confinamiento Covid-19

\begin{tabular}{|c|c|c|c|c|}
\hline & & \multicolumn{2}{|c|}{ Respuestas } & \multirow{2}{*}{$\begin{array}{c}\text { Porcentaje } \\
\text { de casos }\end{array}$} \\
\hline & & № & Porcentaje & \\
\hline \multirow{6}{*}{.$^{a}$} & $\begin{array}{l}\text { Bebidas con } \\
\text { alcohol }\end{array}$ & 200 & $26,0 \%$ & $52,1 \%$ \\
\hline & $\begin{array}{l}\text { Bebidas sin } \\
\text { alcohol }\end{array}$ & 90 & $11,7 \%$ & $23,4 \%$ \\
\hline & Carnes rojas & 188 & $24,4 \%$ & $49,0 \%$ \\
\hline & Pescado fresco & 157 & $20,4 \%$ & $40,9 \%$ \\
\hline & Otros & 105 & $13,6 \%$ & $27,3 \%$ \\
\hline & Ninguno & 30 & $3,9 \%$ & $7,8 \%$ \\
\hline Total & & 770 & $100,0 \%$ & $200,5 \%$ \\
\hline
\end{tabular}

Fuente: Software SPSS 


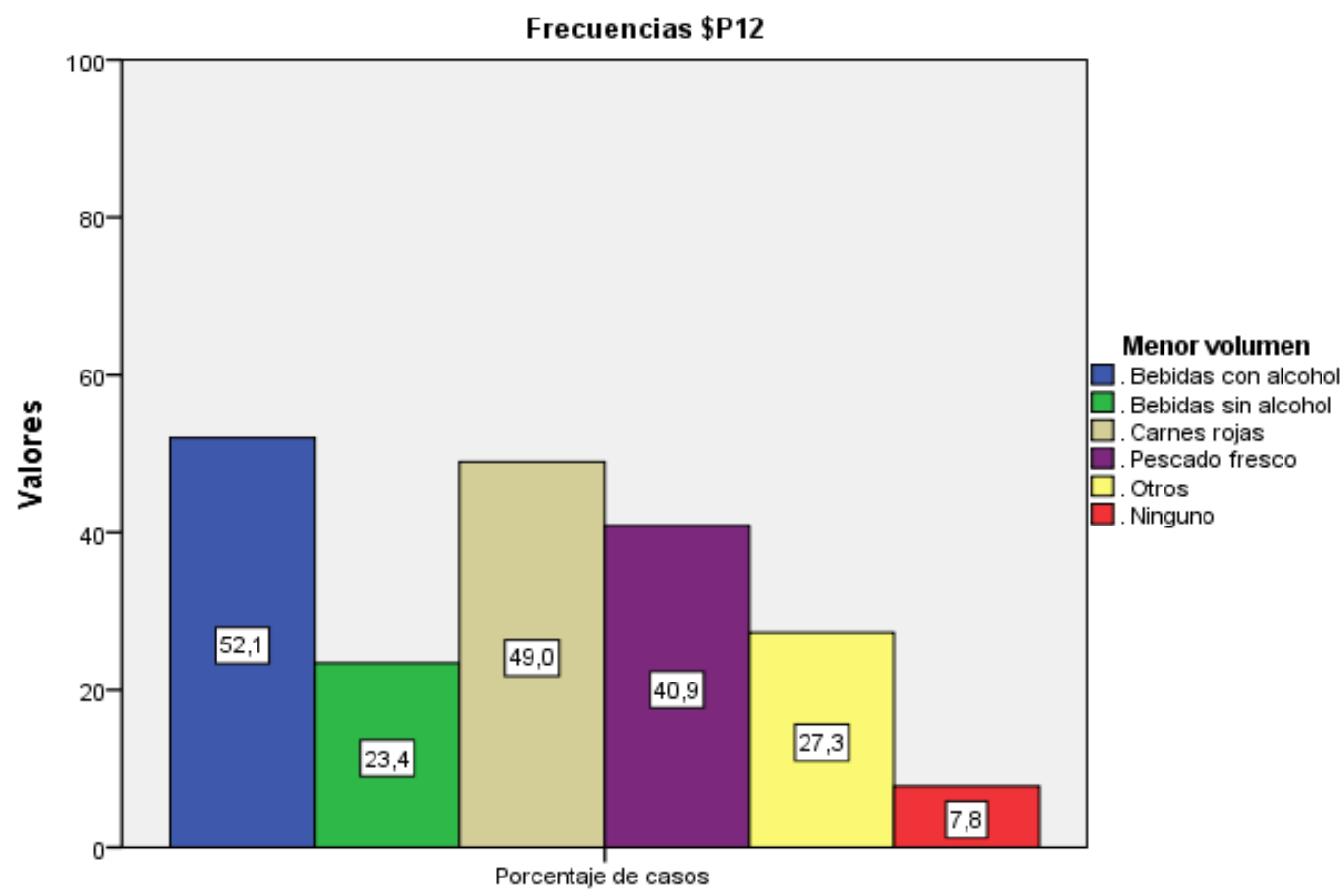

Figura 31. Alimentos con menor volumen de compra durante el confinamiento por Covid-19 Fuente: Elaboración propia

Interpretación: En la figura 31 se observa que un 52.1\% dejó de consumir bebidas alcohólicas, mientras que un $49 \%$ dejó de consumir carnes rojas y finalmente un $40.9 \%$ dejó de consumir pescado fresco.

Tabla 29

Variables valoradas en la elección del canal de compra

\begin{tabular}{|c|c|c|c|c|c|}
\hline & & $\begin{array}{c}\text { Frecuenci } \\
\text { a }\end{array}$ & Porcentaje & $\begin{array}{c}\text { Porcentaje } \\
\text { válido }\end{array}$ & $\begin{array}{l}\text { Porcentaje } \\
\text { acumulado }\end{array}$ \\
\hline & $\begin{array}{l}\text { Cercanía del punto de } \\
\text { venta }\end{array}$ & 46 & 12,0 & 12,0 & 12,0 \\
\hline & $\begin{array}{l}\text { Stock disponible de } \\
\text { producto }\end{array}$ & 15 & 3,9 & 3,9 & 15,9 \\
\hline \multirow[t]{4}{*}{ Válidos } & Medidas sanitarias & 99 & 25,8 & 25,8 & 41,7 \\
\hline & Precios accesibles & 158 & 41,1 & 41,1 & 82,8 \\
\hline & $\begin{array}{l}\text { Poca cantidad de } \\
\text { personas en el lugar }\end{array}$ & 66 & 17,2 & 17,2 & 100,0 \\
\hline & Total & 384 & 100,0 & 100,0 & \\
\hline
\end{tabular}

Fuente: Software SPSS 
P13. Dada la coyuntura actual, al realizar la compra de sus alimentos, ¿qué es lo más valorado por usted para elegir el canal de compra? Opción única

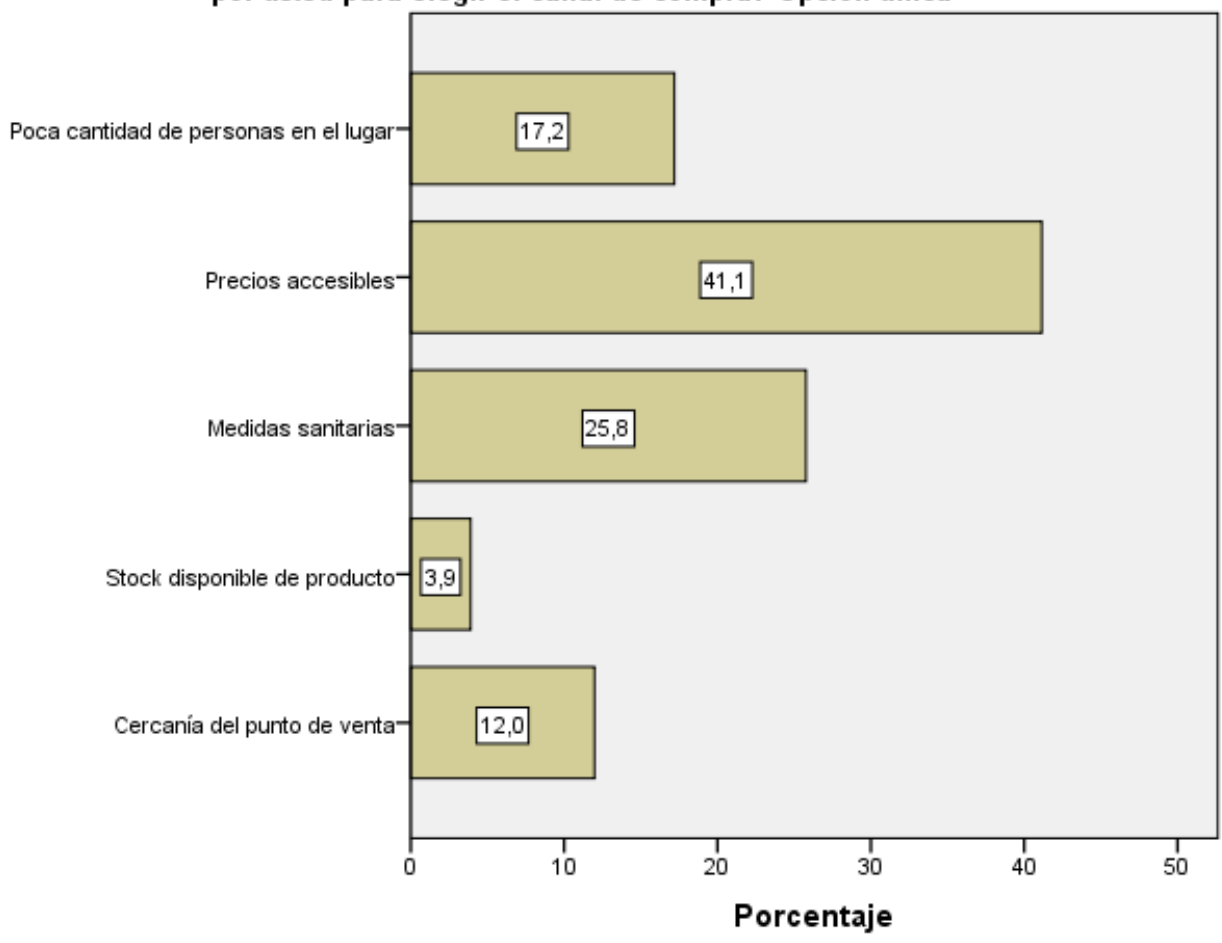

Figura 32. Variables valoradas cuando se selecciona el canal de compra

Fuente: Elaboración propia, encuesta, junio 2020

Interpretación: De acuerdo con la figura 32 que corresponde a la nueva tendencia de consumo por el Covid-19, se observa que un $41.1 \%$ de los encuestados valora los lugares con precios accesibles, mientras que un $25.8 \%$ considera comprar en lugares con medidas sanitarias. Otro grupo con un $17.2 \%$ prefiere comprar donde se encuentre una menor cantidad de personas en el lugar.

\section{Tabla 30}

Frecuencia de adquisición de alimentos

\begin{tabular}{|c|c|c|c|c|c|}
\hline & & $\begin{array}{c}\text { Frecuenci } \\
\text { a }\end{array}$ & Porcentaje & $\begin{array}{c}\text { Porcentaje } \\
\text { válido }\end{array}$ & $\begin{array}{l}\text { Porcentaje } \\
\text { acumulado }\end{array}$ \\
\hline & $\begin{array}{l}\text { Mensualment } \\
\mathrm{e}\end{array}$ & 30 & 7,8 & 7,8 & 7,8 \\
\hline & Quincenal & 97 & 25,3 & 25,3 & 33,1 \\
\hline \multirow[t]{4}{*}{ Válidos } & Semanal & 162 & 42,2 & 42,2 & 75,3 \\
\hline & Interdiario & 47 & 12,2 & 12,2 & 87,5 \\
\hline & Diario & 48 & 12,5 & 12,5 & 100,0 \\
\hline & Total & 384 & 100,0 & 100,0 & \\
\hline
\end{tabular}

Fuente: Software SPSS 
P14. ¿Con qué frecuencia compra los alimentos para su hogar? Opción única

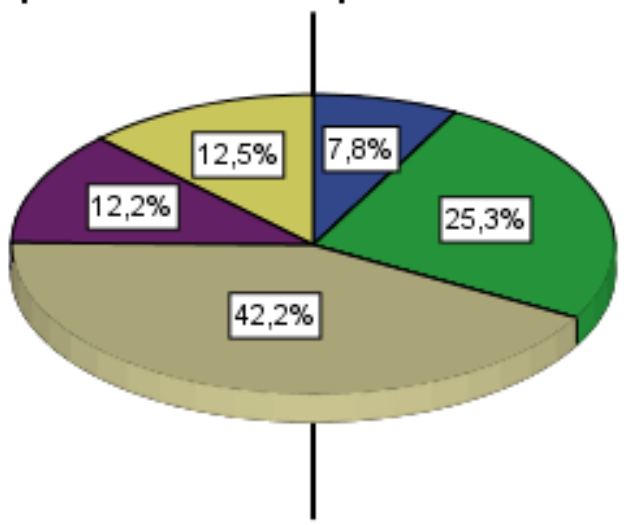

$\square$ Mensualmente

$\square$ Quincenal

$\square$ Semanal

$\square$ Interdiario

$\square$ Diario

Figura 33. Frecuencia de compra de alimentos para el hogar

Fuente: Elaboración propia, encuesta, junio 2020

Interpretación: En la figura 33 se observa que un $42.2 \%$ de los encuestados realizan sus compras de manera semanal, mientras que un $25.3 \%$ considera como mejor opción comprar quincenalmente. Otro grupo con un $12.5 \%$ suele comprar a diario, mientras que un $12.5 \%$ prefiere comprar de manera interdiaria. Por último, tan solo un $7.8 \%$ prefiere realizar compras para el mes.

Tabla 31

Frecuencias de presupuesto mensual para gastos de alimentación

\begin{tabular}{lrrrrr}
\hline & $\begin{array}{c}\text { Frecuenci } \\
\text { a }\end{array}$ & Porcentaje & $\begin{array}{c}\text { Porcentaje } \\
\text { válido }\end{array}$ & $\begin{array}{r}\text { Porcentaje } \\
\text { acumulado }\end{array}$ \\
\hline Menos de 300 soles & 158 & 41,1 & 41,1 & 41,1 \\
De 300 a 450 soles & 151 & 39,3 & 39,3 & 80,5 \\
De 451 a 600 soles & 27 & 7,0 & 7,0 & 87,5 \\
De 601 a 750 soles & 9 & 2,3 & 2,3 & 89,8 \\
Válidos & 6 & 1,6 & 1,6 & 91,4 \\
De 751 a 900 soles & 6 & 1,6 & 1,6 & 93,0 \\
Más de 900 soles & 27 & 7,0 & 7,0 & 100,0 \\
Prefiero no & & & & \\
responder & 384 & 100,0 & 100,0 & \\
Total & & &
\end{tabular}

Fuente: Software SPSS 
P15. En promedio, ¿cuál es su presupuesto mensual para gastos de alimentación? Opción única

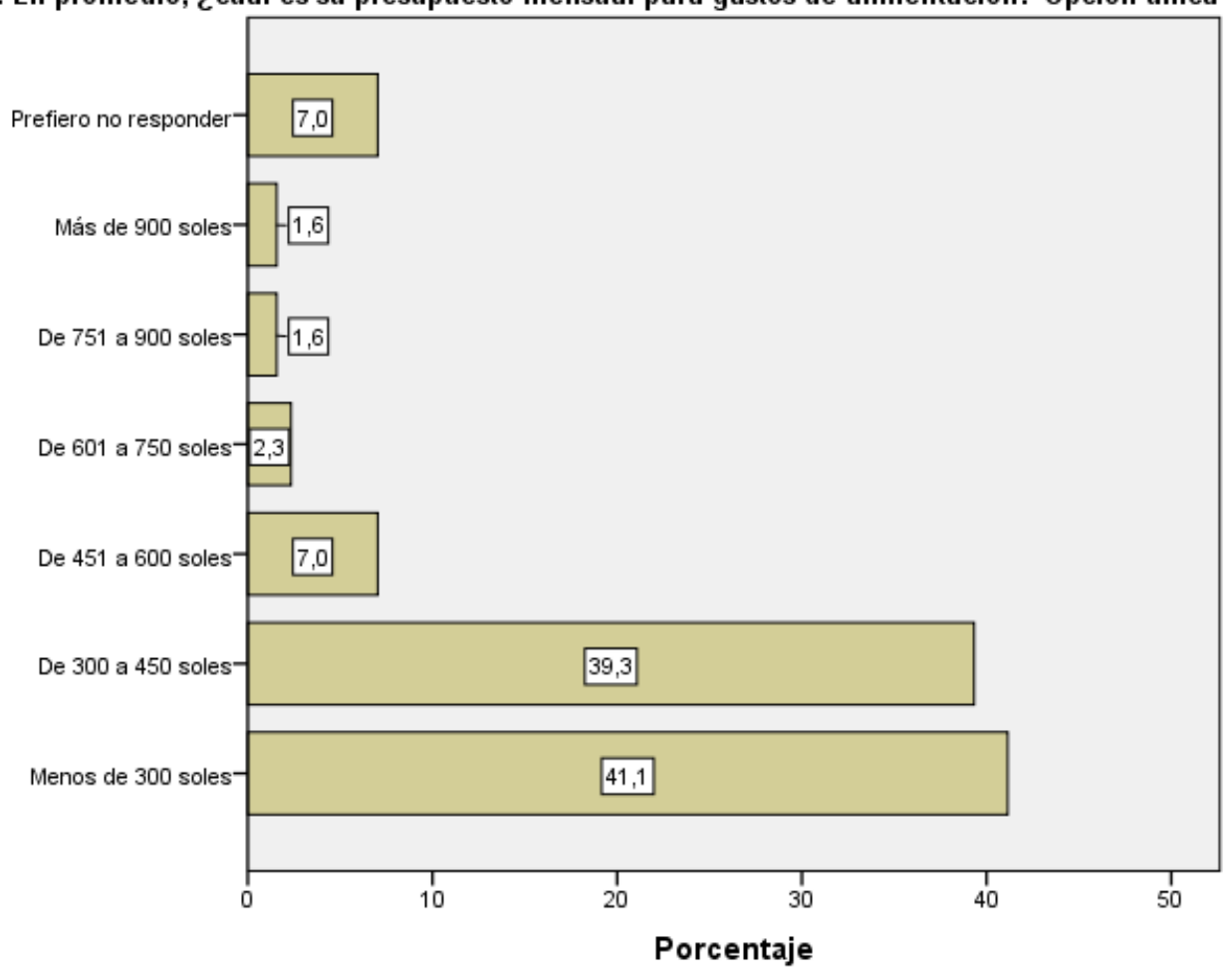

Figura 34. Presupuesto mensual para gastos de alimentación

Fuente: Elaboración propia

Interpretación: Con respecto a la figura 34 podemos visualizar que un $41.1 \%$ considera gastar menos de 300 soles para su compra de alimentos mensuales, mientras que un $39.3 \%$ gasta entre 300 a 450 soles mensualmente en alimentación. 
Tabla 32

Grado de reconocimiento de marcas

\begin{tabular}{|c|c|c|c|c|c|c|c|c|c|c|c|c|}
\hline $\begin{array}{l}\text { Grado de } \\
\text { reconoci- } \\
\text { miento de } \\
\text { marcas }\end{array}$ & $\begin{array}{l}\text { Inca } \\
\text { Kola }\end{array}$ & $\%$ & Nescafe & $\%$ & $\begin{array}{l}\text { Coca } \\
\text { Cola }\end{array}$ & $\%$ & Gloria & $\%$ & Laive & $\%$ & Ideal & $\%$ \\
\hline $\begin{array}{l}\text { Lo } \\
\text { conozco }\end{array}$ & & & & & & & & & & & & \\
\hline $\begin{array}{l}\text { mucho } \\
\text { Lo } \\
\text { conozco }\end{array}$ & 221 & 57.6 & 221 & 57.6 & 326 & 84.9 & 272 & 70.8 & 142 & 37.0 & 111 & 28.9 \\
\hline algo & 157 & 40.9 & 145 & 37.8 & 55 & 14.3 & 103 & 26.8 & 161 & 41.9 & 154 & 40.1 \\
\hline No lo & & & & & & & & & & & & \\
\hline conozco & 6 & 1.6 & 18 & 4.7 & 3 & 0.8 & 9 & 2.3 & 81 & 21.1 & 119 & 31.0 \\
\hline Total & 384 & 100 & 384 & 100 & 384 & 100 & 384 & 100 & 384 & 100 & 384 & 100 \\
\hline
\end{tabular}

P16. Grado de reconocimiento de marcas

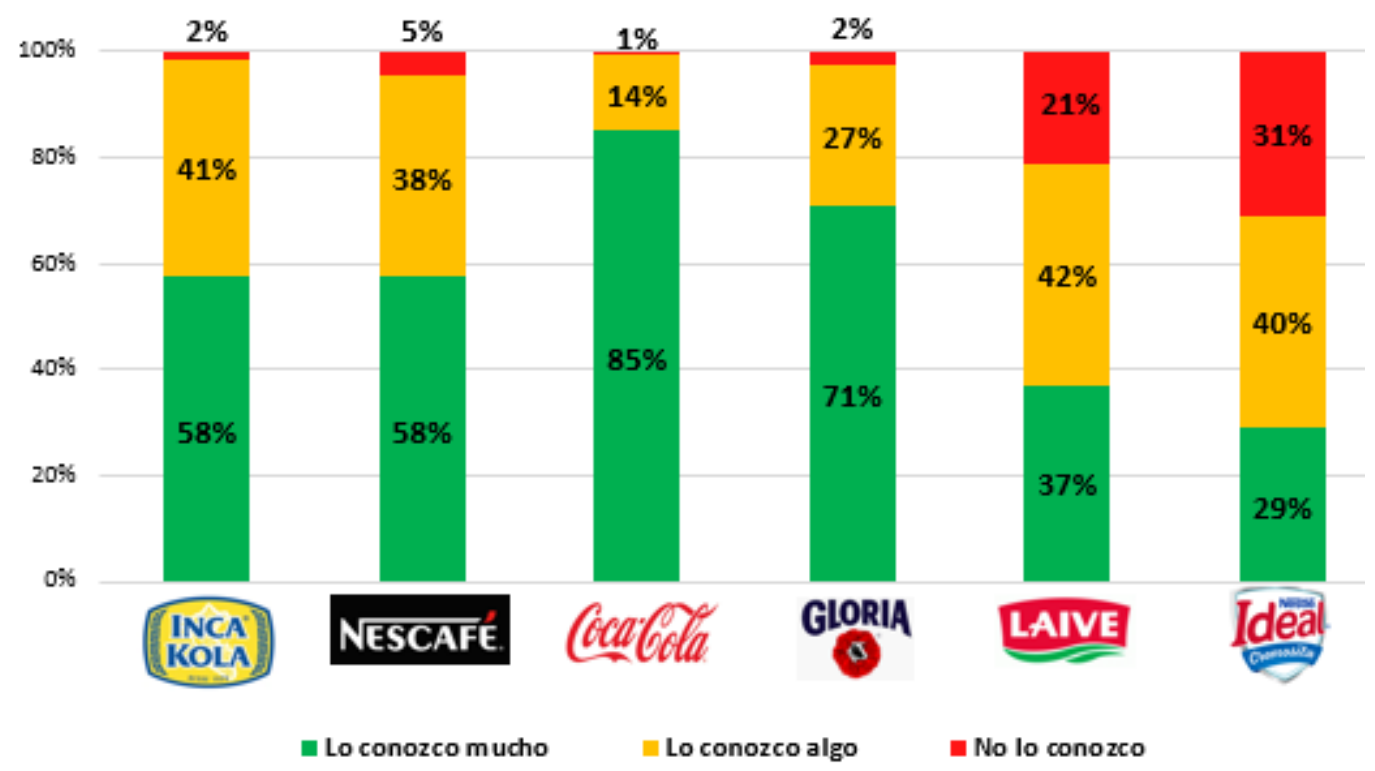

Figura 35. Grado de reconocimiento de marca

Fuente: Elaboración propia

Como se muestra en la figura 35 podemos visualizar que Coca Cola es la marca más reconocida al tener un $85 \%$ de grado de lo conozco mucho, muy cerca está la marca Gloria con un $71 \%$. De forma contradictoria, la marca Ideal se ubica con un $40 \%$ de lo conozco algo y un $31 \%$ de no lo conozco para los migrantes venezolanos. Para el caso de los peruanos, estas 6 marcas son las más reconocidas en base al estudio de Kantar. 
Marcas venezolanas más extrañadas

\begin{tabular}{lrrrr}
\hline & $\begin{array}{c}\text { Frecuenci } \\
\text { a }\end{array}$ & Porcentaje & $\begin{array}{l}\text { Porcentaje } \\
\text { válido }\end{array}$ & $\begin{array}{r}\text { Porcentaje } \\
\text { acumulado }\end{array}$ \\
\hline Budare & 33 & 8,6 & 8,6 & 8,6 \\
Cerelac & 57 & 14,8 & 14,8 & 23,4 \\
Cocosette & 6 & 1,6 & 1,6 & 25,0 \\
Diablitos & 86 & 22,4 & 22,4 & 47,4 \\
Maltín Polar & 124 & 32,3 & 32,3 & 79,7 \\
Válidos & 16 & 4,2 & 4,2 & 83,9 \\
Rica & & & & \\
Chicha & 21 & 5,5 & 5,5 & 89,3 \\
Samba & 15 & 3,9 & 3,9 & 93,2 \\
Susy & 26 & 6,8 & 6,8 & 100,0 \\
Otro & 384 & 100,0 & 100,0 & \\
Total & & & &
\end{tabular}

Fuente: Software SPSS

P17. ¿Qué marca venezolana es la que más extraña al no encontrarla fácilmente en Perú? Opción única

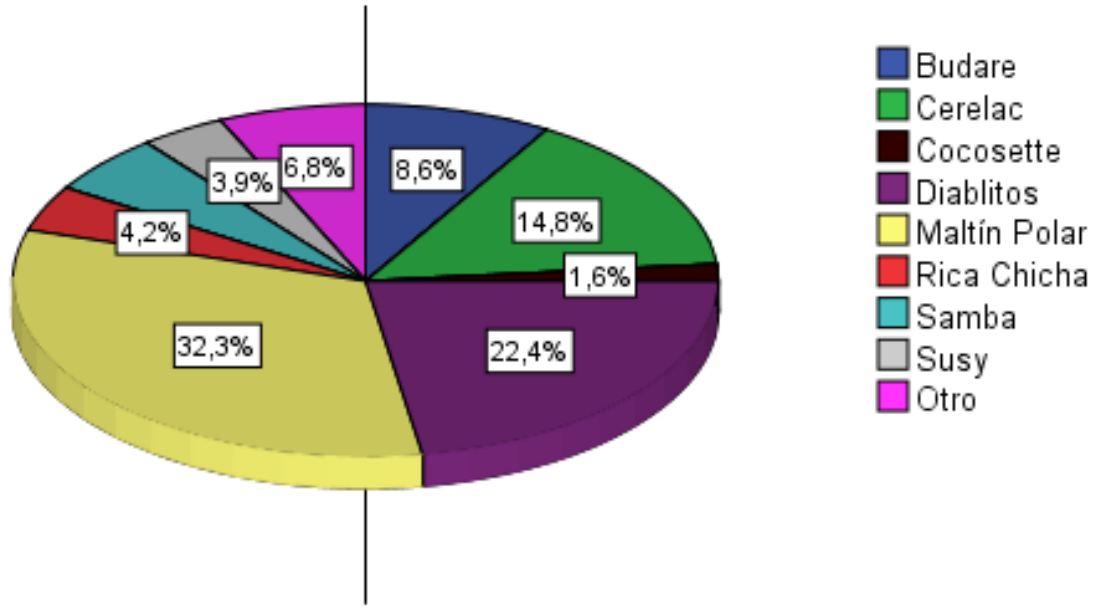

Figura 36. Marcas de productos venezolanos

Fuente: Elaboración propia

Interpretación: En la figura 36 podemos visualizar que un 32.3\% extraña la marca Maltin Polar, mientras que un $22.4 \%$ extraña la marca diablitos. Otro porcentaje de $14.8 \%$ de encuestados extraña el producto Cerelac. 
Tabla 34

Aceptación de nuevo producto

\begin{tabular}{cccccc}
\hline & & $\begin{array}{c}\text { Frecuenci } \\
\text { a }\end{array}$ & $\begin{array}{c}\text { Porcenta } \\
\text { je }\end{array}$ & $\begin{array}{c}\text { Porcentaje } \\
\text { válido }\end{array}$ & $\begin{array}{c}\text { Porcentaje } \\
\text { acumulado }\end{array}$ \\
\hline \multirow{4}{*}{ Válidos } & Sí & 273 & 71,1 & 76,3 & 76,3 \\
& No & 85 & 22,1 & 23,7 & 100,0 \\
& Total & 358 & 93,2 & 100,0 & \\
\hline
\end{tabular}

Fuente: Software SPSS

P18. En base a su anterior respuesta, ¿Si en Perú se comienza a comercializar dicho producto, estaría en la

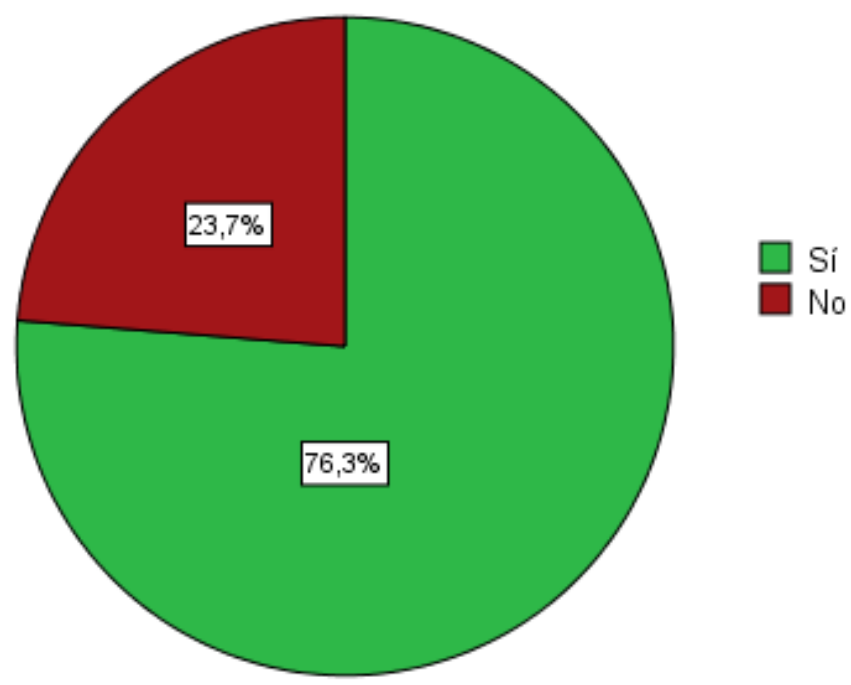

Figura 37. Aceptación de inserción al mercado peruano de la marca venezolana extrañada Fuente: Elaboración propia, encuesta, junio 2020

Interpretación: Tal como se muestra en la figura 37 podemos visualizar que un $76.3 \%$ de los encuestados indican que si compraran los productos anteriormente mencionados si empiezan a comercializarse en el país. 
Tabla 35

Paquetes de harina de consumo en el hogar

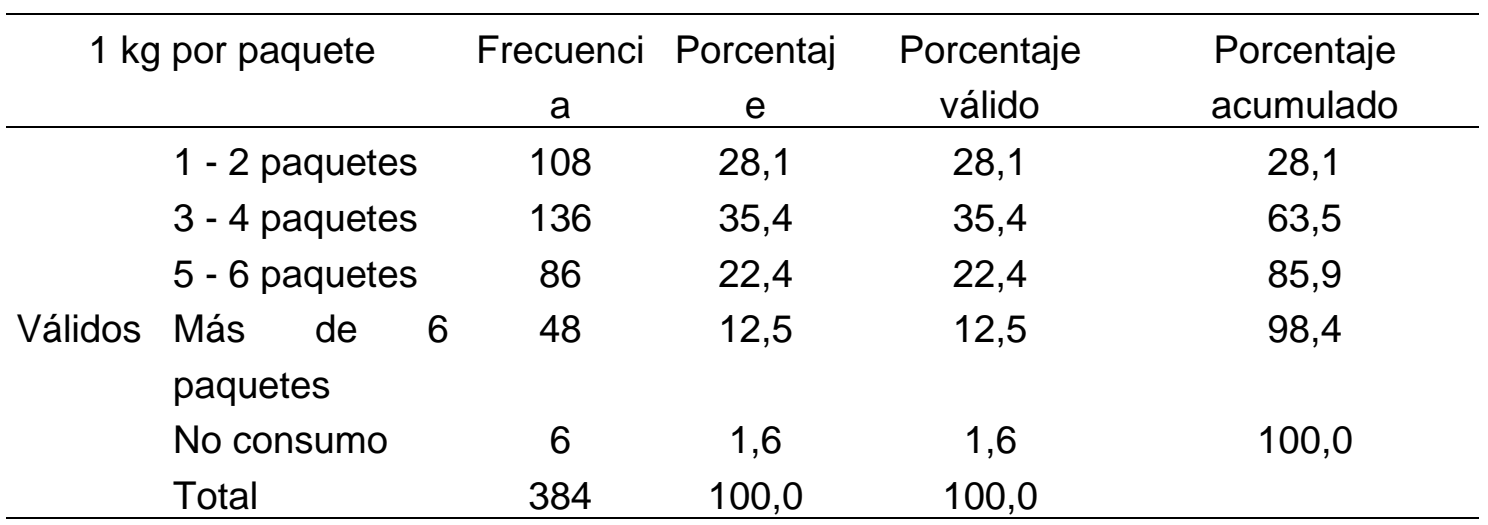

Fuente: Software SPSS

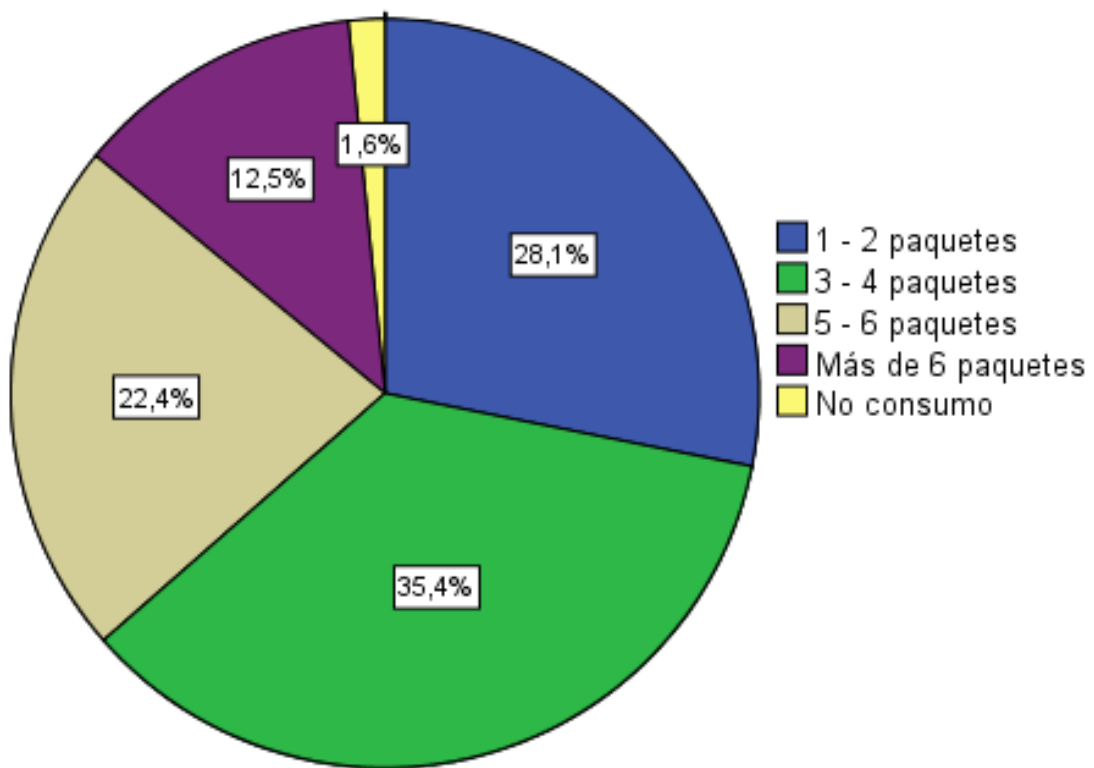

Figura 38. Cantidad de harina de maíz consumida en el hogar

Fuente: Elaboración propia

Interpretación: De la figura 38 se observa que un $35.4 \%$ de los encuestados consumen de 3 a 4 paquetes de harina de maíz de $1 \mathrm{~kg}$ al mes, mientras que otro grupo con un $28.1 \%$ consume de 1 a 2 paquetes de harina de maíz al mes. 
Tabla 36

Marca favorita de harina de maíz

\begin{tabular}{llrrrr}
\hline & $\begin{array}{c}\text { Frecuenci } \\
\text { a }\end{array}$ & $\begin{array}{c}\text { Porcentaj } \\
\text { e }\end{array}$ & \multicolumn{2}{c}{$\begin{array}{c}\text { Porcentaje } \\
\text { válido }\end{array}$} & $\begin{array}{c}\text { Porcentaje } \\
\text { acumulado }\end{array}$ \\
\hline \multirow{4}{*}{ Válidos } & P.A.N. & 324 & 84,4 & 85,7 & 85,7 \\
& Arepasa & 6 & 1,6 & 1,6 & 87,3 \\
& $\mathrm{n}$ & & & & 98,4 \\
& La Nieve & 42 & 10,9 & 11,1 & 99,2 \\
& Del Sol & 3 &, 8 &, 8 & 100,0 \\
& Otro & 3 &, 8 &, 8 & \\
Total & 378 & 98,4 & 100,0 & \\
\hline
\end{tabular}

Fuente: Software SPSS

P20. ¿Cuál es su marca favorita de harina de maíz? Opción única

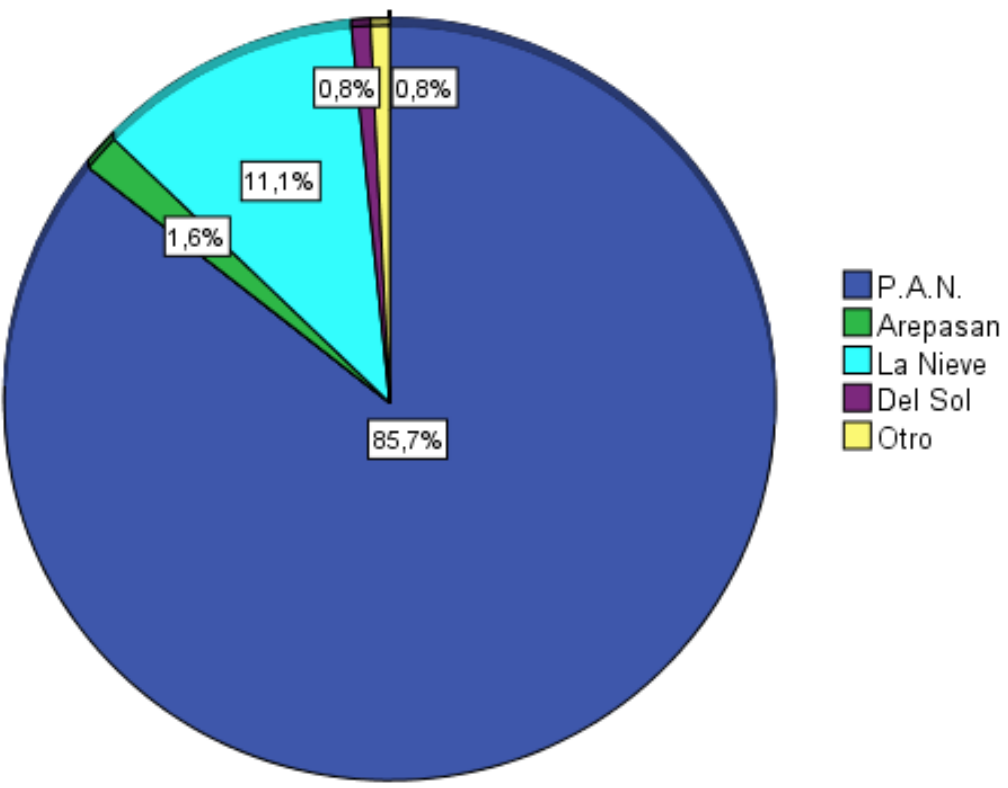

Figura 39. Marca favorita de harina de maíz

Fuente: Elaboración propia

Interpretación: En la figura 39 se observa que un $85.7 \%$ de los encuestados prefieren la harina de maíz marca P.A.N, mientras la segunda marca prefería por ellos es La nieve con un $11.1 \%$, 
Tabla 37

Disponibilidad de la harina de maíz en el punto de venta

\begin{tabular}{llcccc}
\hline & $\begin{array}{c}\text { Frecuenci } \\
\text { a }\end{array}$ & Porcentaje & $\begin{array}{c}\text { Porcentaje } \\
\text { válido }\end{array}$ & $\begin{array}{c}\text { Porcentaje } \\
\text { acumulado }\end{array}$ \\
\hline \multirow{4}{*}{ Válidos } & Siempre & 152 & 39,6 & 40,2 & 40,2 \\
& Casi siempre & 122 & 31,8 & 32,3 & 72,5 \\
& A veces & 89 & 23,2 & 23,5 & 96,0 \\
& Casi nunca & 15 & 3,9 & 4,0 & 100,0 \\
Perdidos & Total & 378 & 98,4 & 100,0 & \\
Total & Sistema & 6 & 1,6 & & \\
\hline
\end{tabular}

Fuente: Software SPSS

P21. Cuando vas al punto de venta, ¿encuentras tu marca favorita de harina de maíz disponible para la compra? Opción única

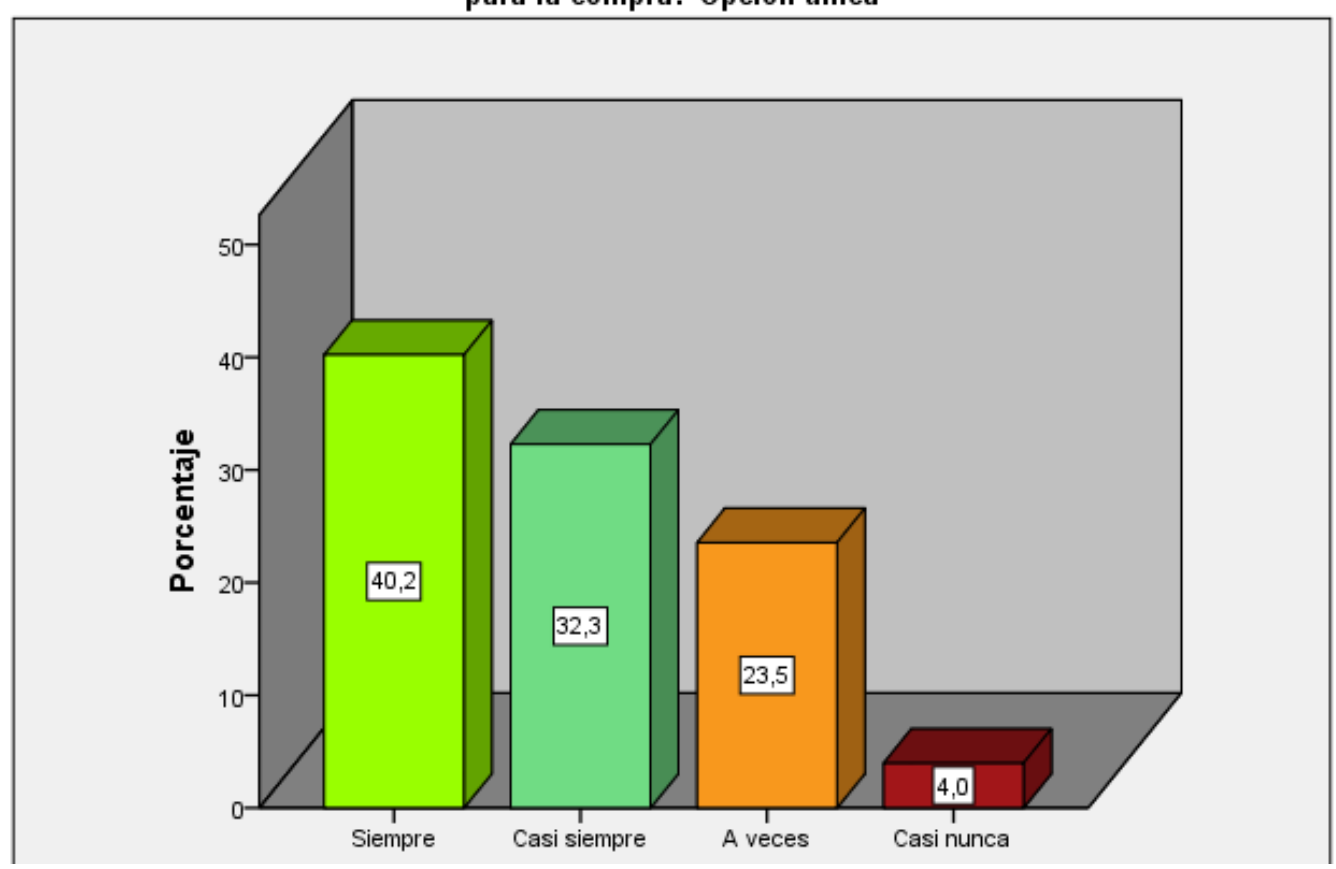

Figura 40. Disponibilidad de harina de maíz en el punto de venta

Fuente: Elaboración propia

Interpretación: Como se demuestra con la figura 40, un 40.2\% indica que cuando va a su lugar de compra preferido siempre encuentra su marca de harina preferida, mientras que un $32.3 \%$ indica que casi siempre encuentra su marca de harina preferida, mientras que un $23.5 \%$ a veces consigue su producto. Aquí vemos que un $55.5 \%$ no está consiguiendo la harina de maíz en el punto de venta. 
Para calcular el impacto de la inmigración venezolana en el 2020, se usa el modelo propuesto por el estudio del BBVA el cual se detalló en el estado del arte.

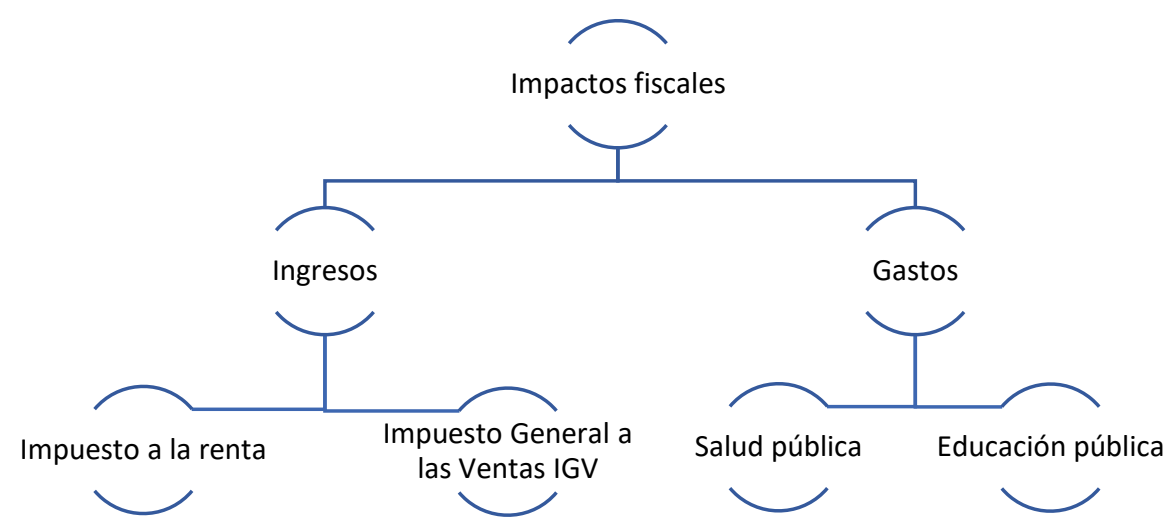

Figura 41. Detalle de impactos fiscales. Adaptado de "Inmigración venezolana a Perú: características e impactos macroeconómicos”, por BBVA Research, 2019.

\section{Impacto sobre la recaudación fiscal}

Impuesto general a las ventas

En primer lugar, se determina la población inmigrante venezolana que se encuentra laborando

Tabla 38

PET, PEA ocupada de migrantes venezolanos 2020

\begin{tabular}{lrr}
\hline Población venezolana & 860,000 & \\
\hline PET & 705,200 & $100 \%$ \\
Inactivo & 59,942 & $8.5 \%$ \\
PEA & 645,258 & $91.5 \%$ \\
PEA ocupada & 492,977 & $69.9 \%$ \\
PEA desocupada* & 152,281 & $21.6 \%$
\end{tabular}

Fuente: Elaboración propia basada en Inmigración venezolana a Perú: características e impactos macroeconómicos (BBVA,2019) 
Donde:

PET: Población en edad de trabajar (entre 14 y 65 años)

Inactiva: PET, pero que no está trabajando ni busca empleo

PEA: PET que está laborando o está buscando empleo

PEA ocupada: PET que trabaja

PEA desocupada: PET que no está trabajando, pero sí buscando empleo

EI BBVA Research propone la siguiente fórmula para la recuperación fiscal en IGV:

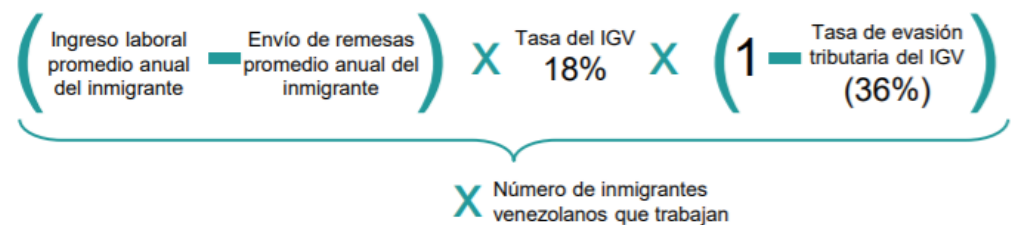

Figura 42. Fórmula para la recaudación fiscal en IGV Adaptado de "Inmigración venezolana a Perú: características e impactos macroeconómicos”, por BBVA Research, 2019.

Supuestos:

El trabajador venezolano gasta todo su ingreso laboral (neto de remesas).

$66 \%$ de venezolanos envía remesas.

Para la recaudación fiscal:

La tasa de desempleo oscila en el $23.6 \%$ por la pérdida de empleos por el impacto del Covid-19 en nuestra economía (ESAN, 2020).

El salario del inmigrante venezolano crece a la misma tasa que el de un trabajador limeño en base a la inflación del 2018 y 2019.

Perú cerró el 2018 con una inflación anualizada de 2.19\% (Gestión, 2019).

En el 2019, se cerró con una inflación anualizada de 1.90\% (América Economía, 2020). 
El sueldo promedio mensual del inmigrante en el 2018 fue de 1116 soles (BBVA Research, 2019).

Se considera que el monto mensual de remesas enviadas a Venezuela es 175 soles considerando la encuesta realizada.

Para la recaudación fiscal potencial

Se considera que el trabajador venezolano obtiene un ingreso laboral del mismo monto que el limeño (BBVA Research, 2019).

Tabla 39

Recaudación fiscal de IGV de inmigración venezolana en 2020

\begin{tabular}{lrr}
\hline & Recaudación fiscal & Recaudación potencial fiscal \\
\hline Sueldo promedio mensual & $1,162.11$ & $1,624.45$ \\
Envío de remesas promedio & & \\
mensual & 175.00 & 175.00 \\
Tasa del IGV & $18 \%$ & $18 \%$ \\
Tasa de evasión tributaria & $36 \%$ & $36 \%$ \\
del IGV & & 492,977 \\
Número de inmigrantes & 492,977 & \\
venezolanos que trabajan & & \\
Estimado 2020 por IGV (en & $672,706,294$ & $987,790,065$ \\
PEN) & & \\
\hline
\end{tabular}

Fuente: Elaboración propia

Impuesto a la renta

El BBVA Research propone la siguiente fórmula para la recuperación del impuesto a la renta: 
Número de

inmigrantes

venezolanos

que trabajan
$\%$ de los inmigrantes

venezolanos que trabajan y

tienen seguro médico

$$
\text { EsSalud }
$$

(seguro médico público pagado

por el empleador, un indicador de formalidad)
Pago promedio anual por IR de

un trabajador dependiente

recaudación fiscal por impuesto a

la renta de 5 ta categoría dividida

EsSalud)

Figura 43. Fórmula para la recaudación fiscal en IR. Adaptado de "Inmigración venezolana a Perú: características e impactos macroeconómicos”, por BBVA Research, 2019.

Supuestos:

Para la recaudación fiscal:

Se considera una estimación de la población de inmigrantes venezolanos utilizando datos de la ENPOVE (2018).

El 2.6\% de los inmigrantes venezolanos que laboran cuentan con el seguro ESSALUD (INEI, 2019).

Para la recaudación fiscal potencial:

Se considera que no habrá un incremento en la tasa de formalidad por la propagación en el Covid-19 (Gestión, 2020).

Tabla 40

Recaudación fiscal de IR de inmigración venezolana en 2020

\begin{tabular}{lrr}
\hline & $\begin{array}{c}\text { Recaudación } \\
\text { fiscal }\end{array}$ & \multicolumn{2}{c}{$\begin{array}{c}\text { Recaudación } \\
\text { potencial fiscal }\end{array}$} \\
\hline Número de inmigrantes venezolanos & & \\
que trabajan & 492,977 & 492,977 \\
$\%$ de inmigrantes venezolanos que & & \\
trabajan y cuentan con seguro de & & $2.6 \%$ \\
EsSalud & $2.6 \%$ & 5,848 \\
IR anual & 4,184 &
\end{tabular}


Estimado 2020 por IR (en PEN)

Fuente: Elaboración propia

\section{Impacto sobre el gasto fiscal}

Educación pública

El BBVA Research propone la siguiente fórmula para este gasto fiscal:

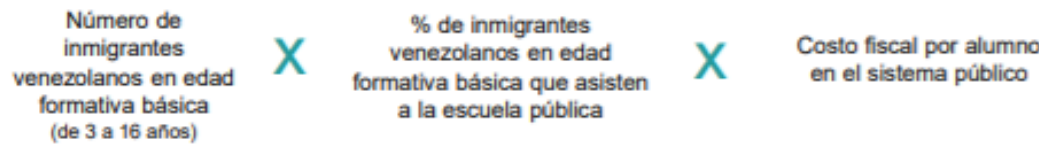

Figura 44. Fórmula para el cálculo de gasto fiscal en educación pública. Adaptado de "Inmigración venezolana a Perú: características e impactos macroeconómicos", por BBVA Research, 2019.

Supuestos:

Para el gasto fiscal

Tomando en cuento que hubo un crecimiento del $6.2 \%$ de dicha población para el 2020, se consideró una estimación de la demanda cubierta por el sistema educativo de la población de inmigrantes venezolanos en base al estudio del Banco Mundial que recopiló la información del MINEDU (Banco Mundial, 2019). 


\begin{tabular}{|l|c|c|}
\hline \multicolumn{1}{|c|}{ Poblaciones } & \multicolumn{2}{c|}{ Número de personas } \\
\hline & MINEDU & ENPOVE \\
\hline Migrantes menores de edad (0-17 años) & 118 & 117.655 \\
\hline Demanda educativa en el sector público escolarizado & 72.564 & - \\
\hline Demanda cubierta por el sistema educativo & 35.152 & 39.42 \\
\hline Demanda aún no cubierta por el sistema educativo & 37.412 & 78.235 \\
\hline Jardín & 12.765 & 36.841 \\
\hline Primaria & 14.072 & 22.575 \\
\hline Secundaria & 10.575 & 18.817 \\
\hline
\end{tabular}

Fuente: MINEDU, ENPOVE 2018.

Figura 45. Número estimado de población en edad escolar. Adaptado de "Una oportunidad para todos", por Banco Mundial, 2019.

Gasto per cápita en el sistema educativo básico es ligeramente inferior 1000 USD, este valor fue ajustado al incremento en el presupuesto en el MINEDU para este año (El Comercio, 2019).

Se considera que todos los inmigrantes venezolanos en edad formativa básica asisten a la escuela, pero se mantiene la proporción entre educación pública $(30 \%)$ y privada (70\%) (BBVA Research, 2019).

Para el gasto fiscal potencial

Se consideró una estimación de la población de inmigrantes venezolanos que se encontrarían en edad formativa, tomando en cuento que hubo un crecimiento del $6.2 \%$ de dicha población para el 2020 (BBVA Research, 2019). 


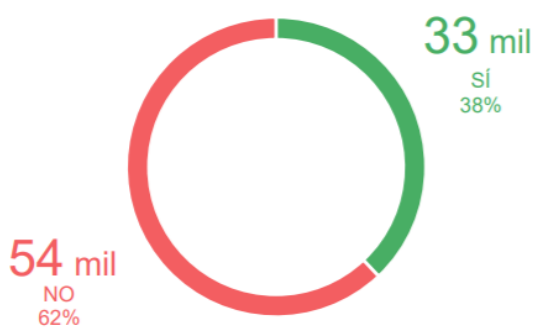

Figura 46. Asistencia a algún centro educativo de población venezolana. Adaptado de "Inmigración venezolana a Perú: características e impactos macroeconómicos", por BBVA Research, 2019.

Gasto per cápita en el sistema educativo básico es ligeramente inferior 1000 USD, este valor fue ajustado al incremento en el presupuesto en el MINEDU para este año (El Comercio, 2019).

\section{Tabla 41}

Gasto fiscal en educación pública de inmigración venezolana en 2020

\begin{tabular}{lrr}
\hline & Gasto fiscal & Gasto fiscal potencial \\
\hline $\begin{array}{l}\text { Inmigrantes venezolanos en edad } \\
\text { formativa básica (de } 3 \text { a } 16 \text { años) }\end{array}$ & & \\
$\begin{array}{l}\text { \% de inmigrantes venezolanos en } \\
\text { edad formativa básica que asisten a la }\end{array}$ & 37,331 & 92,394 \\
$\begin{array}{l}\text { escuela básica pública } \\
\text { Costo fiscal por alumno en el sistema }\end{array}$ & $3,457.20$ & $3,457.20$ \\
$\begin{array}{l}\text { público } \\
\text { Estimado } 2020 \text { por Educación pública }\end{array}$ & & \\
(en PEN) & $129,062,199$ & $319,424,537$ \\
\hline
\end{tabular}

Fuente: Elaboración propia

\section{Salud pública}

El BBVA Research propone la siguiente fórmula para este gasto fiscal: 


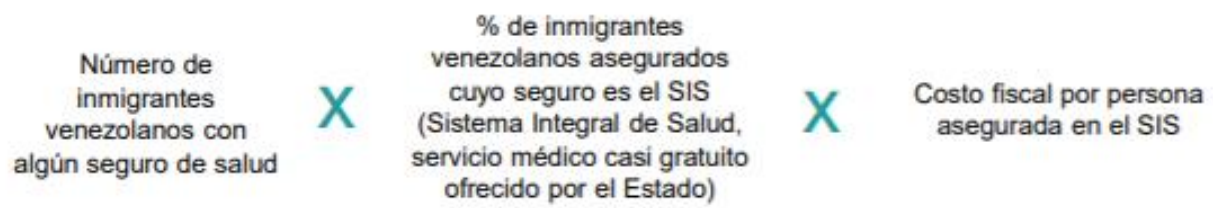

Figura 47. Fórmula planteada para el gasto fiscal en salud pública. Adaptado de “Inmigración venezolana a Perú: características e impactos macroeconómicos”, por BBVA Research, 2019.

Supuestos:

Para el gasto fiscal

Basado en el Monitoreo de flujo de la población venezolana en el Perú, en el 2019 se albergó alrededor de 860 mil ciudadanos venezolanos en nuestro país (Organización Internacional para las Migraciones Perú, 2020).

Se mantiene sin cambios la proporción de inmigrantes con algún seguro de salud, de estos la proporción que cuenta con el SIS. Por lo que el $8.5 \%$ cuentan con un seguro (Banco Mundial, 2019).

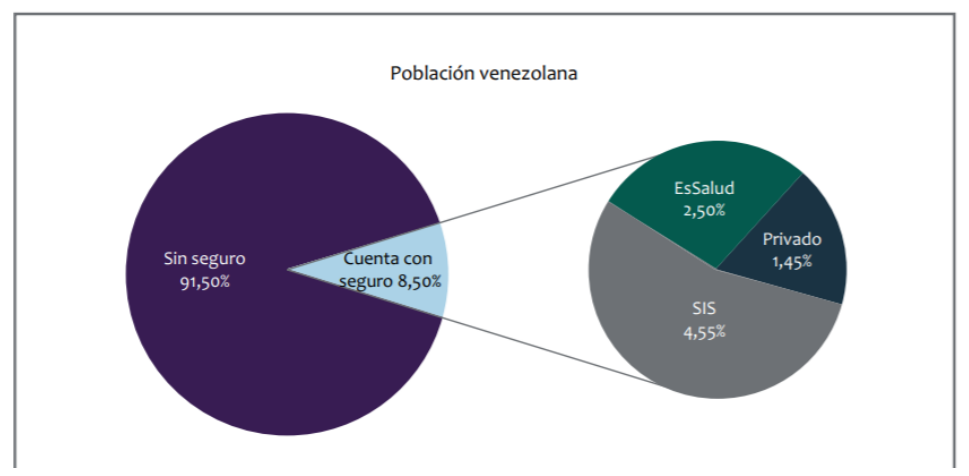

Figura 48. Población venezolana asegurada por fuente de aseguramiento. Adaptado de "Una oportunidad para todos", por Banco Mundial, 2019.

El gasto fiscal por persona asegurada en el SIS es un poco más de 130 soles, este valor fue ajustado al incremento en el presupuesto en el MINEDU del 5.5\% para este año (El Comercio, 2019). 
Para el gasto fiscal potencial

Se considera que todos los inmigrantes venezolanos cuentan con algún seguro de salud.

Se mantiene sin cambios la proporción de los que tienen SIS y el costo fiscal por persona asegurada en el SIS.

Tabla 42

Gasto fiscal en salud pública de inmigración venezolana en 2020

\begin{tabular}{lrr}
\hline & Gasto fiscal & Gasto fiscal potencial \\
\hline $\begin{array}{l}\text { Inmigrantes venezolanos con algún } \\
\text { seguro de salud }\end{array}$ & 73,100 & 860,000 \\
\% de inmigrantes venezolanos & & $53.50 \%$ \\
asegurados con SIS & $53.50 \%$ & \\
Costo fiscal por persona asegurada & & 938.95 \\
en el SIS & 938.95 & \\
Estimado 2020 por Salud Pública (en & & $432,010,895$ \\
PEN) & $36,720,926$ & \\
\hline
\end{tabular}

Fuente: Elaboración propia

Por lo tanto, sobre la base de estos cálculos, los inmigrantes venezolanos tendrán un impacto fiscal positivo de 561 millones de soles para el 2020, tal como sucedió para el año 2018 y 2019. Por el lado, de impacto potencial, sería de 311 millones de soles, esta cifra es menor debido al mayor gasto en salud pública. 


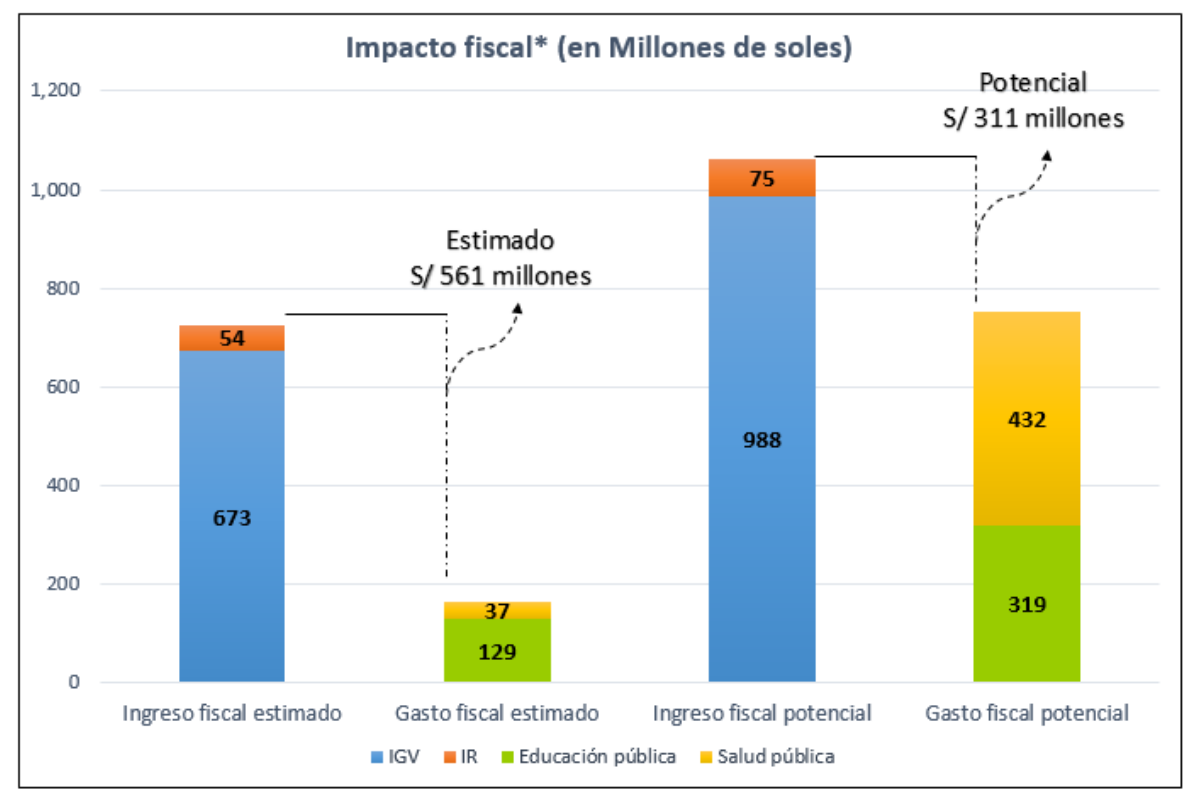

Figura 49. Impacto fiscal de inmigración venezolana en 2020

Fuente: Elaboración propia

Se rechaza la hipótesis nula debido a que la figura 67 demuestra que la población migrante venezolana Sí tiene un impacto positivo fiscal para nuestro país. Este análisis toma los estimados del estudio del BBVA y el análisis propio durante este año. En el año 2018 fue de 507 millones de soles y en el 2019, de 659 millones de soles.

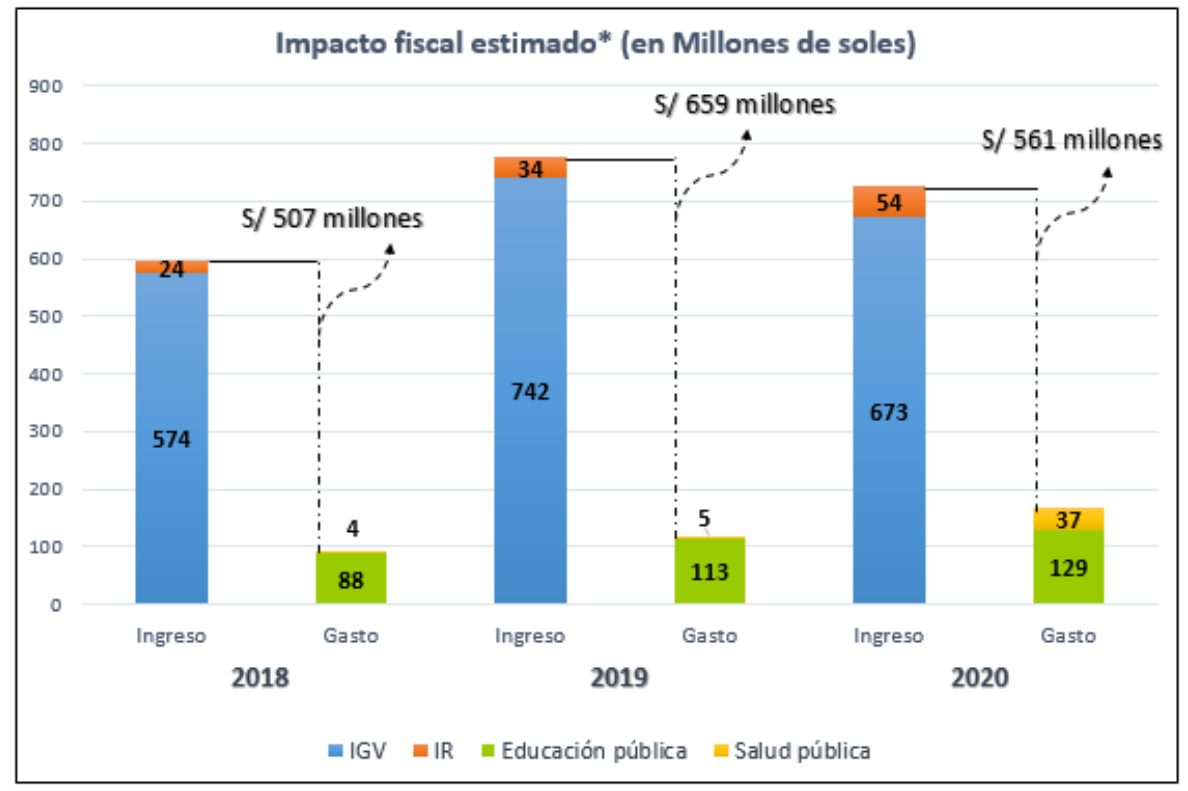

Figura 50. Impacto fiscal estimado 2018-2020

Fuente: Elaboración propia 


\section{CONTRASTACIÓN DE HIPÓTESIS}

\section{Validación de la hipótesis específica 1}

La población migrante venezolana en Lima Norte eligió al Perú por condiciones socioeconómicas.

\section{Hipótesis nula (Ho)}

La población migrante venezolana en Lima Norte NO eligió al Perú por condiciones socioeconómicas.

\section{Hipótesis alternante (H1)}

La población migrante venezolana en Lima Norte Sí eligió al Perú por condiciones socioeconómicas.

Se rechaza la hipótesis nula pues la encuesta demuestra que un $63.6 \%$ de los inmigrantes venezolanos migraron a Perú por el tema de alimentos y medicinas, incluye desabastecimiento, elevados precios y falta de trabajo. En segundo lugar, fue la facilidad que el Perú les ofreció en el trámite migratorio con un $20.1 \%$. Esto indica que esta población busca cubrir sus necesidades básicas de alimentación y acceso a medicamentos al ser su principal preocupación que los motivó a salir de su país. Se logra concluir que la población migrante venezolana en Lima Norte Sí eligió al Perú por condiciones socioeconómicas. 
P2. ¿La principal razón por la que decidió migrar a Perú? Opción única

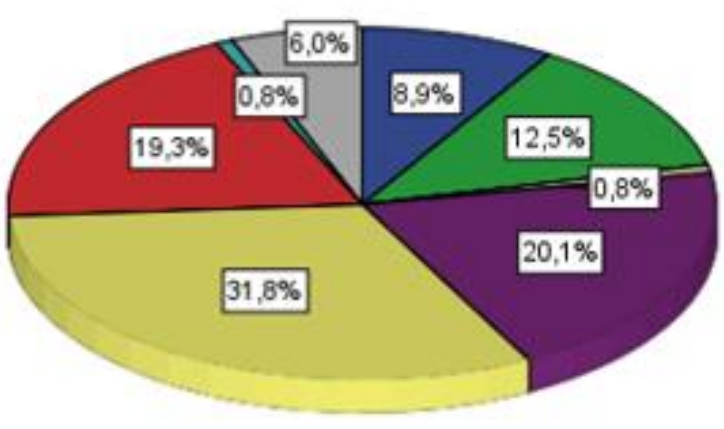

Inseguridad social en Venezuela

$\square$ Falta de trabajo en

Venezuela

$\square$ La cercania del pais y

mismo idioma

Facilidad en el trámite

migratorio en Perú

$\square$ Desabastecimiento de

almentos y medicinas

Elevados precios de

alimentos y medicinas

$\square$ Persecució i politica

$\square$ otros

Figura 51. Razones de migración al Perú

Fuente: Elaboración propia

Para conocer las condiciones de nuestro país para el año 2018 donde se produce el mayor flujo de migraciones, se elaboró un PEST que nos da un panorama general. 


\section{Político}

El gobierno de Pedro Pablo Kuczynski mantuvo una política de puertas abiertas, pero en el 2017 entra en vigor el PTP que permite a los migrantes permanecer en el territorio de forma regular por un año (prorrogable), acceder al mercado de trabajo y obtener un permiso de residencia eventualmente

Creación del Grupo de Lima en el 2017 con 14 países con el objetivo de dar seguimiento y buscar una salida pacífica a la crisis en Venezuela y desconocer al presidente Nicolas Maduro

\section{Económico}

El crecimiento económico del Perú era un ejemplo para muchos otros en la región y las proyecciones de PBI.

Según el diario La Nación, Perú se ubicaba como el cuarto país en América Latina con el costo de vida más bajo en cuanto a poder adquisitivo local, índice de renta, índice de comestibles, índice de precio de restaurantes y el precio al consumidor.

\section{Social}

Situación de mayor vulnerabilidad, discriminación y acoso en el empleo que afecta a las mujeres venezolanas.

Las características del mercado laboral peruano que es un mercado altamente informal donde incluso los venezolanos en situación irregular pueden encontrar trabajo. Según el INEl, el trabajo formal solo representa el $27.4 \%$ de la economía, mientras que el informal, el $72.6 \%$

\section{Tecnológico}

La brecha digital se está reduciendo en Perú.

Las redes sociales como Facebook WhatsApp conectaron a venezolanos y comunidades receptoras a seguir fomentando la migración al Perú.

El uso intenso de la tencología en los datos biométricos de los migrantes. trámites en línea y el sistema de identificación facial y decadactilar en el Centro Binacional de Atención en Frontera (CEBAF) de Tumbes.

Figura 52. Gráfica de PEST aplicado al país durante el 2018

Fuente: Elaboración propia

\section{Validación de la hipótesis 2}

La demanda de nuevos productos de consumo masivo corresponde a ser símbolo de identidad, cultura y tradición, pero a la vez adaptando su patrón de consumo. 


\section{Hipótesis nula (Ho)}

La demanda de nuevos productos de consumo masivo NO corresponde a ser símbolo de identidad, cultura y tradición, pero a la vez adaptando su patrón de consumo.

\section{Hipótesis alternante $(\mathbf{H 1})$}

La demanda de nuevos productos de consumo masivo sí corresponde a ser símbolo de identidad, cultura y tradición, pero a la vez adaptando su patrón de consumo.

Primero, se analiza el canal favorito de compra. El canal tradicional que incluye el mercado con un $63.8 \%$ y las bodegas con un $12 \%$ hace que prevalezca este canal con un $75.8 \%$. Esta realidad es muy similar a la de los peruanos.

P9. ¿Dónde adquiere los alimentos para su hogar con mayor frecuencia?

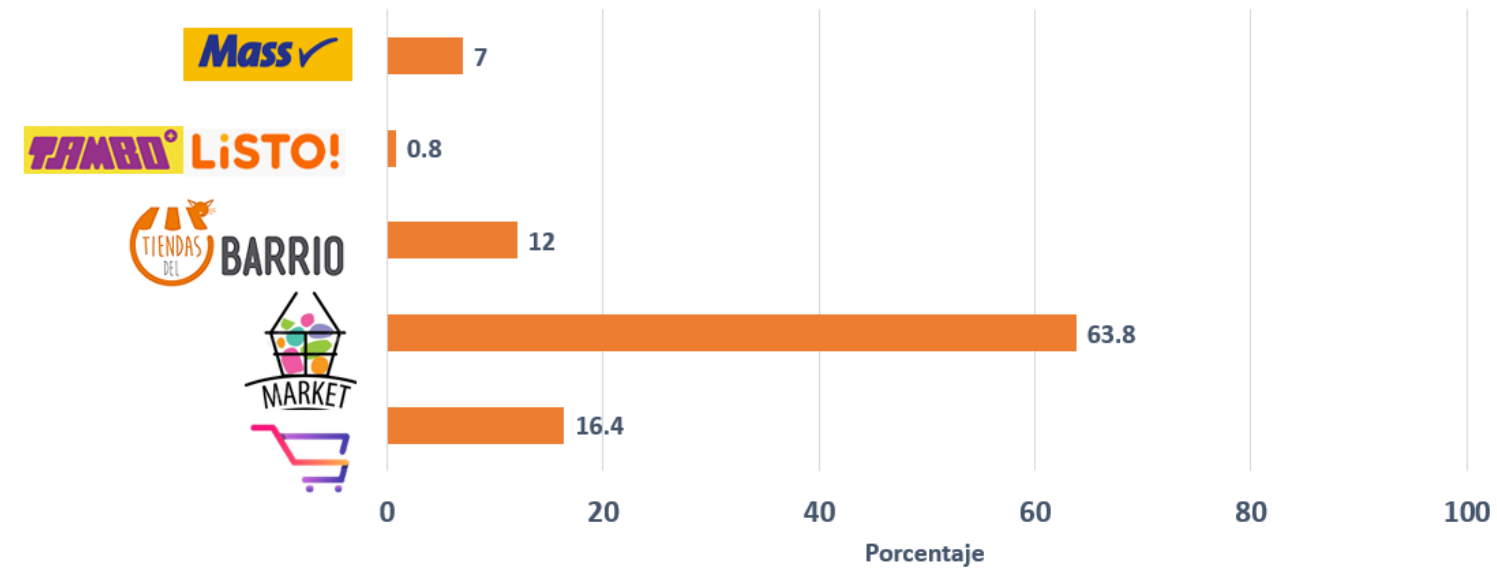

Figura 53. Canales de compra para los alimentos

Fuente: Elaboración propia

Hay 7 productos que lideran en preferencia en la canasta de los inmigrantes venezolanos:

Arroz: $97.7 \%$.

Pollo: 90.6\% 
Huevo: $68.2 \%$

Pastas: $66.7 \%$

Varias verduras: $64.3 \%$

Papa: $64.1 \%$

Harina de maíz: $63 \%$

Esta composición de la canasta difiere de los peruanos únicamente por la harina de maíz, pastas y frutas. En el caso de los peruanos, este primer alimento es reemplazado por el pan de trigo. Esto nos hace pensar que los venezolanos han alineado su dieta a productos peruanos locales como el arroz que lidera este ranking de productos.

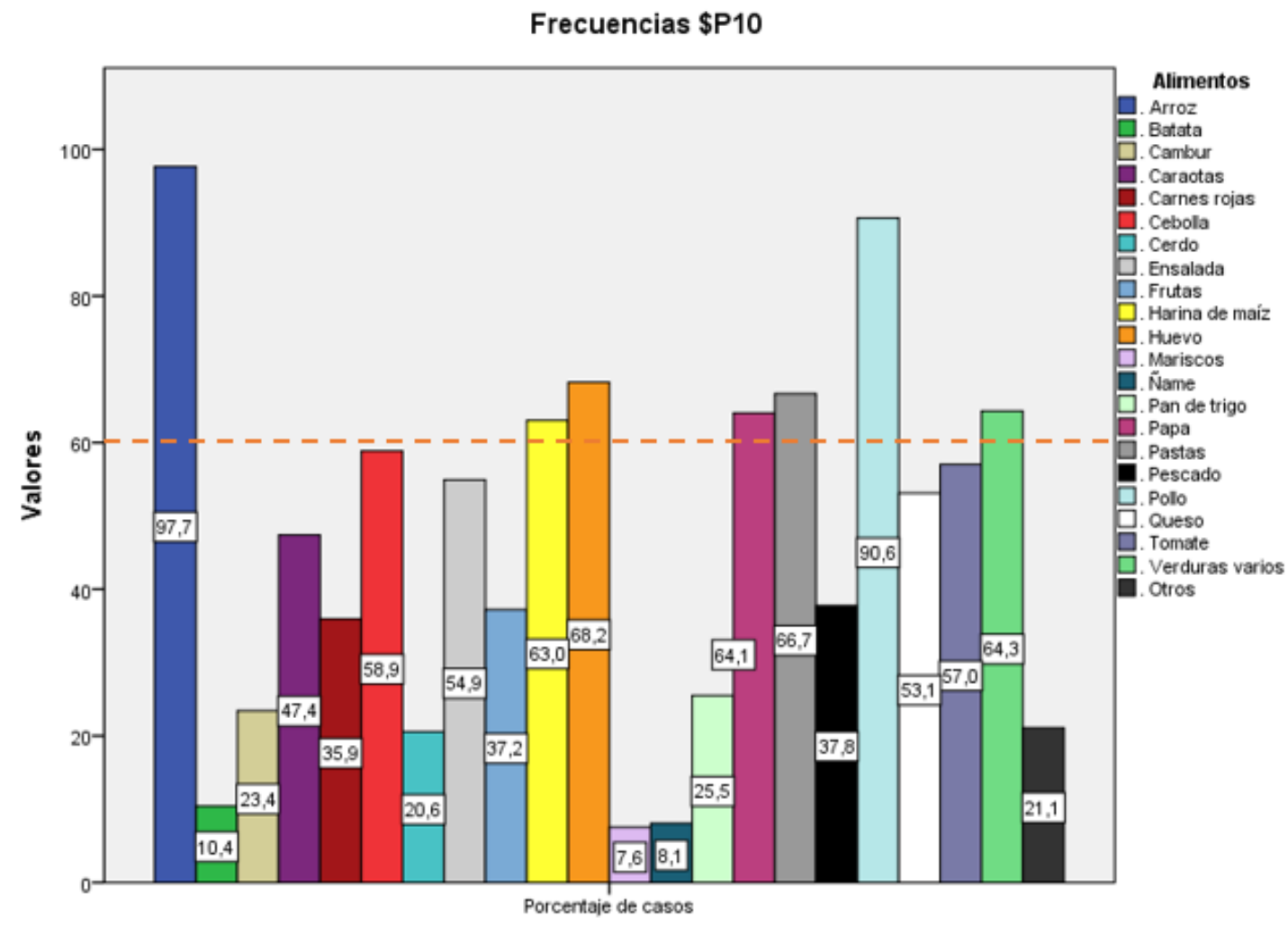

Figura 54. Alimentos básicos para la dieta de los migrantes venezolanos

Fuente: Elaboración propia

Debido al confinamiento por el Covid-19, se hizo un contraste con el estudio de Nielsen en cuanto a las demandas aumentadas y disminuidas que tuvo ciertos productos. En el primer caso, los venezolanos también compraron mayor volumen de harina de trigo con un $50.5 \%$, seguido por las hamburguesas con un $18.5 \%$, pero existe un $17.4 \%$ que indica que 
adquirió otros productos con mayor volumen, por lo cual no se comparte el mismo comportamiento de los peruanos en un $100 \%$.

\section{Frecuencias \$P11}

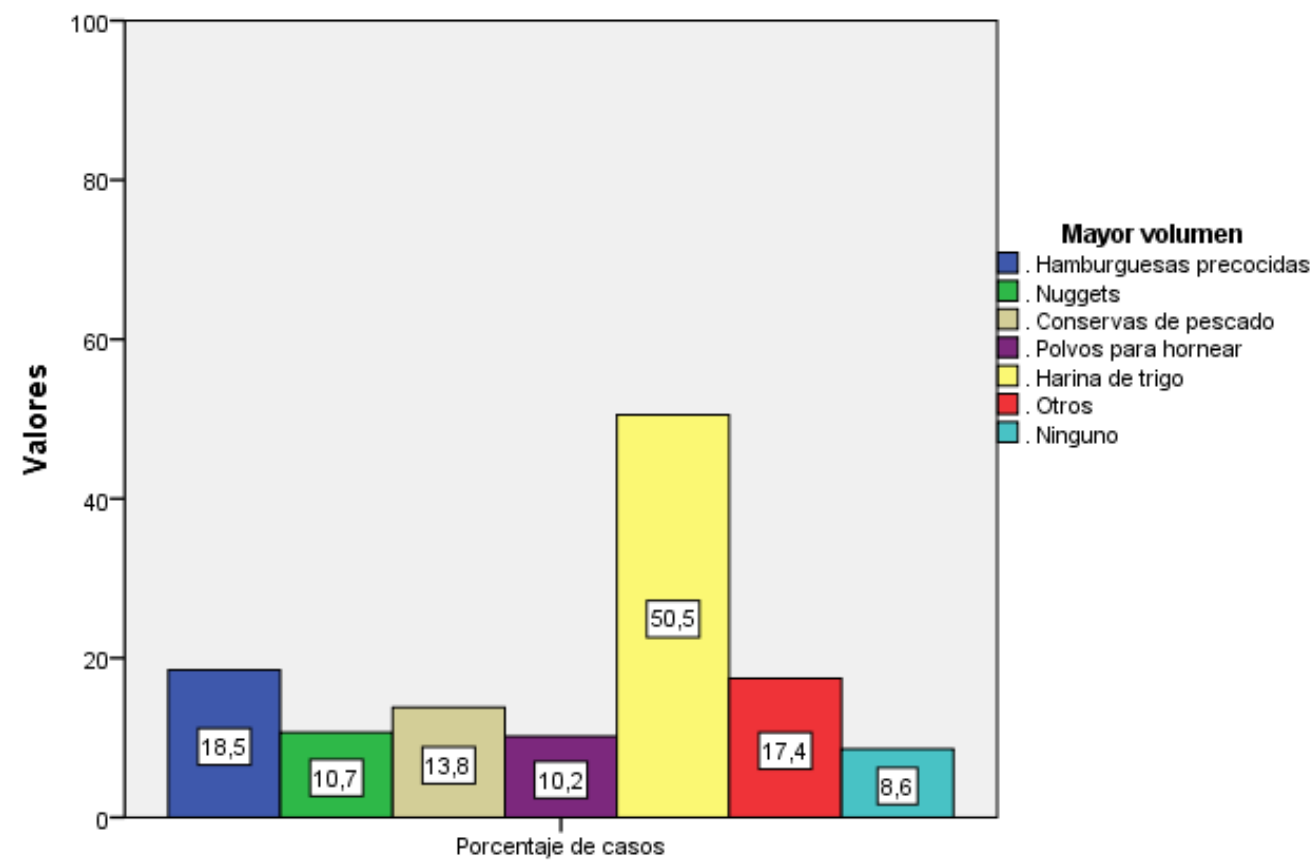

Figura 55. Alimentos con mayor volumen de compra durante el confinamiento

Fuente: Elaboración propia

Tomando en cuenta la figura 46 y continuando con la coyuntura de la pandemia, al hacer el contraste con el estudio de Nielsen, al igual que los peruanos se dejó de comprar bebidas alcohólicas en un $52.1 \%$ y muy cerca se ubicó las carnes rojas, pero a la vez, se nota la presencia de otros productos que la población migrante venezolana dejó de adquirir. Entonces, podemos concluir que tampoco se siguió el mismo comportamiento de los peruanos. 


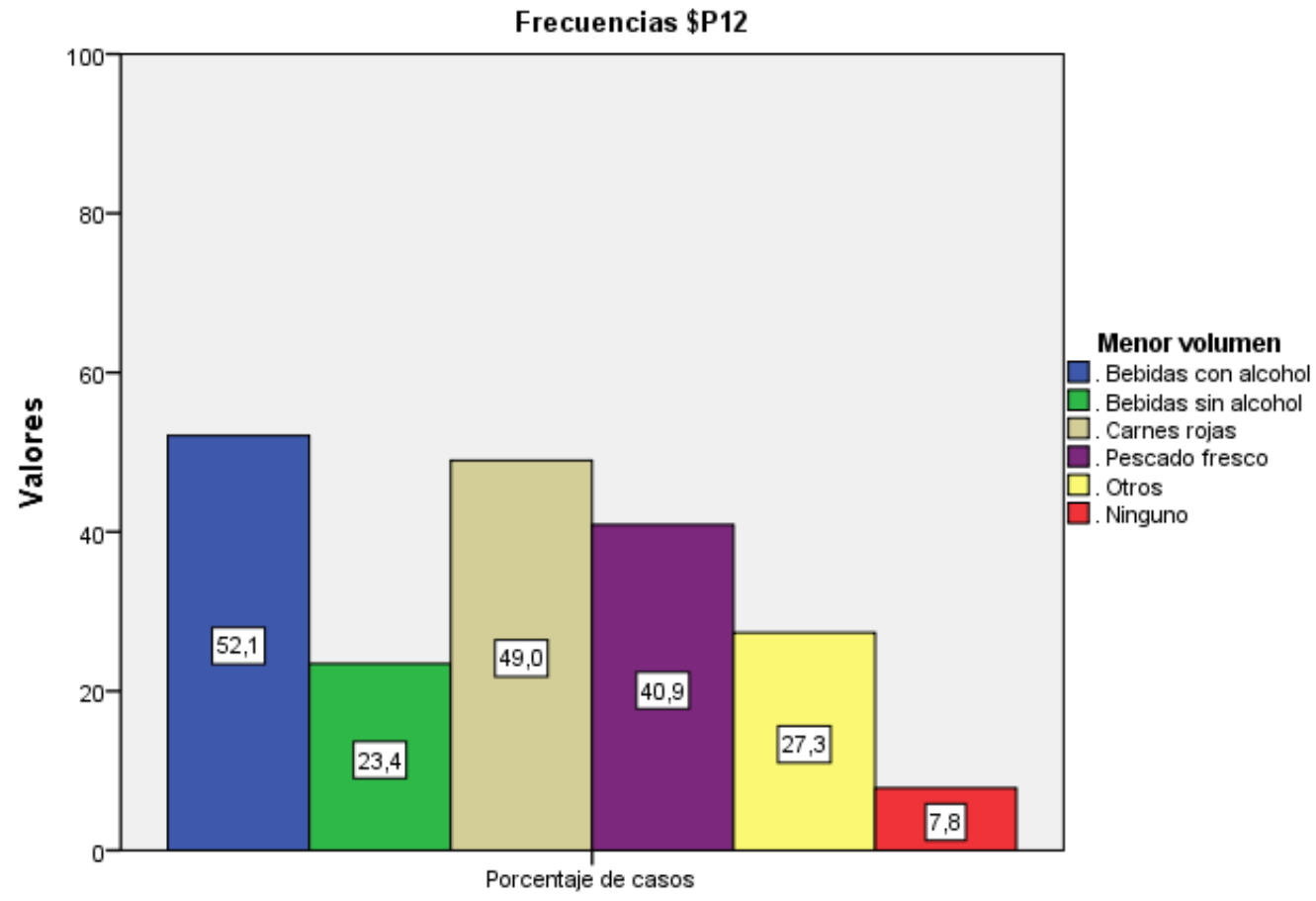

Figura 56. Alimentos con menor volumen de compra durante el confinamiento Covid-19

Fuente: Elaboración propia

Realizando una comparación con el estudio de Kantar sobre los seis factores al momento de elegir el canal de compra, los migrantes venezolanos tendrían un comportamiento similar al nivel socioeconómico $\mathrm{E}$ por lo que dan mayor importancia a los precios accesibles con un $41.1 \%$, de acuerdo con la figura 47.

En cuanto a la figura 48, al presupuesto destinado a su alimentación es menos de 300 soles. Este monto es ligeramente menor a la realidad peruana que es de S/ 344 por miembro, tomando en cuenta el estudio de Palacios Dongo. 
P13. Dada la coyuntura actual, al realizar la compra de sus alimentos, ¿qué es lo más valorado por usted para elegir el canal de compra? Opción única

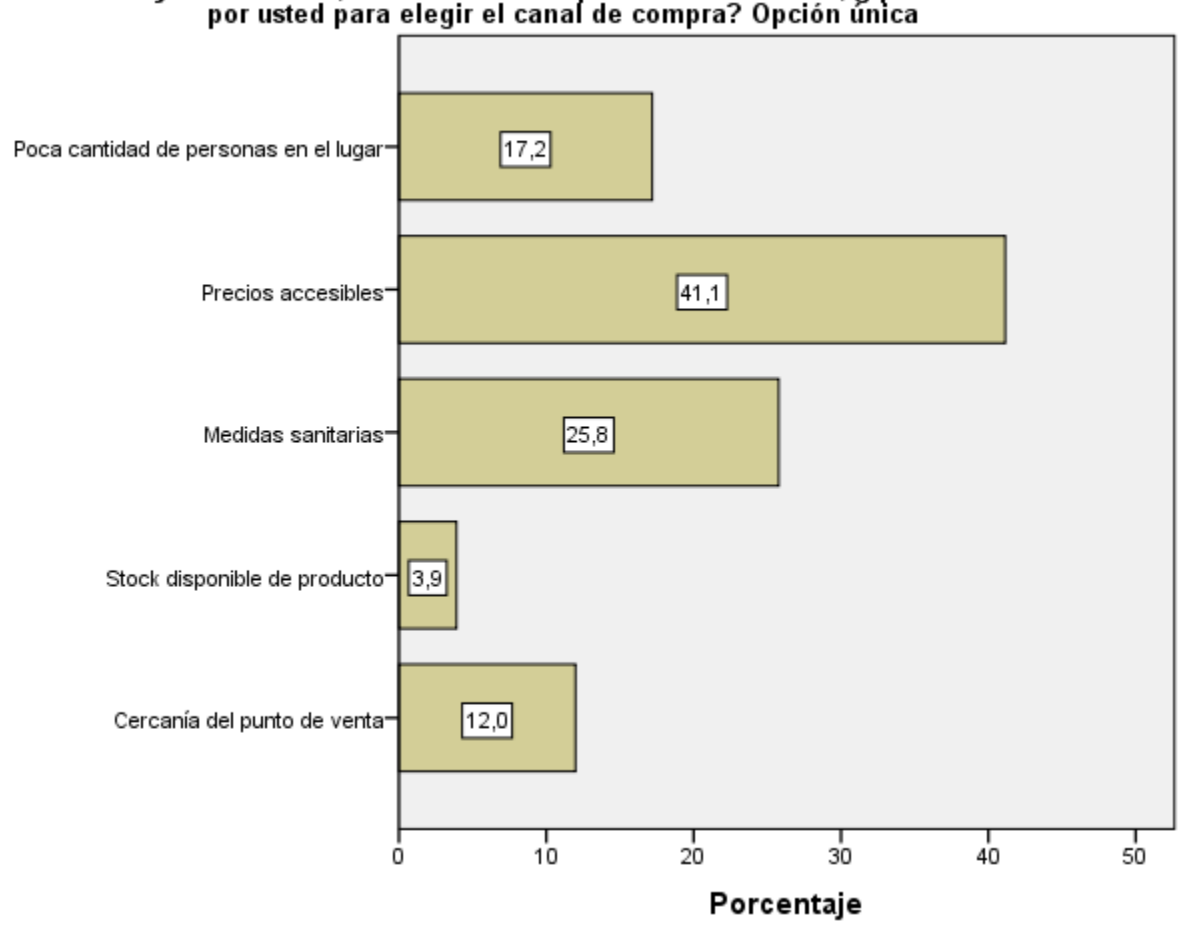

Figura 57. Variables valoradas para elegir el canal de compra

Fuente: Elaboración propia

P15. En promedio, ¿cuál es su presupuesto mensual para gastos de alimentación? Opción única

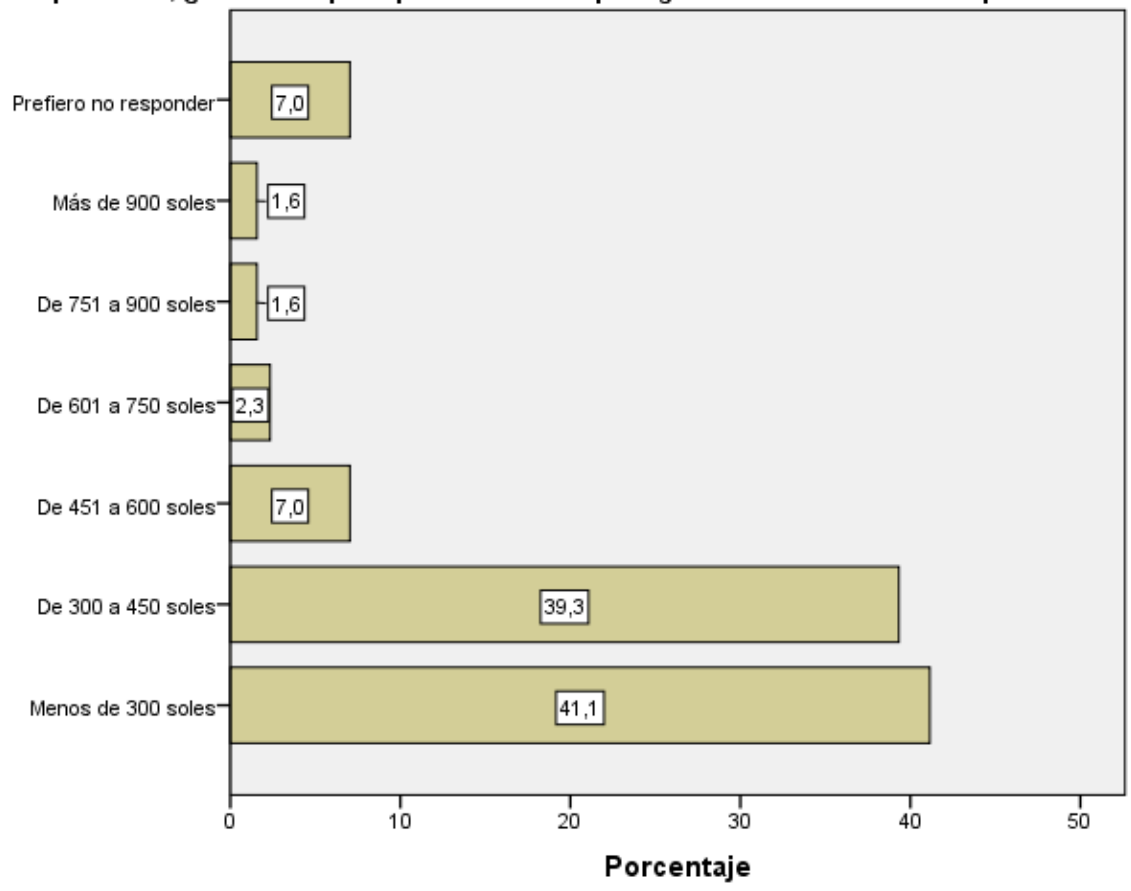

Figura 58. Presupuesto mensual destinado a gastos de alimentos

Fuente: Elaboración propia 
Con referencia a la cantidad de harina de maíz que un venezolano compra al mes es de 3-4 paquetes de $1 \mathrm{~kg}$ con un 35.4\%. Esto demuestra que este producto es parte de su dieta.

P19. ¿Cuántos paquetes de harina de maíz consume al mes en su hogar? Considerar que cada paquete es de $1 \mathrm{~kg}$. Opción única

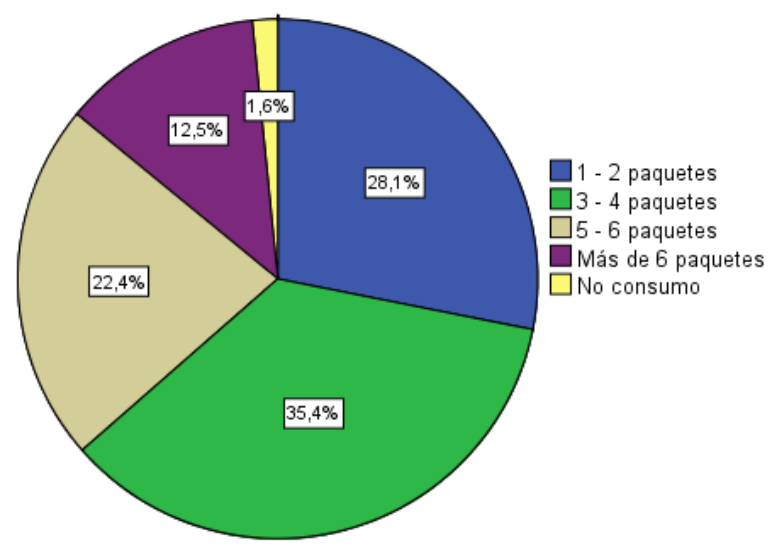

Figura 59. Paquetes de harina de maíz consumidos al mes en el hogar Fuente: Elaboración propia

Cuando se les consultó por su marca favorita de esta categoría de harinas, ellos indicaron que es Harina P.A.N. con un $85.7 \%$.

Finalmente, un dato que da el indicio que la disponibilidad de este producto no está siendo gestionada correctamente ni aprovechada es que un $32.3 \%$ casi siempre logra encontrarlo en el punto de venta y un $23.5 \%$ que lo ubica a veces. 
P20. ¿Cuál es su marca favorita de harina de maíz? Opción única

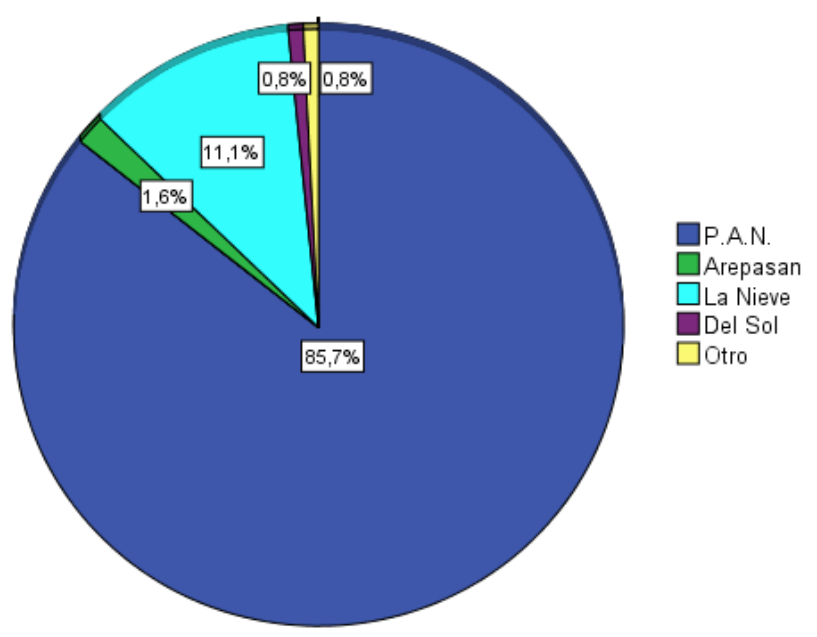

Figura 60. Marca favorita de harina de maíz

Fuente: Elaboración propia

P21. Cuando vas al punto de venta, $¿$ encuentras tu marca favorita de harina de maíz disponible para la compra? Opción única

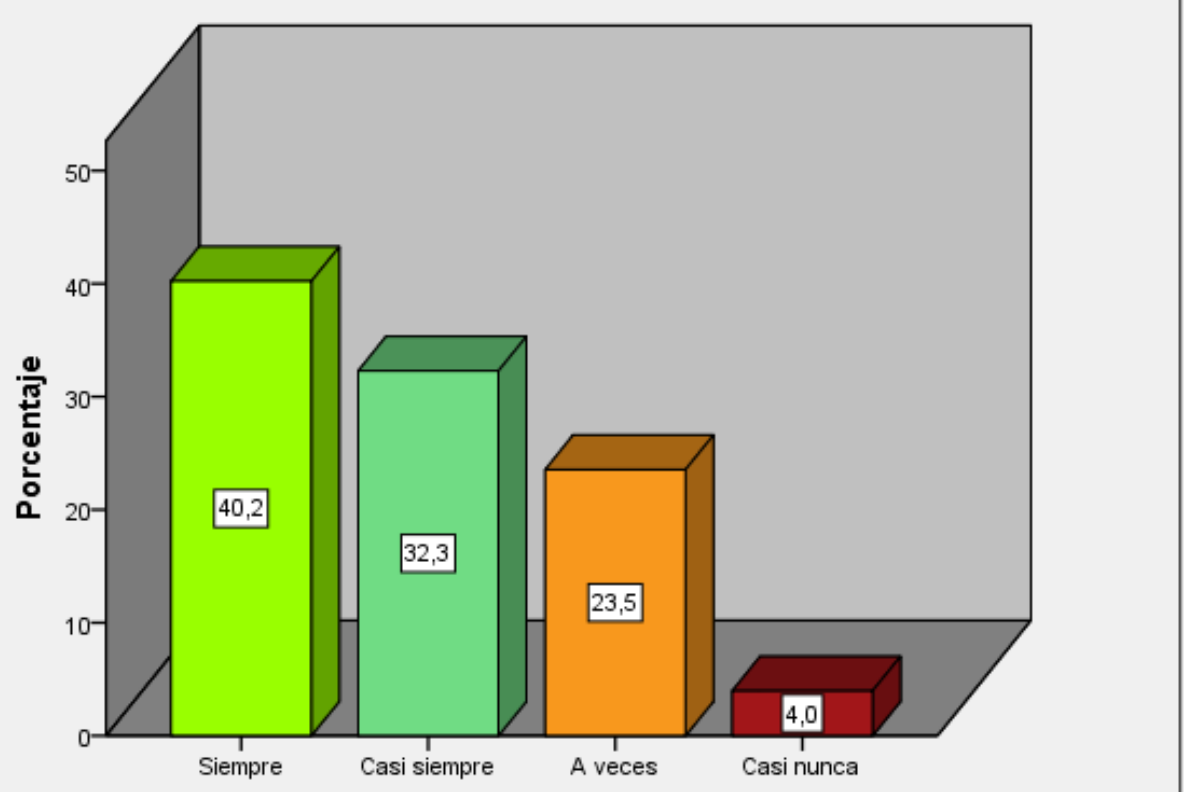

Figura 61. Disponibilidad de harina de maíz en el punto de venta Fuente: Elaboración propia 
Tabla 43

Procesamiento de datos P4 vs P5

\begin{tabular}{|c|c|c|c|c|c|c|}
\hline & \multicolumn{6}{|c|}{ Casos } \\
\hline & \multicolumn{2}{|c|}{ Válidos } & \multicolumn{2}{|c|}{ Perdidos } & \multicolumn{2}{|c|}{ Total } \\
\hline & $\mathrm{N}$ & Porcentaje & $\mathrm{N}$ & Porcentaje & $\mathrm{N}$ & Porcentaje \\
\hline $\begin{array}{l}\text { P4. ¿Cuál es su } \\
\text { ocupación principal? }\end{array}$ & 285 & $74,2 \%$ & 99 & $25,8 \%$ & 384 & $100,0 \%$ \\
\hline Opción única * P5. & & & & & & \\
\hline ¿Cuál de las siguientes & & & & & & \\
\hline opciones describe & & & & & & \\
\hline mejor su situación en & & & & & & \\
\hline estos momentos? & & & & & & \\
\hline Opción única & & & & & & \\
\hline
\end{tabular}

Fuente: Software SPSS

Tabla 44

Ocupación principal vs situación actual

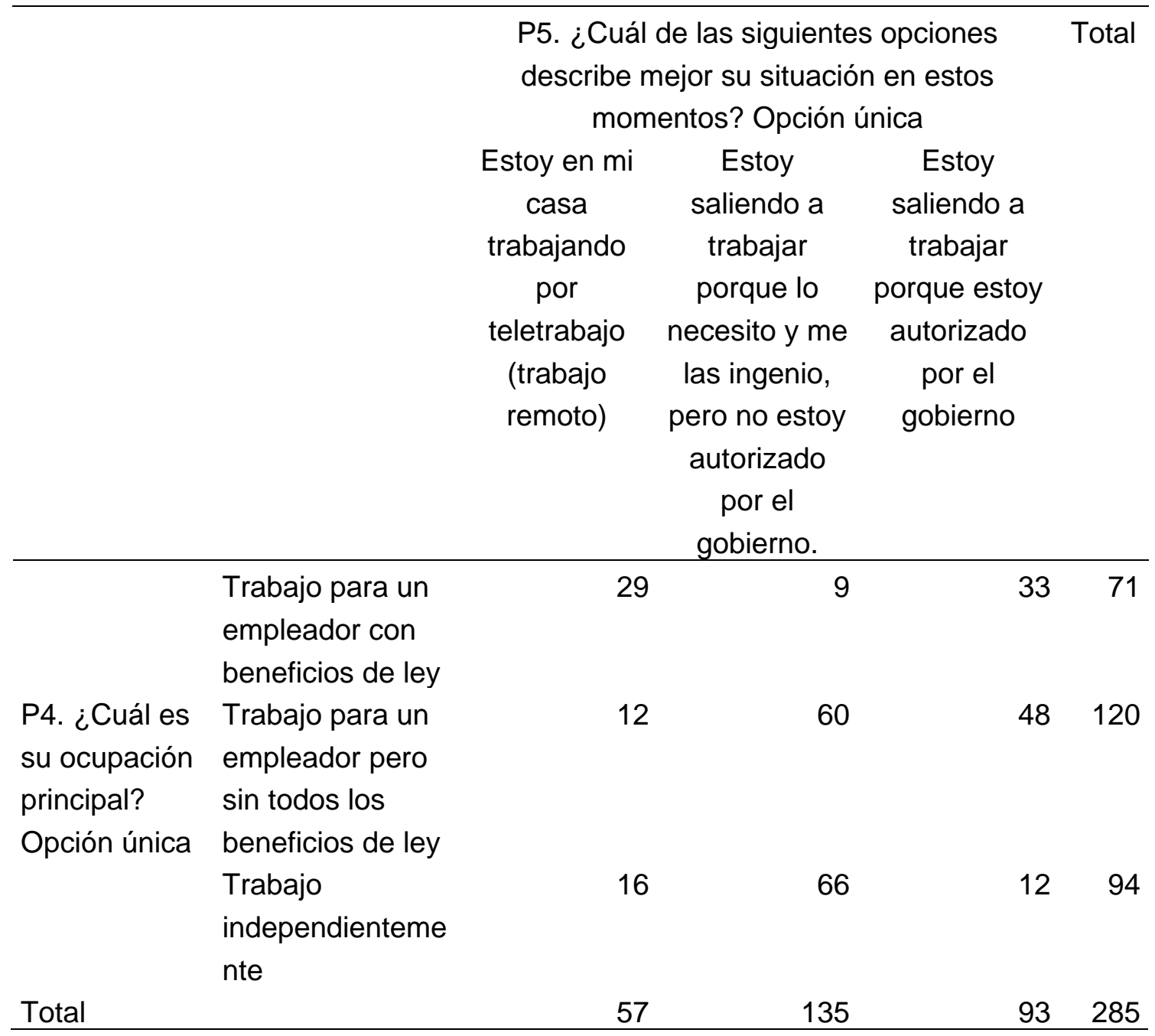


Fuente: Software SPSS

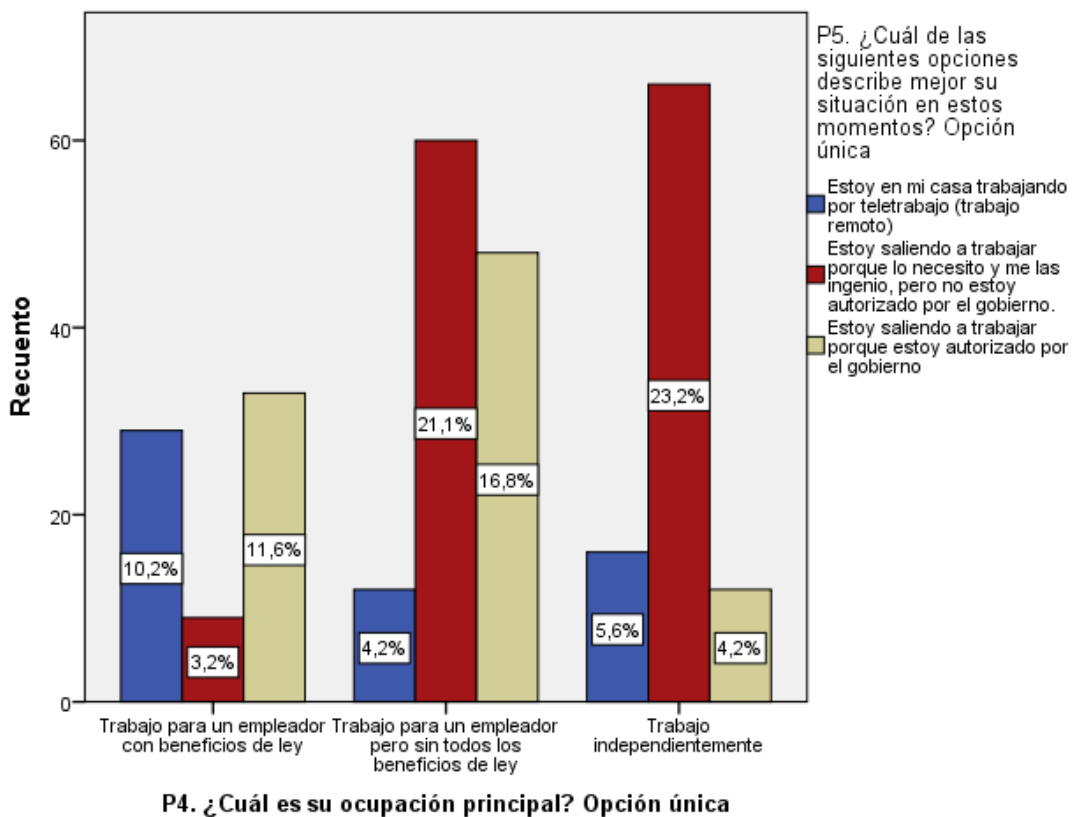

Figura 62. Ocupación principal vs situación actual

Fuente: Elaboración propia

Como se muestra en la figura 53 , un $23.2 \%$ de los que trabajan independientemente lo están haciendo sin tener la autorización del gobierno, lo cual es probable que sean signos de la informalidad de los migrantes venezolanos. Muy de cerca, está el 21.1\% de venezolanos que laboran con un empleador sin todos los beneficios de ley cuyas empresas también estarían operando a pesar de no ser incluidos en la etapa de reactivación propuesta por las medidas del gobierno por la pandemia. 


\begin{tabular}{|c|c|c|c|c|c|c|c|}
\hline & & \multicolumn{5}{|c|}{$\begin{array}{l}\text { P13. Dada la coyuntura actual, al realizar la } \\
\text { compra de sus alimentos, ¿qué es lo más } \\
\text { valorado por usted para elegir el canal de } \\
\text { compra? Opción única }\end{array}$} & \multirow[t]{2}{*}{ Total } \\
\hline & & $\begin{array}{l}\text { Cercaní } \\
\text { a del } \\
\text { punto } \\
\text { de venta }\end{array}$ & $\begin{array}{l}\text { Stock } \\
\text { disponible } \\
\text { de } \\
\text { producto }\end{array}$ & $\begin{array}{l}\text { Medidas } \\
\text { sanitaria } \\
\text { s }\end{array}$ & $\begin{array}{l}\text { Precios } \\
\text { accesibl } \\
\text { es }\end{array}$ & $\begin{array}{c}\text { Poca } \\
\text { cantidad } \\
\text { de } \\
\text { persona } \\
\text { s en el } \\
\text { lugar }\end{array}$ & \\
\hline $\begin{array}{l}\text { P7. } \\
\text { Considerand } \\
\text { o que el }\end{array}$ & $\begin{array}{l}\text { Por debajo } \\
\text { del salario } \\
\text { básico }\end{array}$ & 3 & 6 & 38 & 70 & 15 & 132 \\
\hline $\begin{array}{l}\text { salario } \\
\text { básico en el } \\
\text { Perú es S/ }\end{array}$ & $\begin{array}{l}\text { Igual al } \\
\text { salario } \\
\text { básico }\end{array}$ & 25 & 3 & 24 & 34 & 18 & 104 \\
\hline $\begin{array}{l}\text { 930. ¿Usted } \\
\text { diría que su } \\
\text { ingreso }\end{array}$ & $\begin{array}{l}\text { Mayor que el } \\
\text { salario } \\
\text { básico }\end{array}$ & 9 & 3 & 25 & 21 & 6 & 64 \\
\hline $\begin{array}{l}\text { personal } \\
\text { mensual es } \\
\text { de ...? } \\
\text { Opción única }\end{array}$ & $\begin{array}{l}\text { Prefiero no } \\
\text { responder }\end{array}$ & 9 & 3 & 12 & 33 & 27 & 84 \\
\hline Total & & 46 & 15 & 99 & 158 & 66 & 384 \\
\hline
\end{tabular}




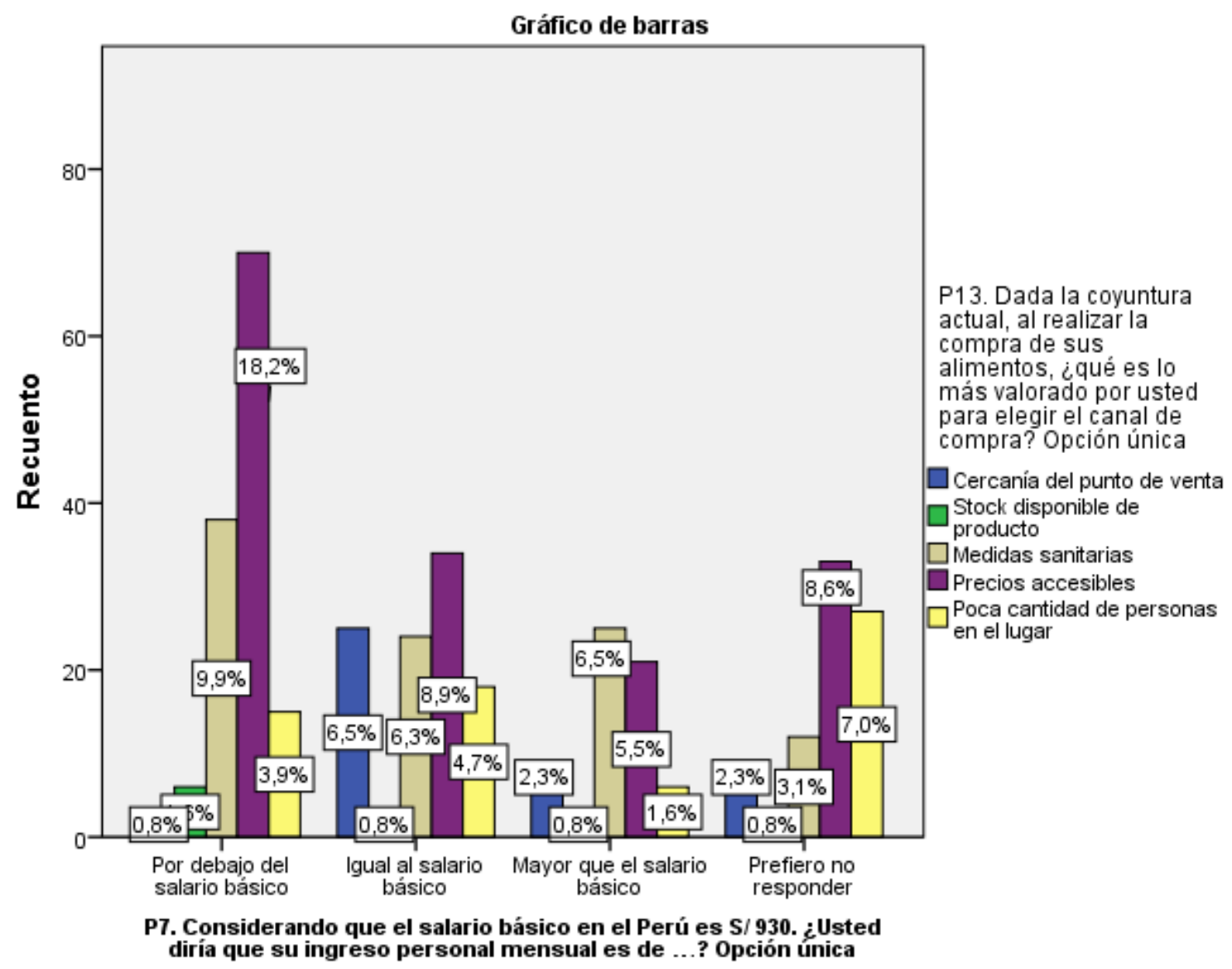

Figura 63. Salario básico vs variables de compra en el tiempo de Covid-19

\section{Fuente: Elaboración propia}

En la figura 54, se muestra que los venezolanos con una remuneración menor al salario básico valoran muchísimo los precios bajos al escoger el punto de venta de sus productos con un $18.2 \%$; mientras que el otro frente de venezolanos con una remuneración mayor al salario básico da más preferencia a las medidas sanitarias con un $6.5 \%$.

También se extrajo un histórico de la plataforma de Veritrade de la partida arancelaria 1102200000 de harina de maíz de las importaciones que el Perú realizó desde el 2015 hasta mayo 2020. Esto permitió graficar y tener la visibilidad de como la harina de maíz sufrió un crecimiento flagrante desde marzo 2018, por lo que se consideraría un nuevo producto comercializado en el Perú y el más demandado por la población venezolana. 


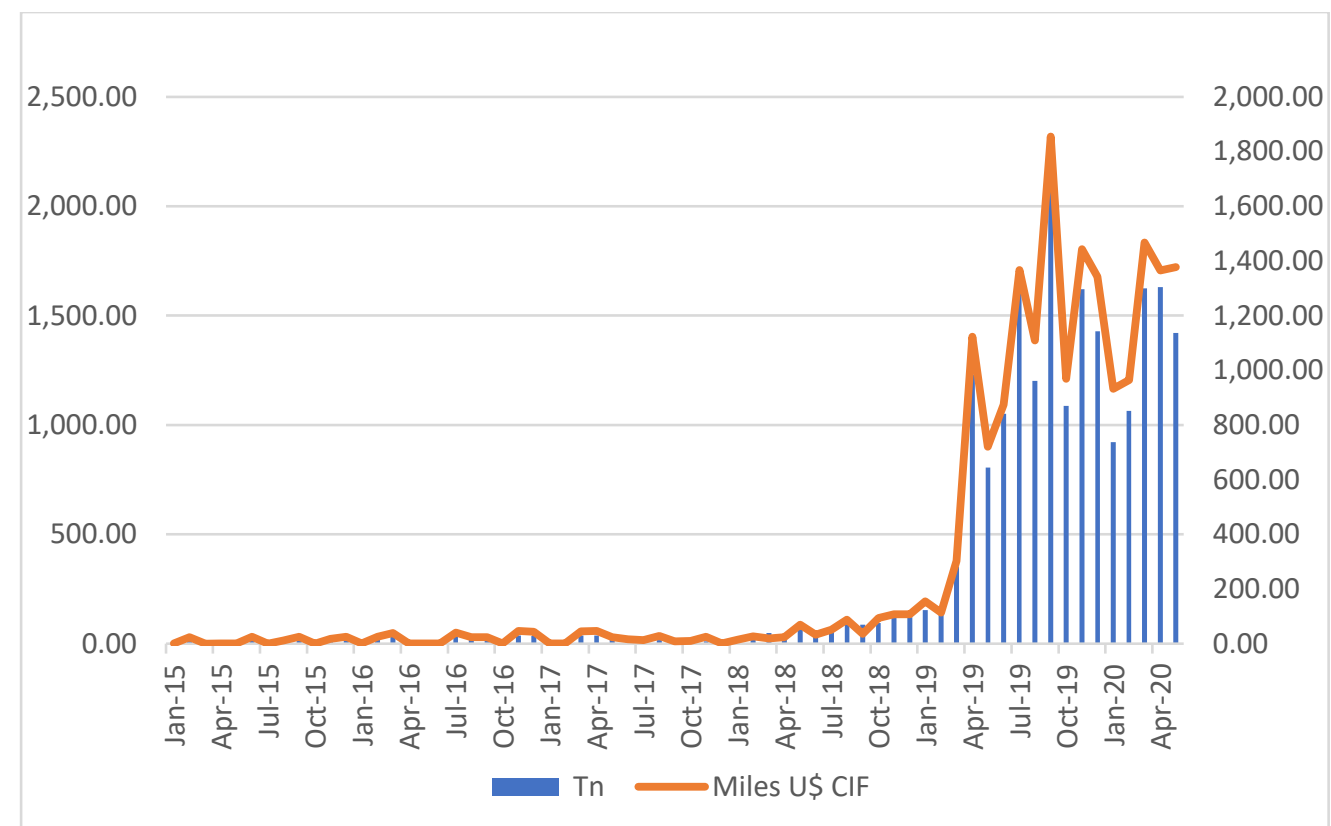

Figura 64. Histórico de importaciones de harina de maíz en Perú

Fuente: Elaboración propia

Se pensó que la harina de maíz puede tener un comportamiento estacional, pero las cifras demuestran lo contrario. Se hizo un análisis desde el 2018 pues es este año donde la importación tiene un comportamiento anormal de lo que solía tener en nuestro mercado.

Tabla 46

Importaciones de harina de maíz en Tm en Perú

\begin{tabular}{lrrr}
\hline Meses & \multicolumn{1}{c}{2018} & \multicolumn{1}{c}{2019} & \multicolumn{1}{c}{2020} \\
\hline Enero & 20.30 & 154.37 & 921.63 \\
Febrero & 30.36 & 170.86 & $1,065.25$ \\
Marzo & 49.61 & 352.16 & $1,624.10$ \\
Abril & 35.00 & $1,231.18$ & $1,631.15$ \\
Mayo & 79.00 & 804.96 & $1,420.07$ \\
Junio & 45.40 & $1,051.60$ & \\
Julio & 66.24 & $1,639.44$ & \\
Agosto & 109.19 & $1,201.88$ & \\
Setiembre & 87.50 & $2,302.69$ & \\
Octubre & 94.45 & $1,087.52$ & \\
Noviembre & 117.33 & $1,620.61$ & \\
Diciembre & 121.36 & $1,429.13$ & \\
Total & 855.74 & $13,046.40$ & $6,662.20$ \\
\hline
\end{tabular}

Fuente: Elaboración propia basada en Veritrade 
Al ser la harina de maíz un producto de consumo masivo no demuestra estacionalidad.

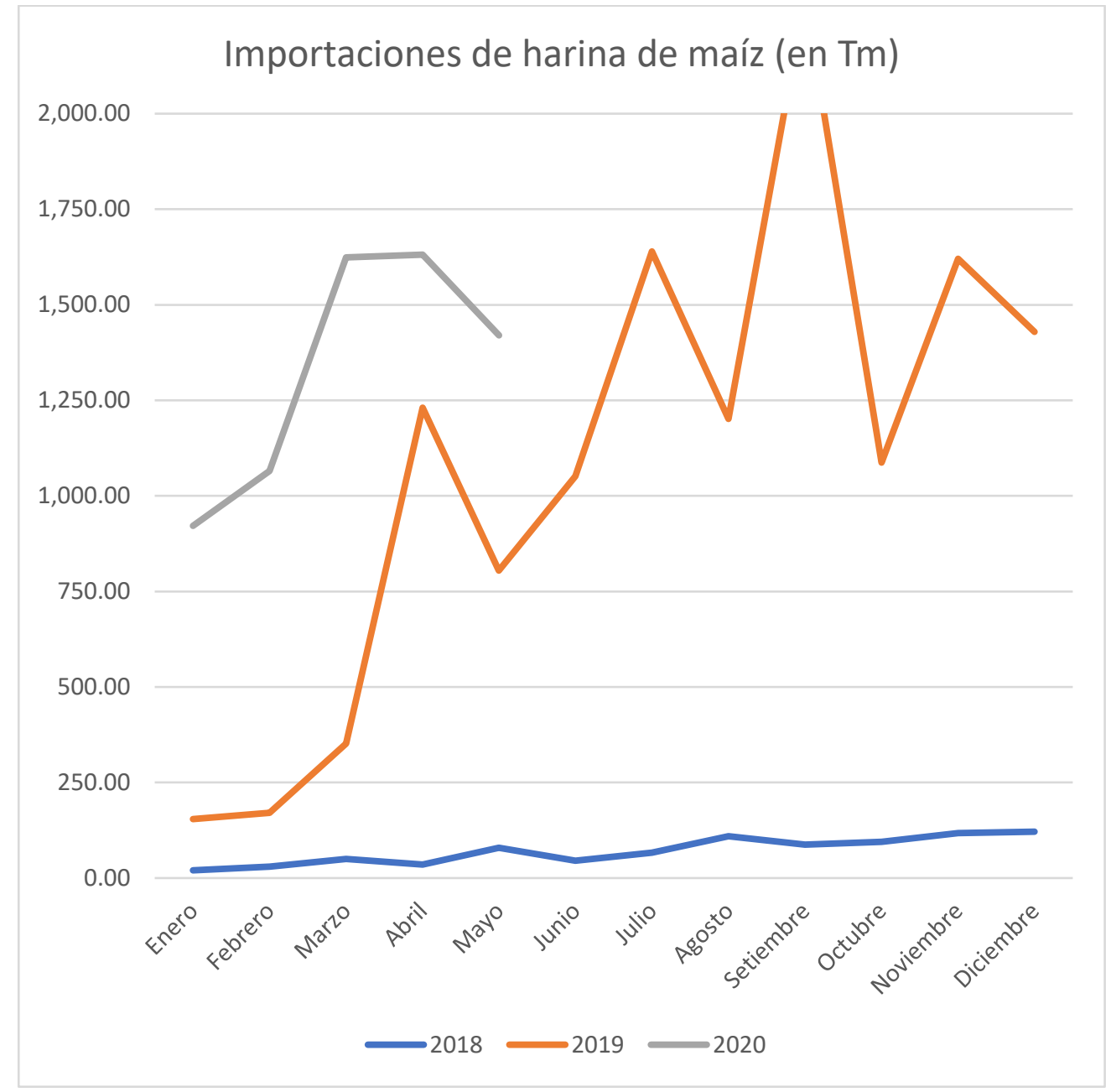

Figura 65. Importaciones de harina de maíz en los últimos 3 años en Perú Fuente: Elaboración propia

Si bien las tendencias de las importaciones han sufrido una contracción por el Covid19 debido a los problemas logísticos surgidos por el coronavirus, la harina de maíz pertenece al sector de alimentos, por lo que vale la pena realizar un pronóstico pues es un sector que se recupera en el corto plazo.

Se seleccionó 4 tipos de pronósticos: 


\section{Pronóstico con promedio móvil ponderado}

Se optó por estas alfas de tal forma que se minimiza el EPMA, pero aun así se obtuvo un $25.91 \%$.

\begin{tabular}{cc}
\hline ALFAS & $\%$ \\
\hline 1 & $5.2 \%$ \\
2 & $43.2 \%$ \\
3 & $51.7 \%$ \\
\hline 6 & $100.0 \%$ \\
\hline
\end{tabular}

Tabla 47

Pronóstico con promedio móvil ponderado

Prom. Móvil

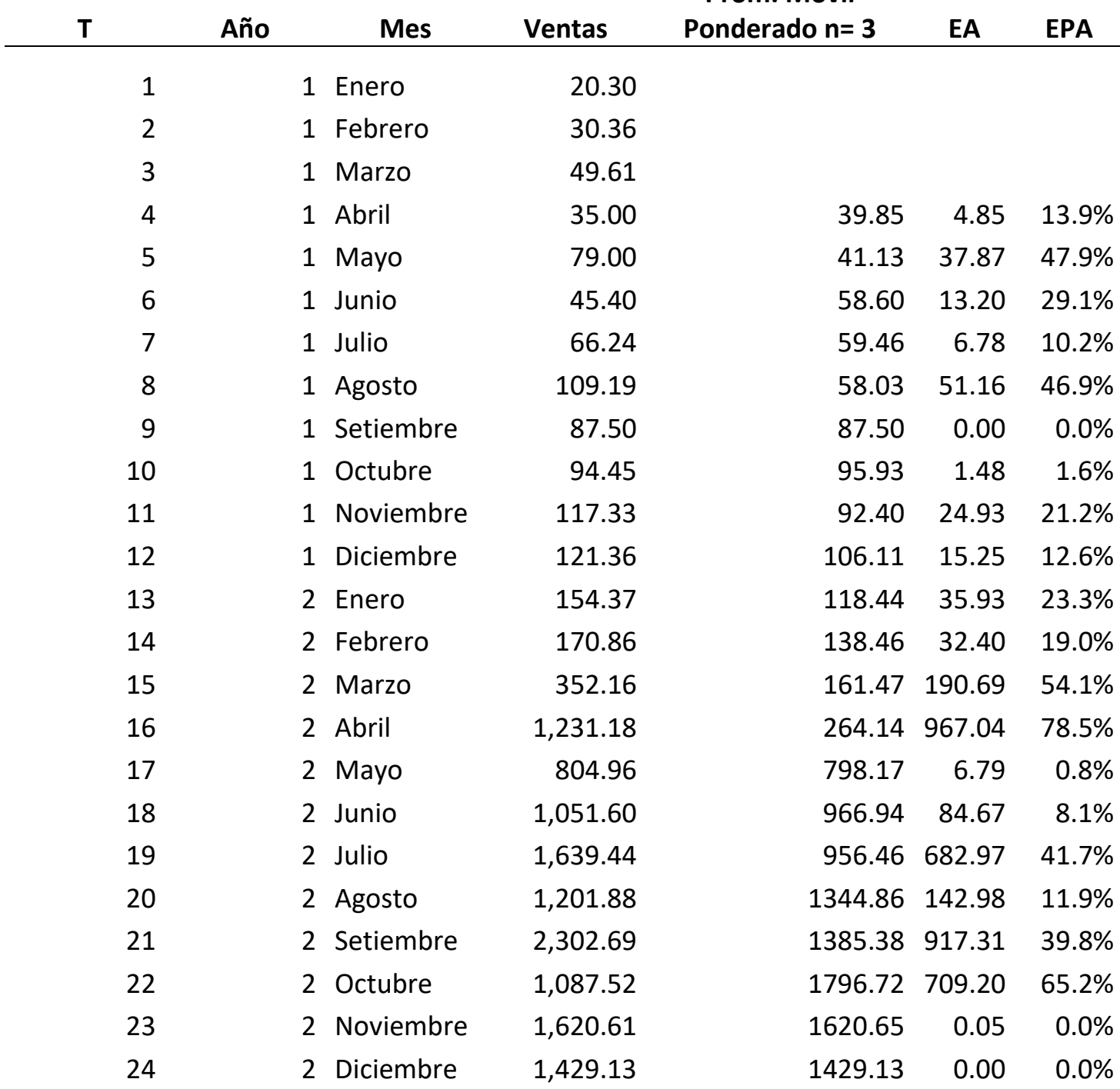




\begin{tabular}{|c|c|c|c|c|c|c|}
\hline 25 & 3 & Enero & 921.63 & 1496.71 & 575.08 & $62.4 \%$ \\
\hline 26 & 3 & Febrero & $1,065.25$ & 1179.32 & 114.07 & $10.7 \%$ \\
\hline 27 & 3 & Marzo & $1,624.10$ & 1024.31 & 599.79 & $36.9 \%$ \\
\hline 28 & 3 & Abril & $1,631.15$ & 1348.94 & 282.21 & $17.3 \%$ \\
\hline 29 & 3 & Mayo & $1,420.07$ & 1601.58 & 181.51 & $12.8 \%$ \\
\hline 30 & 3 & Junio & & 1524.70 & & \\
\hline 31 & 3 & Julio & & & & \\
\hline 32 & 3 & Agosto & & & & \\
\hline 33 & 3 & Setiembre & & & & \\
\hline 34 & 3 & Octubre & & & & \\
\hline 35 & 3 & Noviembre & & & & \\
\hline 36 & 3 & Diciembre & & & & \\
\hline & & & & & 218.39 & $25.61 \%$ \\
\hline
\end{tabular}

Fuente: Elaboración propia

\section{Pronóstico con suavizamiento exponencial simple}

Se optó por el alfa de 0.23709873 de tal forma que se minimiza el EPMA, pero aun así se obtuvo un $34.42 \%$.

\begin{tabular}{cc}
\hline ALFA \\
\hline A & 0.23709873 \\
\hline
\end{tabular}

Tabla 48

Pronóstico con el suavizamiento exponencial simple

\begin{tabular}{rrlrlrr}
\hline T Año & & Mes & \multicolumn{1}{l}{ Ventas } & \multicolumn{1}{l}{ EA } & \multicolumn{1}{c}{ EPA } \\
\hline 1 & 1 Enero & 20.30 & 34.22 & 13.92 & $68.6 \%$ \\
2 & 1 Febrero & 30.36 & 30.92 & 0.56 & $1.8 \%$ \\
3 & 1 Marzo & 49.60 & 30.79 & 18.82 & $37.9 \%$ \\
4 & 1 Abril & 35 & 35.25 & 0.25 & $0.7 \%$ \\
5 & 1 Mayo & 79 & 35.19 & 43.81 & $55.5 \%$ \\
6 & 1 Junio & 45.40 & 45.58 & 0.18 & $0.4 \%$ \\
7 & 1 Julio & 66.24 & 45.54 & 20.70 & $31.3 \%$ \\
8 & 1 Agosto & 109.19 & 50.44 & 58.75 & $53.8 \%$ \\
9 & 1 Setiembre & 87.50 & 64.37 & 23.13 & $26.4 \%$ \\
10 & 1 Octubre & 94.450 & 69.86 & 24.59 & $26.0 \%$ \\
11 & 1 Noviembre & 117.33 & 75.69 & 41.65 & $35.5 \%$ \\
12 & 1 Diciembre & 121.36 & 85.56 & 35.79 & $29.5 \%$ \\
13 & 2 Enero & 154.37 & 94.05 & 60.32 & $39.1 \%$
\end{tabular}




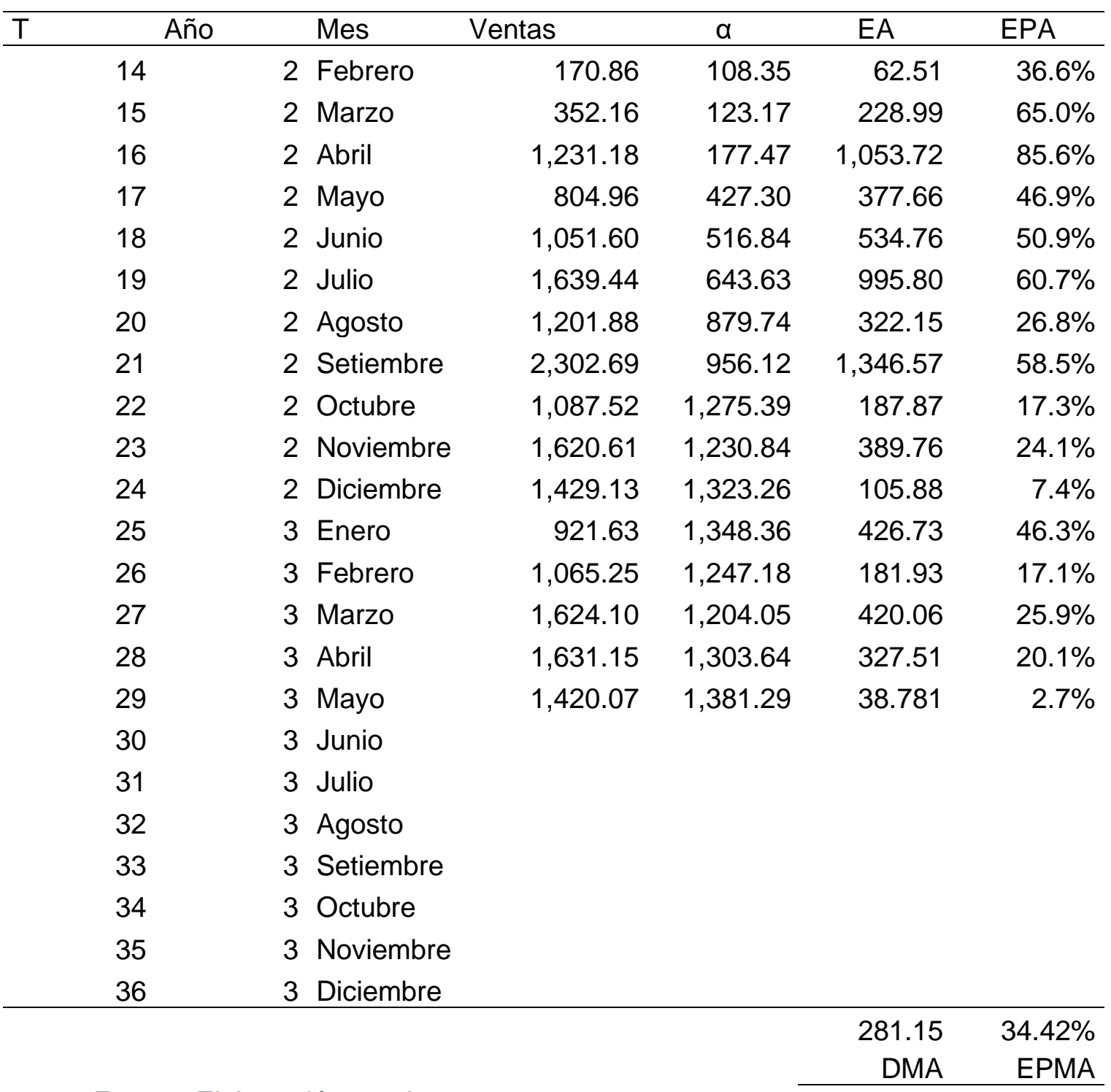

Fuente: Elaboración propia

\section{Pronóstico con el modelo Holt}

Se optó por la siguiente alfa, beta, de tal forma que se minimiza el EPMA, pero aun así se obtuvo un $25.90 \%$.

\begin{tabular}{cc}
\hline A & 0.419724584 \\
B & 0 \\
Tend.inicial T & 6.96 \\
Nivel inicial L & 23.40 \\
\hline
\end{tabular}

Tabla 49

Pronóstico con el modelo Holt 


\begin{tabular}{|c|c|c|c|c|c|c|c|c|}
\hline $\mathbf{T}$ & Año & Mes & Ventas & & & & & \\
\hline 1 & 1 & Enero & 20.30 & 23.40 & 6.96 & & & \\
\hline 2 & 1 & Febrero & 30.36 & 30.36 & 6.96 & 30.36 & 0.00 & $0.00 \%$ \\
\hline 3 & 1 & Marzo & 49.61 & 42.48 & 6.96 & 37.32 & 12.28 & $24.76 \%$ \\
\hline 4 & 1 & Abril & 35.00 & 43.38 & 6.96 & 49.43 & 14.43 & $41.24 \%$ \\
\hline 5 & 1 & Mayo & 79.00 & 62.37 & 6.96 & 50.33 & 28.67 & $36.29 \%$ \\
\hline 6 & 1 & Junio & 45.40 & 59.28 & 6.96 & 69.32 & 23.92 & $52.70 \%$ \\
\hline 7 & 1 & Julio & 66.24 & 66.24 & 6.96 & 66.24 & 0.00 & $0.00 \%$ \\
\hline 8 & 1 & Agosto & 109.19 & 88.31 & 6.96 & 73.20 & 35.99 & $32.96 \%$ \\
\hline 9 & 1 & Setiembre & 87.50 & 92.01 & 6.96 & 95.26 & 7.76 & $8.87 \%$ \\
\hline 10 & 1 & Octubre & 94.45 & 97.07 & 6.96 & 98.96 & 4.51 & $4.78 \%$ \\
\hline 11 & 1 & Noviembre & 117.33 & 109.61 & 6.96 & 104.03 & 13.31 & $11.34 \%$ \\
\hline 12 & 1 & Diciembre & 121.36 & 118.58 & 6.96 & 116.57 & 4.79 & $3.94 \%$ \\
\hline 13 & 2 & Enero & 154.37 & 137.64 & 6.96 & 125.54 & 28.83 & $18.68 \%$ \\
\hline 14 & 2 & Febrero & 170.86 & 155.62 & 6.96 & 144.60 & 26.26 & $15.37 \%$ \\
\hline 15 & 2 & Marzo & 352.16 & 242.15 & 6.96 & 162.58 & 189.58 & $53.83 \%$ \\
\hline 16 & 2 & Abril & $1,231.18$ & 661.31 & 6.96 & 249.11 & 982.07 & $79.77 \%$ \\
\hline 17 & 2 & Mayo & 804.96 & 725.64 & 6.96 & 668.27 & 136.69 & $16.98 \%$ \\
\hline 18 & 2 & Junio & $1,051.60$ & 866.49 & 6.96 & 732.60 & 319.01 & $30.34 \%$ \\
\hline 19 & 2 & Julio & $1,639.44$ & 1194.95 & 6.96 & 873.45 & 765.99 & $46.72 \%$ \\
\hline 20 & 2 & Agosto & $1,201.88$ & 1201.90 & 6.96 & 1201.91 & 0.03 & $0.00 \%$ \\
\hline 21 & 2 & Setiembre & $2,302.69$ & 1667.96 & 6.96 & 1208.86 & 1093.83 & $47.50 \%$ \\
\hline 22 & 2 & Octubre & $1,087.52$ & 1428.37 & 6.96 & 1674.92 & 587.40 & $54.01 \%$ \\
\hline 23 & 2 & Noviembre & $1,620.61$ & 1513.10 & 6.96 & 1435.33 & 185.27 & $11.43 \%$ \\
\hline 24 & 2 & Diciembre & $1,429.13$ & 1481.89 & 6.96 & 1520.05 & 90.92 & $6.36 \%$ \\
\hline 25 & 3 & Enero & 921.63 & 1250.77 & 6.96 & 1488.85 & 567.22 & $61.55 \%$ \\
\hline 26 & 3 & Febrero & $1,065.25$ & 1176.94 & 6.96 & 1257.73 & 192.48 & $18.07 \%$ \\
\hline 27 & 3 & Marzo & $1,624.10$ & 1368.66 & 6.96 & 1183.90 & 440.20 & $27.10 \%$ \\
\hline 28 & 3 & Abril & $1,631.15$ & 1482.87 & 6.96 & 1375.62 & 255.52 & $15.67 \%$ \\
\hline 29 & 3 & Mayo & $1,420.07$ & 1460.55 & 6.96 & 1489.83 & 69.76 & $4.91 \%$ \\
\hline 30 & 3 & Junio & & & & 1467.51 & & \\
\hline 31 & 3 & Julio & & & & 1474.47 & & \\
\hline 32 & 3 & Agosto & & & & 1481.43 & & \\
\hline 33 & 3 & Setiembre & & & & 1488.38 & & \\
\hline 34 & 3 & Octubre & & & & 1495.34 & & \\
\hline 35 & 3 & Noviembre & & & & 1502.30 & & \\
\hline \multirow[t]{3}{*}{36} & 3 & Diciembre & & & & 1509.26 & & \\
\hline & & & & & & & 233.25 & $25.90 \%$ \\
\hline & & & & & & & DMA & EPMA \\
\hline
\end{tabular}


Se rechaza la hipótesis nula, concluyendo que la demanda de nuevos productos de consumo masivo Sí corresponde a ser símbolo de identidad, cultura y tradición, pero a la vez adaptando su patrón de consumo. Bajo el modelamiento de pronóstico ponderado $n=3$ periodos al obtener el menor EPMA.

\section{Validación de la hipótesis 3}

A mayor población migrante venezolana, mayor demanda de nuevos productos de consumo masivo insertados al canal tradicional por el nuevo perfil de consumo en Lima Norte.

\section{Hipótesis nula (Ho)}

A mayor población migrante venezolana, NO hay mayor demanda de nuevos productos de consumo masivo insertados al canal tradicional por el nuevo perfil de consumo en Lima Norte.

\section{Hipótesis alternante (H1)}

A mayor población migrante venezolana, Sí hay mayor demanda de nuevos productos de consumo masivo insertados al canal tradicional por el nuevo perfil de consumo en Lima Norte.

Para validarlo, se armó la tabla 47 de cantidad de venezolanos en el Perú tomando como referencia diversas fuentes a el periódico (El Tiempo, 2018). Asimismo, se consideró la data mostrada en otro periódico reconocido (Correo, 2020).

\section{Tabla 50}

Venezolanos en Perú vs harina importada de maíz

\begin{tabular}{crr}
\hline Año & Venezolanos en el Perú & Tm harina de maíz \\
\hline 2015 & 2,351 & 121.35 \\
2016 & 6,615 & 206.85 \\
2017 & 109,778 & 184.98 \\
2018 & 669,690 & 855.74 \\
2019 & 861,690 & $13,046.40$ \\
\hline
\end{tabular}




\begin{tabular}{rr}
2020 & 860,000 \\
\hline
\end{tabular}

Fuente: Elaboración propia basada en Veritrade y Diario Correo, 2019

Los datos de toneladas de harina de maíz no son normales ya que en la prueba de Shapiro-Wilk se obtuvo un valor por debajo del 0.05 en nivel se significancia. Por lo que se alinea a una estadística no paramétrica.

\section{Tabla 51}

Prueba de normalidad

\begin{tabular}{|c|c|c|c|c|c|c|}
\hline & \multicolumn{3}{|c|}{ Kolmogorov-Smirnova } & \multicolumn{3}{|c|}{ Shapiro-Wilk } \\
\hline & Estadístico & $\mathrm{Gl}$ & Sig. & Estadístico & $\mathrm{gl}$ & Sig. \\
\hline $\begin{array}{l}\text { Tm de harina de } \\
\text { maíz }\end{array}$ & ,358 & 6 &, 016 & ,734 & 6 & ,014 \\
\hline
\end{tabular}

Fuente: Software SPSS

Se procederá a calcular el coeficiente de Spearman en SPSS para las variables toneladas importadas de harina de maíz y la cantidad de venezolanos inmigrantes que nuestro país albergó.

Tabla 52

Correlación de coeficiente de Spearman

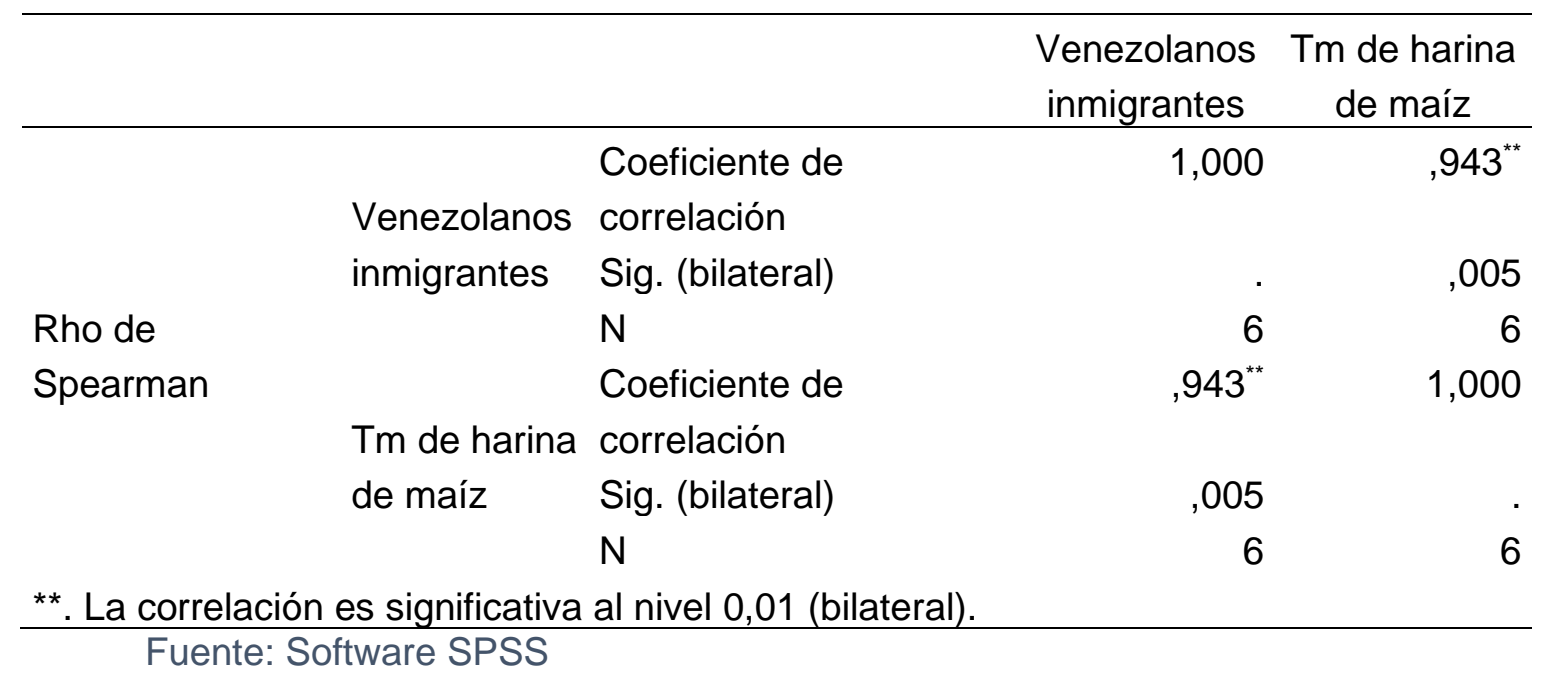

Por lo tanto, se rechaza la hipótesis nula al encontrarse una asociación estadísticamente significativa muy buena y directamente proporcional a las toneladas 
importadas de harina de maíz y la cantidad de venezolanos inmigrantes que nuestro país albergó al obtener el valor de 0.943 en el coeficiente de Spearman. Por lo que se concluye que, a mayor población migrante venezolana, Sí hay mayor demanda de nuevos productos de consumo masivo insertados al canal tradicional por el nuevo perfil de consumo en Lima Norte.

\section{Validación de la hipótesis específica 4}

Las marcas de productos de consumo masivo que sí tienen potencial aceptación por los migrantes venezolanos son Maltín Polar, Diablitos y Cerelac.

\section{Hipótesis nula (Ho)}

Las marcas de productos de consumo masivo que NO tienen potencial aceptación por los migrantes venezolanos son Maltín Polar, Diablitos y Cerelac.

\section{Hipótesis alternante (H1)}

Las marcas de productos de consumo masivo que Sí tienen potencial aceptación por los migrantes venezolanos son Maltín Polar, Diablitos y Cerelac.

De acuerdo con los resultados obtenidos del cuestionario pregunta 17 sobre las marcas más extrañadas, se obtuvo los siguientes resultados:

\section{Tabla 53}

Marcas venezolanas más extrañadas

\begin{tabular}{llrrrr}
\hline & Frecuencia & Porcentaje & $\begin{array}{c}\text { Porcentaje } \\
\text { válido }\end{array}$ & \multicolumn{2}{c}{$\begin{array}{c}\text { Porcentaje } \\
\text { acumulado }\end{array}$} \\
\hline \multirow{3}{*}{ Válidos } & Budare & 33 & 8,6 & 8,6 & 8,6 \\
& Cerelac & 57 & 14,8 & 14,8 & 23,4 \\
& Cocosette & 6 & 1,6 & 1,6 & 25,0
\end{tabular}




\begin{tabular}{lrrrr} 
Diablitos & 86 & 22,4 & 22,4 & 47,4 \\
Maltín Polar & 124 & 32,3 & 32,3 & 79,7 \\
Rica & 16 & 4,2 & 4,2 & 83,9 \\
Chicha & & & & \\
Samba & 21 & 5,5 & 5,5 & 89,3 \\
Susy & 15 & 3,9 & 3,9 & 93,2 \\
Otro & 26 & 6,8 & 6,8 & 100,0 \\
Total & 384 & 100,0 & 100,0 & \\
\hline
\end{tabular}

Fuente: Software SPSS

P17. ¿Qué marca venezolana es la que más extraña al no encontrarla fácilmente en Perú? Opción única

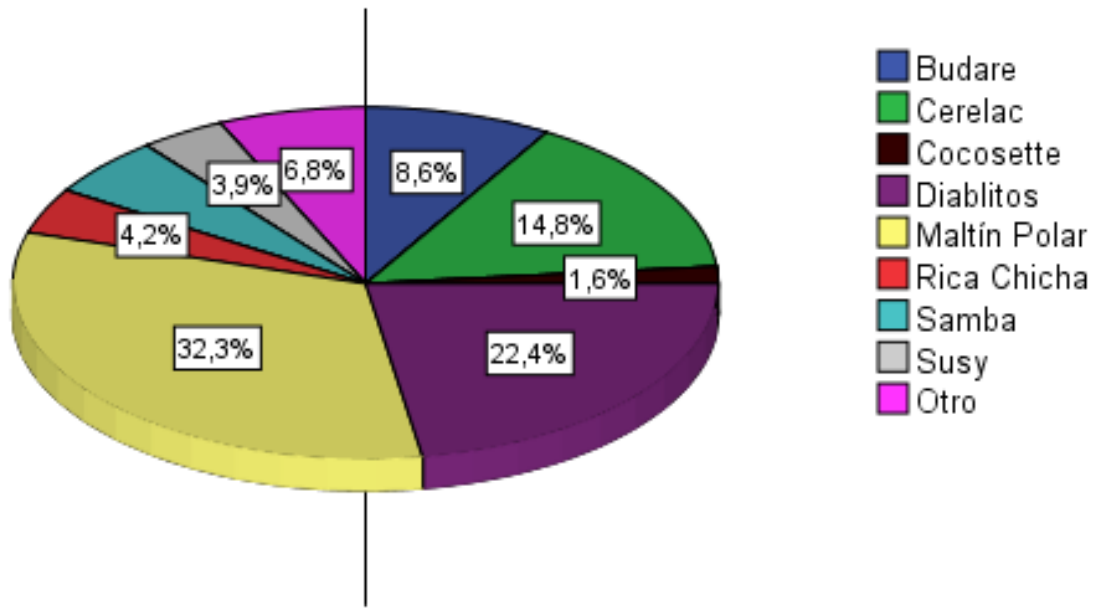

Figura 66. Marcas de productos venezolanos

Fuente: Elaboración propia

En la figura 68, se concluye que un $32.3 \%$ extraña la marca Maltin Polar, mientras que un $22.4 \%$ extraña la marca diablitos. Otro porcentaje de $14.8 \%$ de encuestados extraña el producto Cerelac.

Tabla 54

Potencial aceptación de nuevo producto

\begin{tabular}{cccccc}
\hline & & Frecuencia & Porcentaje & Porcentaje válido & $\begin{array}{c}\text { Porcentaje } \\
\text { acumulado }\end{array}$ \\
\hline \multirow{3}{*}{ Válidos } & Sí & 273 & 71,1 & 76,3 & 76,3 \\
& No & 85 & 22,1 & 23,7 & 100,0 \\
& Total & 358 & 93,2 & 100,0 & \\
\hline
\end{tabular}


Fuente: Software SPSS

P18. En base a su anterior respuesta, ¿Si en Perú se comienza a comercializar dicho producto, estaría en la ...

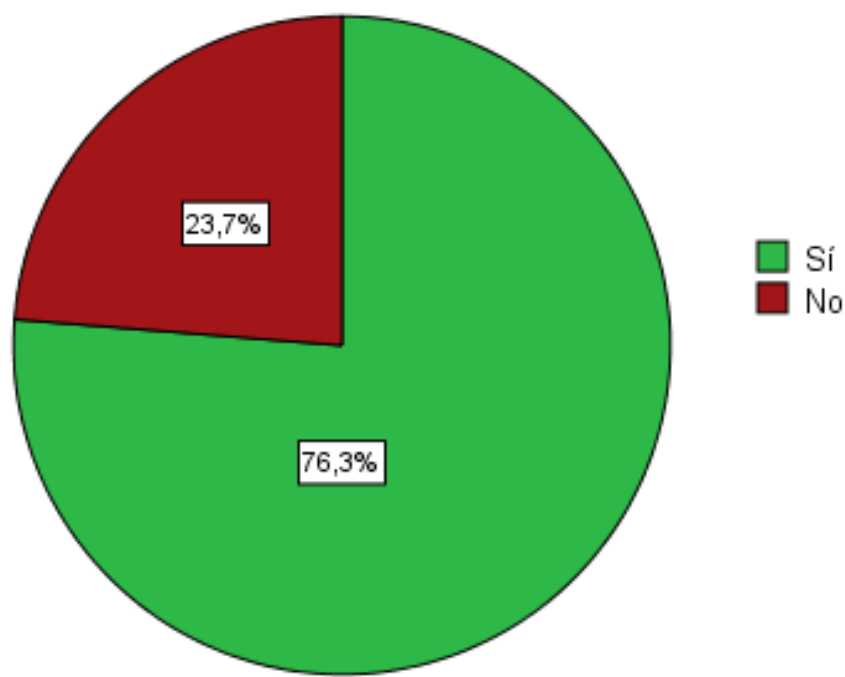

Figura 67. Potencial aceptación de inserción de la marca venezolana extrañada Fuente: Elaboración propia, encuesta, junio 2020

Se demuestra en la figura 69 que un $76.3 \%$ de los encuestados indican que sí comprarán los productos anteriormente mencionados si empiezan a comercializarse en el país.

Se rechaza la hipótesis nula debido a que la figura 68 y 69 demuestran que las marcas venezolanas más favoritas son Maltín Polar, Diablitos y Cerelac con un $70 \%$ de productos extrañados y con un $76.3 \%$ de aceptación en el caso que comience a venderse en Perú.

\section{Hipótesis general}

La población migrante venezolana en Lima Norte tiene un impacto significativo en la demanda de nuevos productos de consumo masivo. 


\section{Hipótesis nula (Ho)}

La población migrante venezolana en Lima Norte NO tiene un impacto significativo en la demanda de nuevos productos de consumo masivo.

\section{Hipótesis Alterna (H1)}

La población migrante venezolana en Lima Norte Sí tiene un impacto significativo en la demanda de nuevos productos de consumo masivo.

Se rechaza la hipótesis nula pues las inferencias estadísticas y la validación de las afirmaciones anteriores hacen sostener que la población migrante venezolana en Lima Norte Sí tiene un impacto significativo en la demanda de nuevos productos de consumo masivo. 


\section{DISCUSIÓN}

Es necesario discutir algunos aspectos de gran importancia respecto a los resultados de la presente tesis.

El Perú se encontraba como el segundo país más atractivo para poder satisfacer las necesidades básicas de alimentación y salud de los migrantes venezolanos, esperando conseguir un trabajo digno para superar la crisis vivida en Venezuela.

Si bien puede existir una diferencia cultural entre venezolanos y peruanos, los migrantes venezolanos han adaptado su canasta básica de alimentos a los productos locales, teniendo siempre presente a la harina de maíz como parte de su alimentación. Un hallazgo interesante es que esta población destina menos de 300 soles para sus alimentos, mientras que los peruanos invierten 344 soles de acuerdo con el análisis de Alfredo Palacios Dongo en el marco de la Encuesta Nacional de Presupuestos Familiares (ENAPREF) 2019-2020.

Al inyectarse un gran flujo de migrantes venezolanos al país, esto afecta proporcionalmente a la inserción de productos importados de baja demanda en los consumidores peruanos, pero de alta preferencia por los migrantes venezolanos como es el caso de la harina de maíz tomando en cuenta el informe de la Cámara de Comercio de Lima. Este producto es buscado en los mercados y bodegas, es decir, en el canal tradicional con una preferencia del $75.8 \%$. Los hallazgos demuestran que desde marzo de 2018 la importación de harina de maíz creció a un ritmo acelerado. Ante la coyuntura Covid-19, las importaciones se han visto afectadas, pero al ubicarse en el sector de consumo masivo, se tiene mucho optimismo de recuperación. 
Como último punto de discusión, el Banco Mundial recomienda que migrantes venezolanos no deben ser vistos como una amenaza para el país, sino como una oportunidad de desarrollo económico tal como lo propone el Banco Mundial en su publicación del 2019.

El $64.8 \%$ de los venezolanos que llega al Perú tiene una carrera universitaria o son técnicos profesionales calificados. No contamos con políticas de inserción laboral para estos migrantes. El proyecto migratorio de estas personas seguirá atado únicamente a la generación de ingresos para la supervivencia principalmente para satisfacer sus necesidades básicas de vida. 


\section{CONCLUSIONES}

Se concluye en primer lugar que un $63.6 \%$ de la población migrante venezolana en Lima Norte eligió al Perú por en relación con el tema de alimentos y medicinas, que incluye desabastecimiento, elevados precios y falta de trabajo. En segundo lugar, fue la facilidad que el Perú les ofreció en el trámite migratorio con un $20.1 \%$. Esto demuestra que esta población busca cubrir sus necesidades básicas de alimentación y acceso a medicamentos al ser su principal preocupación que los motivó a salir de su país.

Se demuestra que los venezolanos migrantes residentes en Lima Norte tienen una preferencia por el canal tradicional con un $75.8 \%$, el cual abarca los mercados y bodegas de barrio. Producto de la pandemia Covid-19, el factor que determina el canal de compra son los precios accesibles, teniendo un comportamiento similar al nivel socioeconómico $E$ de los peruanos.

Se concluye que la composición de la canasta de alimentos de los venezolanos difiere de los peruanos únicamente al incluir harina de maíz, pastas y excluir a las frutas. En el caso de los peruanos, este primer alimento es reemplazado por el pan de trigo. Por lo que se deduce que los venezolanos han adaptado su alimentación a productos peruanos locales donde el arroz lidera este ranking de productos con un $97.7 \%$ de presencia.

Según los datos obtenidos se concluye que, a mayor migración venezolana, mayor variedad de nuevos productos importados que no solían tener presencia en el mercado nacional. El producto analizado fue la harina de maíz el cual comenzó a tener un crecimiento anormal desde marzo de 2018 donde se logró el pico más alto en comparación con los meses previos. Se establece que el consumo mensual de harina de maíz es de 3 a 4 paquetes, siendo la marca Harina P.A.N la más preferida con un $85.7 \%$.

De acuerdo con el valor obtenido de 0.943 en el coeficiente de Spearman se encontró una asociación estadísticamente significativa muy buena y directamente proporcional a las toneladas importadas de harina de maíz y la cantidad de venezolanos inmigrantes que nuestro país alberga. 
Según los resultados obtenidos, los datos de las importaciones de harina de maíz se ajustan a un pronóstico con el método móvil ponderado.

Se demuestra que la marca Maltín Polar (categoría bebidas no alcohólicos) y Diablitos (categoría embutidos) tienen un gran potencial para ingresar al mercado peruano al ser el más extrañado con un $32.3 \%$ y $22.4 \%$ respectivamente.

Se determinó que la migración venezolana (860 mil aproximadamente, equivalente al $2.7 \%$ de la población peruana) trae beneficios a los países receptores como sería el caso de Perú al dinamizar la economía local, incrementan el consumo interno. 


\section{RECOMENDACIONES}

De acuerdo con los resultados de la investigación se da las siguientes recomendaciones:

Se sugiere que los productos venezolanos de consumo masivo sean potenciales de nuevos ingresos al mercado local. Los empresarios nacionales deben crear acuerdos comerciales o representación de marca con Empresa Polar, quien produce la marca P.A.N y Maltín Polar cuya fábrica se encuentra en Colombia y Estados Unidos. También con Underwood Company, quien produce el jamón Diablitos y tiene sede principal en Boston, para así satisfacer la nueva demanda interna y surtir el nuevo mix al canal tradicional.

Se recomienda a los bodegueros y comerciantes de mercados que comiencen a destinar un espacio en el anaquel al producto más buscado por los venezolanos, es decir, la harina de maíz, principalmente Harina P.A.N. Así se logra la foto de éxito del trade marketing y se atrae al nuevo perfil de consumidor en la que no solo compraría dicho producto, sino el resto de la canasta básica de alimentos, generando un mayor ticket de compra para aquel punto de venta.

Finalmente, se sugiere a las grandes transnacionales tales como Nestlé Perú y Coca Cola puedan ofertar productos similares a los que producen en Venezuela, pero que no se encuentran disponibles en el mercado peruanos, tales como Frescolita que pertenece a Coca Cola Company y los siguientes productos que pertenecen a Nestle Venezuela como: Cerelac, Cocosete , Samba, Rica Chicha y Susy. 


\section{REFERENCIAS}

Anderson, D., Sweeney, D., Williams, T., Camm, J., \& Martin, K. (2011). Métodos cuantitativos para los negocios. México: Cengage.

Araujo García, L., Del Castillo Rodríguez, J., Reátegui del Aguila, J., \& Poma Marroquín, C. (2017). Plan de negocios para la implementación de una cadena de food trucks de comida fusión peruano-venezolana en la ciudad de Lima (Tesis de postgrado). Obtenido de https://repositorio.esan.edu.pe/handle/20.500.12640/1106

Arellano Cueva, R. (2020). Los estilos de vida en el Perú. Obtenido de Los Estilos de Vida (EdV): https://www.arellano.pe/estilos-de-vida/

Banco Mundial. (2019). Una oportunidad para todos. Obtenido de https://openknowledge.worldbank.org/bitstream/handle/10986/32816/143724.pdf?se quence $=3 \&$ isAllowed $=y$

BBVA Research. (2019). Inmigración venezolana a Perú: características e impactos macroeconómicos. Obtenido de https://bit.ly/2Z0k7Uk

Blouin, C., Hurtado, E., Jave Pinedo, I., Vargas Canales, G., \& Jáuregui, A. (2019). Estudio sobre el perfil socio económico de la población venezolana y sus comunidades de acogida: una mirada hacia la inclusión. Obtenido de https://cdn01.pucp.education/idehpucp/wpcontent/uploads/2019/08/02195731/estudio-final-.pdf

Bravo, E., Rodríguez, M. E., \& Salazar, S. (2001). Coeficientes de asociación. México D.F.: Plaza y Valdés.

Castillo Castro, T., \& Reguant Álvarez, M. (2017). Percepciones sobre la migración venezolana: Causas, España como destino, expectativas de retorno. Obtenido de https://revistas.comillas.edu/index.php/revistamigraciones/article/view/7898/7683

CCL. (2019). Importación de harina de maíz alcanzó récord de US\$7.2 millones. CE Noticias Financieras. Obtenido de https://search.proquest.com/docview/2275813737?accountid=4384

Chinchilla, F. (10 de marzo de 2018). Estos son los países más baratos para vivir en América Latina. La Nación. Obtenido de https://www.nacion.com/economia/indicadores/estos-son-los-paises-mas-baratospara-vivir-en/CZCMDOJTUFDN3LUSHA7YWU6QCl/story/ 
Consumo de pollo por habitante en el Perú llegará a 48 kilogramos este año. (27 de junio de 2019). Gestión. Obtenido de: https://gestion.pe/economia/consumo-habitante-perullegara-48-kilogramos-ano-271506-noticia/

Crisis en Venezuela: cómo se beneficia la economía de Perú de la inmigración venezolana y qué problemas genera. (30 de mayo de 2019). BBC. Obtenido de https://www.bbc.com/mundo/noticias-america-latina-48440934

Cronbach, L. (1951). Coefficient alpha and the internal structure of tests.

Decreto supremo № 057-2020-PCM. (2020). El Peruano Diario Oficial. Obtenido de: https://bit.ly/37kTbBy

Déficit fiscal e inversión en educación. (10 de mayo de 2019). El Comercio. Obtenido de https://elcomercio.pe/economia/opinion/deficit-fiscal-e-inversion-educacion-albertopasco-font-noticia-633980-noticia/

Díaz, A. (2009). Diseño estadístico de experimentos. Medellín: Universidad de Antioquía.

ESAN. (2020). Impacto del COVID-19 en el empleo en el Perú. Obtenido de https://www.esan.edu.pe/conexion/actualidad/2020/04/24/impacto-del-covid-19-enel-empleo-en-el-peru/

El coronavirus en medio de la informalidad laboral peruana. (13 de marzo de 2020). Gestión. Obtenido de https://gestion.pe/economia/el-coronavirus-en-medio-de-lainformalidad-laboral-peruana-noticia/?ref=gesr

Heizer, J., \& Render, B. (2014). Principios de Administración de Operaciones. Juárez: Pearson.

Human Rights Watch. (2016). Crisis humanitaria en Venezuela. La inadecuada y represiva respuesta del gobierno ante la grave escasez de medicinas, insumos y alimentos. Obtenido de https://www.hrw.org/sites/default/files/report_pdf/venezuela1016sp_web_2.pdf

Hyndman, R., Makridakis, S., \& Wheelwright, S. (2008). Forecasting: methods and applications. New Delhi: Wiley India Pvt. Limited.

IBM. (2020). IBM SPSS Statistics. Obtenido de https://www.ibm.com/es-es/products/spssstatistics

IBM. (2020). Modelos personalizados de suavizado exponencial. Obtenido de https://www.ibm.com/support/knowledgecenter/es/SSLVMB_25.0.0/statistics_mainhe Ip_ddita/spss/trends/idh_idd_exp_smooth_crit.html 
INEI. (2000). El Patrimonio y las Condiciones de Vida en los Hogares del Perú. Obtenido de: https://www.inei.gob.pe/media/MenuRecursivo/publicaciones_digitales/Est/Lib0382/c ap-02.htm

INEI. (2012). INEl. Obtenido de Perú: Consumo per cápita de los principales alimentos, 2008- 2009: https://bit.ly/2A2QRTD

INEI. (2012). Perú: Consumo per cápita de los principales alimentos 2008-2009. Obtenido de

https://www.inei.gob.pe/media/MenuRecursivo/publicaciones_digitales/Est/Lib1028/Li bro.pdf

INEI. (2019). Condiciones de vida de la población venezolana que reside en Perú. Obtenido de https://data2.unhcr.org/en/documents/download/70521

Inflación cerró el 2018 en $2.19 \%$ luego de reportar un alza de $0.18 \%$ en diciembre. ( 1 de junio de 2019). Gestión. Obtenido de https://gestion.pe/economia/inflacion-cerro2018-2-19-luego-reportar-alza-0-18-diciembre-254377-noticia/?ref=gesr

Instituto Profesional Esucomex. (2016). Dirección de Desarrollo Curricular. Obtenido de: https://docplayer.es/70098049-Herramienta-de-analisis-pest.html

Izar, J. M. (2019). Método de Holt. Obtenido de https://www.researchgate.net/publication/331844153_Metodo_de_Holt

Kantar Worldpanel. (2019). Brand Footprint. Obtenido de Brand Footprint: https://bit.ly/3fOg53H

Kantar Worldpanel. (2020). Cuarentena: provoca cambios en el hogar. Obtenido de: https://bit.ly/3eWTvZJ

Koechlin, J., \& Eguren, J. (2018). El exódo venezolano: entre el exilio y la emigración (Vol. 4). Lima: Observatorio Iberoamericano sobre Movilidad Humana, Migraciones y Desarrollo. Obtenido de https://www.uarm.edu.pe/FondoEditorial/etica-desarrollo/elexodo-venezolano-entre-exilio-emigracion\#.Xt8BWDozbIW

La migración venezolana en curva de descenso. (3 de febrero de 2020). Correo. Obtenido de https://diariocorreo.pe/peru/la-oleada-venezolana-inicia-curva-de-descensonoticia/?ref=dcr

Landaeta-Jiménez, M., Herrera Cuenca, M., Ramírez, G., \& Vásquez, M. (2018). Las precarias condiciones de alimentación de los venezolanos. Encuesta Nacional de 
Condiciones de Vida 2017. Obtenido de

https://www.analesdenutricion.org.ve/ediciones/2018/1/art-3/

Lind, D., Marchal, W., \& Wathen, S. (2012). Estadística aplicada a los negocios y la economía. México D.F.: McGraw-Hill.

Mankiw, G. (2012). Principios de Economía. En N. G. Mankiw, Principios de Economía. Santa Fe: Cengage Learning Editores.

Martínez, Z. (2015). Gastronomía, S.A. Un negocio para el que no existen recetas. (R. D. IESA, Ed.) $X X(1), 100$. Obtenido de https://issuu.com/debatesiesa/docs/debates_iesa_xx-1-gastronom_a_ene-m

ONU. (1999). Recomendacion sobre estadisticas de las migraciones internacionales. En ONU. New York: ONU.

Organización Internacional para las Migraciones. (2020). Términos fundamentales sobre migración. Obtenido de: https://www.iom.int/es/terminos-fundamentales-sobremigracion\#migracion

Organización Internacional para las Migraciones Perú. (2020). Monitoreo de flujo de la población venezolana en el Perú DTM Reporte 7. Obtenido de OIM Web site: https://r4v.info/es/documents/download/74086

Organizacion Mundial de la Salud. (2019). Conoce qué es el coronavirus COVID-19. Obtenido de Conoce qué es el coronavirus COVID-19: https://bit.ly/2XLCDPT

Palacios Dongo, A. (27 de abril de 2019). Canasta básica familiar y remuneración mínima vital. Expreso. Obtenido de: https://bit.ly/3dCaWyq

Perú cierra 2019 con inflación de 1,9\% por debajo de la meta anual y aumenta buenos pronósticos para el 2020.(1 de enero de 2020). América Economía. Obtenido de shorturl.at/MPQT0

Perú Retail. (2018a). ¿Qué es shopper marketing?. Obtenido de: https://www.peruretail.com/que-es-shopper-marketing/

Peru Retail. (2018b). ¿Qué es Canal Tradicional? Obtenido de: https://www.peruretail.com/canal-tradicional-peru/

Peru Retail. (2020). La canasta básica en Perú representa el 34.8\% del sueldo mínimo. Obtenido de: https://www.peru-retail.com/la-canasta-basica-en-peru-representa-el34-8-del-sueldo-minimo/ 
Propuesta de seguro universal: ¿Cuáles son los retos para el SIS? (12 de agosto de 2019). El Comercio. Obtenido de https://elcomercio.pe/economia/peru/propuesta-segurouniversal-son-retos-sis-presupuesto-pea-noticia-ecpm-664217-noticia/

Reátegui, A. (2019). ¿Cuáles son las consecuencias de la migración venezolana? (J. Gambini, Entrevistador) Obtenido de https://www.esan.edu.pe/sala-deprensa/2019/04/cuales-son-las-consecuencias-de-la-migracion-venezolana/

Reuters. (24 de julio de 2019). Obtenido de https://ta.reuters.com/article/idLTAKCN1UK008

Roca Martínez, C. (2016). Qué son los productos de consumo masivo y sus mejores prácticas. lebschool. Obtenido de: https://www.iebschool.com/blog/productos-deconsumo-masivo-comercio-ventas/

Rojas Mora, C., \& Monterroso Coronado, C. (2019). Perfil de Competencias Profesionales de la Población Inmigrante Venezolana al Perú 2017-2018. Obtenido de https://dialnet.unirioja.es/servlet/articulo?codigo $=7062676$

Suito, J. (2019). Estos son los productos venezolanos que ya se venden en Perú. Obtenido de Mercado Negro Marketing: https://bit.ly/3hdfZaW

Superintendencia Nacional de Migraciones. (2018). Obtenido de https://cdn.www.gob.pe/uploads/document/file/1260611/Caracteristicassociodemograficas-de-ciudadanos-venezolanos.pdf

The Nielsen Company. (2020). Covid 19 Perú Tracking the impact on FMCG and retail.

Universidad Autónoma del Estado de México. (2011). Tiempo de Educar. Obtenido de Tiempo de Educar revista de investigacion: https://www.redalyc.org/pdf/311/31121089006.pdf

Venezuela a la Fuga: análisis de la crisis migratoria. (7 de marzo de 2018). El Tiempo. Obtenido de https://www.eltiempo.com/datos/cuantos-venezolanos-estan-saliendode-su-pais-y-a-donde-se-dirigen-189354 


\section{ANEXOS}

\section{Anexo A: Requisitos para tramitar el PTP en Perú}

Para obtener el PTP, debes cumplir las siguientes condiciones:

Haber ingresado de manera legal al país hasta el 31 de octubre de 2018.

Estar en el país en situación irregular debido al vencimiento de tu autorización de permanencia o residencia o que, estando en situación regular, optes por el permiso.

No tener antecedentes penales o judiciales a nivel nacional e internacional.

Requisitos

EI PTP se solicita personalmente. Para tramitarlo, necesitarás lo siguiente:

Copia simple del pasaporte o cédula de identidad con la que ingresó al Perú.

Declaración jurada de no tener antecedentes policiales, penales y judiciales a nivel nacional e internacional. Los menores de edad y personas con discapacidad no requieren este documento.

Ficha de canje internacional de INTERPOL, solo para mayores de edad con derechos y obligaciones civiles. Esta debe tramitarse en dicha entidad policial y tiene un costo de $\mathbf{S} /$ 80.50 .

En caso de menores de edad, partida o acta de nacimiento apostillada. De no contar con la apostilla, declaración jurada de autenticidad del documento. 


\section{Anexo B: Encuesta}

\section{Cuestionario de preguntas}

Somos universitarios y nos encontramos realizando un estudio. El objetivo de esta encuesta es recabar información valiosa sobre la inmigración de venezolanos en Perú, para valorar sus expectativas y realidades con respecto a la situación que poseen, así como realizar propuestas de soluciones a este tema. Le agradeceríamos si pudiera responder a unas cuantas preguntas.

Sexo:

Femenino ___ Masculino

¿Cuál es su edad?

18 a 24 años

25 a 29 años

30 a 34 años

35 a 39 años

40 a 59 años

60 a más

¿Cuál es su estado civil?

Soltero(a)

Casado(a)

Conviviente

Divorciado(a)

Viudo(a) 
¿Cuál es el último grado de instrucción que completó?

Primaria

Secundaria

Técnico

Universitario

Postgrado

En el Perú, ¿con quién está viviendo?

Con su familia

Con amigos/as

Con su familia y amigos/as

Solo/a

¿En qué distrito vives?

San Martín de Porres

Los Olivos

Comas

Independencia

Puente Piedra

Carabayllo

Ancón

Santa Rosa

Otro distrito 
1. ¿Desde qué año usted reside en el Perú? Opción única

Antes del 2017

2017

2018

2019

2020

2. ¿La principal razón por la que decidió migrar a Perú? Opción única

Inseguridad social en Venezuela

Falta de trabajo en Venezuela

La cercanía del país y mismo idioma

Facilidad en el trámite migratorio en Perú

Desabastecimiento de alimentos y medicinas

Elevados precios de alimentos y medicinas

Persecución política

Otros

3. ¿La decisión de migrar al Perú se vio influenciada principalmente por su familia, amigos o fue una iniciativa propia? Opción única

Pareja

Familia

Amigos

Iniciativa propia 
4. ¿Cuál es su ocupación principal? Opción única

Trabajo para un empleador con beneficios de ley

Trabajo para un empleador, pero sin todos los beneficios de ley

Trabajo independientemente

Estudio

Ama de casa

Jubilado

Estoy sin trabajo

5. ¿Cuál de las siguientes opciones describe mejor su situación en estos momentos? Opción única

Estoy en mi casa trabajando por teletrabajo (trabajo remoto)

Estoy saliendo a trabajar porque lo necesito y me las ingenio, pero no estoy autorizado por el gobierno.

Estoy saliendo a trabajar porque estoy autorizado por el gobierno

6. Dada la coyuntura actual a causa del Covid-19 en el Perú, ¿usted considera...? Opción única

Migrar a otro país de la región

Migrar a otro país en otra región (América del Norte, Europa, Asia, etc)

Retornar a Venezuela

Continuar viviendo en Perú

7. Considerando que el salario básico en el Perú es S/ 930. ¿Usted diría que su ingreso personal mensual es de ...? Opción única

Por debajo del salario básico 
Igual al salario básico

Mayor que el salario básico

Prefiero no responder

8. ¿Cuál es el monto mensual enviado en remesas a Venezuela? Opción única Menos de 100 soles

De 100 a 200 soles

Más de 200 soles

No envío remesas

CANASTA DE ALIMENTOS

9. ¿Dónde adquiere los alimentos para su hogar con mayor frecuencia? Opción única

Supermercados

Mercados

Bodegas de barrio

Tiendas de conveniencia: Tambo, Repsol y Listo

Cash \& carry: Makro, Vega

Discounter: Mass

Delivery

10. ¿Qué alimentos consume regularmente en su almuerzo? Puede seleccionar más de 1 alimento

Arroz

Batata

Cambur 
Caraotas

Carnes rojas

Cebolla

Cerdo

Ensalada

Frutas

Harina de maíz

Huevo

Mariscos

Ñame

Pan de trigo

Papa

Pastas

Pescado

Pollo

Queso

Tomate

Verduras varios

Otros

11. ¿Adquirió alguno de estos productos con mayor volumen durante el confinamiento por el Covid-19? Puede seleccionar más de 1 opción

Hamburguesas precocidas

Nuggets

Pollo precocido envasado

Conservas de pescado 
Polvos para hornear

Harina de trigo

Otros

Ninguno

12. ¿Adquirió alguno de estos productos con menor volumen durante el confinamiento por el Covid-19? Puede seleccionar más de 1 opción

Bebidas con alcohol

Bebidas sin alcohol

Carnes rojas

Pescado fresco

Otros

Ninguno

13. Dada la coyuntura actual, al realizar la compra de sus alimentos, ¿qué es lo más valorado por usted para elegir el canal de compra? Opción única

Cercanía del punto de venta

Stock disponible de producto

Medidas sanitarias

Precios accesibles

Poca cantidad de personas en el lugar

14. ¿Con qué frecuencia compra los alimentos para su hogar? Opción única 
Quincenal

Semanal

Interdiario

Diario

15. En promedio, ¿cuál es su presupuesto mensual para gastos de alimentación? Opción única

Menos de 300 soles

De 300 a 450 soles

De 451 a 600 soles

De 601 a 750 soles

De 751 a 900 soles

Más de 900 soles

Prefiero no responder

16. De las siguientes imágenes, valorar cada marca de acuerdo a cuanto lo conoce

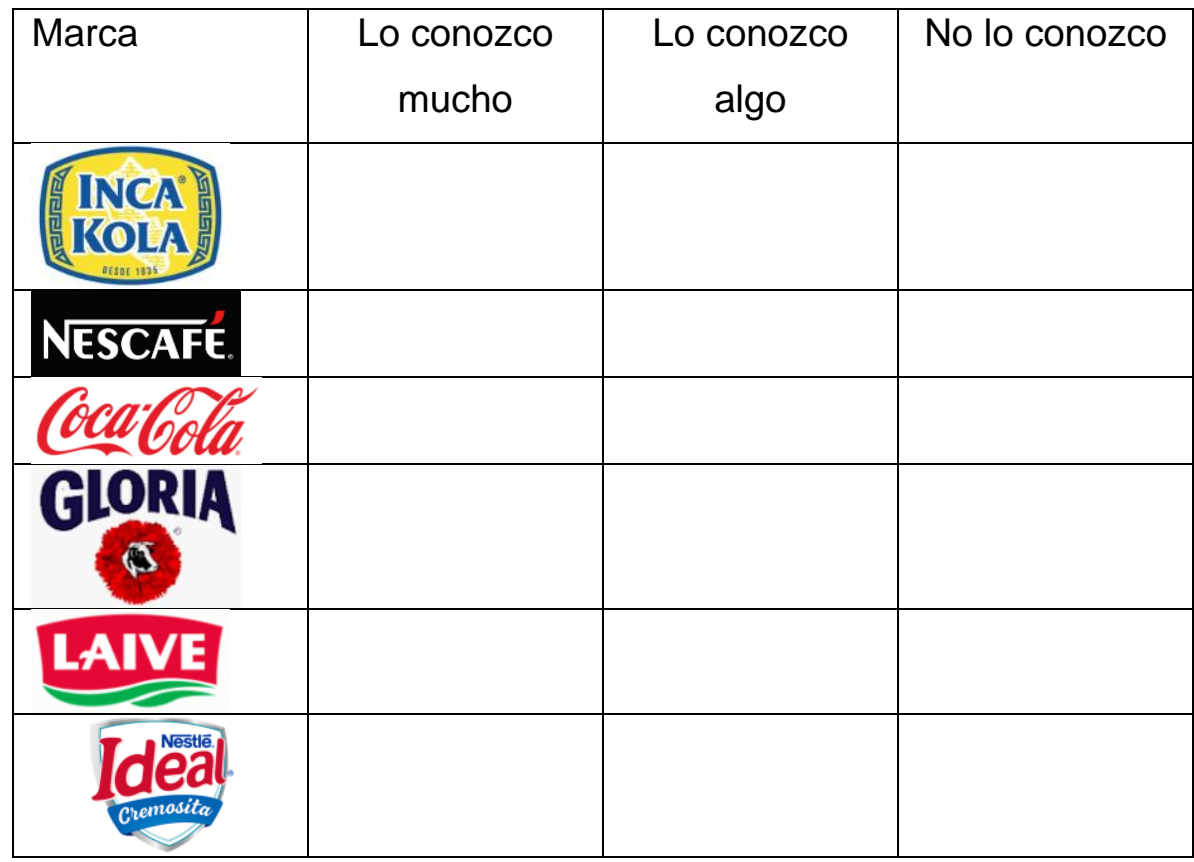




\section{NUEVA TENDENCIA DE PRODUCTOS}

17. ¿Qué marca venezolana es la que más extraña al no encontrarla fácilmente en Perú? Opción única

Budare

Cerelac

Cocosette

Diablitos

Maltín Polar

Rica Chicha

Samba

Susy

Otro

18. En base a su anterior respuesta, ¿Si en Perú se comienza a comercializar dicho producto, estaría en la capacidad económica de comprarlo? Opción única

Sí

No

19. ¿Cuántos paquetes de harina de maíz consume al mes en su hogar? Considerar que cada paquete es de $1 \mathrm{~kg}$. Opción única

1 - 2 paquetes

3 - 4 paquetes

5 - 6 paquetes

Más de 6 paquetes 
No consumo

20. ¿Cuál es su marca favorita de harina de maíz? Opción única

P.A.N.

Arepasan

La Nieve

Del Sol

Maseca

Otro

21. Cuando vas al punto de venta, ¿encuentras tu marca favorita de harina de maíz disponible para la compra? Opción única

Siempre

Casi siempre

$A$ veces

Casi nunca

Nunca 


\begin{tabular}{|c|c|c|c|c|c|c|c|c|c|c|c|}
\hline \multirow{3}{*}{$\begin{array}{c}\text { ÍTE } \\
\text { M }\end{array}$} & \multicolumn{10}{|c|}{ CRITERIOS A EVALUAR } & $\begin{array}{l}\text { Observaciones (si debe } \\
\text { eliminarse o modificarse } \\
\text { un ítem por favor indique) }\end{array}$ \\
\hline & \multicolumn{2}{|c|}{$\begin{array}{l}\text { Claridad } \\
\text { en la } \\
\text { redacción }\end{array}$} & \multicolumn{2}{|c|}{$\begin{array}{l}\text { Coheren } \\
\text { cia } \\
\text { interna }\end{array}$} & \multicolumn{2}{|c|}{$\begin{array}{l}\text { Inducci } \\
\text { ón a la } \\
\text { respues } \\
\text { ta } \\
\text { (sesgo) }\end{array}$} & \multicolumn{2}{|c|}{$\begin{array}{l}\text { Lenguaje } \\
\text { adecuado } \\
\text { con el nivel } \\
\text { de } \\
\text { información }\end{array}$} & \multicolumn{2}{|c|}{$\begin{array}{l}\text { Mide lo } \\
\text { que } \\
\text { pretend } \\
\text { e }\end{array}$} & \\
\hline & Sí & No & Sí & No & Sí & No & Sí & No & Sí & No & \\
\hline 1 & $\mathrm{X}$ & & $X$ & & & $\mathrm{X}$ & $\mathrm{X}$ & & $\mathrm{X}$ & & $\begin{array}{l}\text { Se debe modificar para } \\
\text { precisar que nos } \\
\text { referimos a año en el que } \\
\text { llegó a Perú }\end{array}$ \\
\hline 2 & & $X$ & & $X$ & & $X$ & & $X$ & & $X$ & $\begin{array}{l}\text { Se debe modificar el texto } \\
\text { de la pregunta y } \\
\text { desagregar las opciones. } \\
\text { Algunas de ellas son muy } \\
\text { generales y podrían } \\
\text { inducir a muchas } \\
\text { respuestas. }\end{array}$ \\
\hline 3 & & $\mathrm{X}$ & & $X$ & & $X$ & & $X$ & $X$ & & $\begin{array}{l}\text { Se debe modificar el texto } \\
\text { de la pregunta para ser } \\
\text { más precisos. }\end{array}$ \\
\hline 4 & $\mathrm{X}$ & & $X$ & & & $\mathrm{X}$ & & $\mathrm{X}$ & & $\mathrm{X}$ & $\begin{array}{l}\text { Se puede modificar la } \\
\text { pregunta para ser más } \\
\text { específicos en lo que } \\
\text { estamos buscando }\end{array}$ \\
\hline 5 & $\mathrm{X}$ & & $X$ & & & $X$ & $X$ & & $\mathrm{X}$ & & \\
\hline 6 & $x$ & & $\mathrm{X}$ & & & $\mathrm{X}$ & $x$ & & $\mathrm{X}$ & & \\
\hline 7 & & $\mathrm{X}$ & $X$ & & & $\mathrm{X}$ & & $X$ & $\mathrm{X}$ & & $\begin{array}{l}\text { Se sugiere modificar el } \\
\text { texto de la respuesta y } \\
\text { agregar opciones }\end{array}$ \\
\hline 8 & & $X$ & & $\mathrm{X}$ & & $X$ & & $\mathrm{X}$ & & $X$ & $\begin{array}{l}\text { Se debe precisar si lo que } \\
\text { se busca es el ingreso } \\
\text { personal o del hogar, así } \\
\text { como modificar el texto de } \\
\text { la pregunta para facilitar la } \\
\text { comprensión. }\end{array}$ \\
\hline 9 & & $x$ & $X$ & & & $X$ & $X$ & & $X$ & & $\begin{array}{l}\text { Se sugieren algunos } \\
\text { cambios en la redacción } \\
\text { de la pregunta }\end{array}$ \\
\hline 10 & & $x$ & $X$ & & & $X$ & $X$ & & $X$ & & $\begin{array}{l}\text { Se sugieren algunos } \\
\text { cambios en la redacción } \\
\text { de la pregunta }\end{array}$ \\
\hline 11 & $x$ & & $x$ & & & $x$ & $x$ & & $\mathrm{X}$ & & \\
\hline 12 & & $X$ & & $\mathrm{X}$ & & $\mathrm{X}$ & & $\mathrm{X}$ & & $X$ & $\begin{array}{l}\text { Se sugiere precisar si lo } \\
\text { que se busca es evaluar } \\
\text { el establecimiento donde }\end{array}$ \\
\hline
\end{tabular}




\begin{tabular}{|c|c|c|c|c|c|c|c|c|c|c|c|}
\hline & & & & & & & & & & & $\begin{array}{l}\text { realiza las compras o a los } \\
\text { alimentos. En función a } \\
\text { eso, las opciones de } \\
\text { respuesta tendrían que } \\
\text { adecuarse. }\end{array}$ \\
\hline 13 & $X$ & & $\mathrm{X}$ & & & $\mathrm{X}$ & $X$ & & $\mathrm{x}$ & & $\begin{array}{l}\text { Se sugiere precisar si nos } \\
\text { referimos al hogar o a la } \\
\text { persona }\end{array}$ \\
\hline 14 & & $x$ & $x$ & & & $X$ & $\mathrm{X}$ & & $X$ & & $\begin{array}{l}\text { Se sugiere precisar si nos } \\
\text { referimos al hogar o a la } \\
\text { persona }\end{array}$ \\
\hline 15 & & $\mathrm{x}$ & $\mathrm{X}$ & & & $\mathrm{X}$ & $\mathrm{X}$ & & $X$ & & $\begin{array}{l}\text { Se sugieren algunos } \\
\text { cambios en la redacción } \\
\text { de la pregunta }\end{array}$ \\
\hline 16 & & $x$ & & $X$ & $X$ & & & $x$ & & $X$ & $\begin{array}{l}\text { Se sugieren cambios en la } \\
\text { forma como se está } \\
\text { haciendo la pregunta }\end{array}$ \\
\hline 17 & $x$ & & $\mathrm{x}$ & & & $x$ & $\mathrm{X}$ & & $\mathrm{x}$ & & \\
\hline 18 & $\mathrm{X}$ & & $x$ & & & $X$ & $\mathrm{X}$ & & $\mathrm{X}$ & & \\
\hline 19 & $\mathrm{X}$ & & $\mathrm{X}$ & & & $x$ & $\mathrm{X}$ & & $\mathrm{X}$ & & \\
\hline 20 & $\mathrm{x}$ & & $x$ & & & $X$ & $X$ & & $X$ & & $\begin{array}{l}\text { Precisar si el consumo es } \\
\text { personal o del hogar }\end{array}$ \\
\hline 21 & & $x$ & $X$ & & & $x$ & $X$ & & $X$ & & $\begin{array}{l}\text { Se sugieren algunos } \\
\text { cambios en la redacción } \\
\text { de la pregunta }\end{array}$ \\
\hline \multicolumn{9}{|c|}{ Aspectos Generales } & Sí & No & $\ldots \ldots \ldots$ \\
\hline \multicolumn{9}{|c|}{$\begin{array}{c}\text { El instrumento contiene instrucciones claras y precisas } \\
\text { para responder el cuestionario }\end{array}$} & $\mathrm{X}$ & & $\begin{array}{l}\text { Sí, pero se tiene que } \\
\text { precisar mucho más a } \\
\text { quién van referidas } \\
\text { algunas preguntas de } \\
\text { consumo y de gasto }\end{array}$ \\
\hline \multicolumn{9}{|c|}{$\begin{array}{c}\text { Los ítems permiten el logro del objetivo de la } \\
\text { investigación }\end{array}$} & $x$ & & \\
\hline \multicolumn{9}{|c|}{$\begin{array}{l}\text { Los ítems están distribuidos en forma lógica y } \\
\text { secuencial. }\end{array}$} & $x$ & & \\
\hline \multicolumn{9}{|c|}{$\begin{array}{l}\text { El número de ítems es suficiente para recoger la } \\
\text { información. En caso de ser negativo su respuesta, } \\
\text { sugerir los ítems a añadir }\end{array}$} & & $X$ & $\begin{array}{l}\text { Sugiero realizar la p16 } \\
\text { para cada una de las } \\
\text { empresas, además de } \\
\text { agregar un módulo de } \\
\text { características } \\
\begin{array}{ll}\text { sociodemográficas del } \\
\text { encuestado } & \text { que } \\
\text { permitirán enriquecer el } \\
\text { análisis. }\end{array}\end{array}$ \\
\hline \multicolumn{12}{|c|}{ VALIDEZ } \\
\hline & & CA & & & & & $\mathrm{NOH}$ & ICAB & & & \\
\hline \multicolumn{11}{|c|}{ APLICABLE ATENDIENDO A LAS OBSERVACIONES } & $\mathrm{X}$ \\
\hline \multicolumn{5}{|c|}{$\begin{array}{l}\text { VALIDADO POR: Almendra } \\
\text { Piedra Delgado }\end{array}$} & DNI. & 4 & 320 & & & \multicolumn{2}{|c|}{ Fecha: 18 de junio del 2020} \\
\hline
\end{tabular}




\begin{tabular}{|l|l|l|}
\hline $\begin{array}{l}\text { Firma: Almendra Piedra } \\
\text { Delgado }\end{array}$ & Teléfono: 980630737 & $\begin{array}{l}\text { E-mail: } \\
\text { almendra.piedra@ipsos.com }\end{array}$ \\
\hline \multicolumn{2}{|c|}{$\begin{array}{c}\text { Nota: Modificado de Formato de la facultad de Odontología de la universidad de Carabobo } \\
(2007) .\end{array}$} \\
\hline
\end{tabular}


Anexo D: Formato de validación de instrumento por el segundo experto

\begin{tabular}{|c|c|c|c|c|c|c|c|c|c|c|c|}
\hline \multirow{3}{*}{$\begin{array}{l}\text { ÍTE } \\
\text { M }\end{array}$} & \multicolumn{10}{|c|}{ CRITERIOS A EVALUAR } & $\begin{array}{l}\text { Observaciones (si debe } \\
\text { eliminarse o modificarse } \\
\text { un ítem por favor indique) }\end{array}$ \\
\hline & \multicolumn{2}{|c|}{$\begin{array}{l}\text { Claridad } \\
\text { en la } \\
\text { redacción }\end{array}$} & \multicolumn{2}{|c|}{$\begin{array}{l}\text { Coheren } \\
\text { cia } \\
\text { interna }\end{array}$} & \multicolumn{2}{|c|}{$\begin{array}{l}\text { Inducci } \\
\text { ón a la } \\
\text { respues } \\
\text { ta } \\
\text { (sesgo) }\end{array}$} & \multicolumn{2}{|c|}{$\begin{array}{c}\text { Lenguaje } \\
\text { adecuado } \\
\text { con el nivel } \\
\text { de } \\
\text { información }\end{array}$} & \multicolumn{2}{|c|}{$\begin{array}{l}\text { Mide lo } \\
\text { que } \\
\text { pretend } \\
\text { e }\end{array}$} & \\
\hline & Sí & No & Sí & No & Sí & No & Sí & No & Sí & No & \\
\hline 1 & $X$ & & $X$ & & & $X$ & $X$ & & $X$ & & $\begin{array}{l}\text { Ojo, la familia, amigos o } \\
\text { pareja pueden además } \\
\text { de influenciar la } \\
\text { decisión ser la principal } \\
\text { razón }\end{array}$ \\
\hline 2 & $X$ & & $X$ & & & $X$ & $X$ & & $X$ & & $\begin{array}{l}\text { Pareja } \\
\text { necesariamente } \\
\text { familia) }\end{array}$ \\
\hline 3 & $\mathrm{X}$ & & $x$ & & & $\mathrm{X}$ & $\mathrm{x}$ & & $\mathrm{X}$ & & \\
\hline 4 & $\mathrm{X}$ & & $x$ & & & $\mathrm{X}$ & $x$ & & $\mathrm{X}$ & & \\
\hline 5 & $\mathrm{X}$ & & $x$ & & & $X$ & $x$ & & $\mathrm{X}$ & & \\
\hline 6 & $X$ & & $X$ & & & $\mathrm{X}$ & $\mathrm{X}$ & & $\mathrm{X}$ & & \\
\hline 7 & $\mathrm{X}$ & & $\mathrm{X}$ & & & $\mathrm{X}$ & $\mathrm{X}$ & & $\mathrm{X}$ & & \\
\hline 8 & $x$ & & $X$ & & & $\mathrm{X}$ & $x$ & & $\mathrm{X}$ & & \\
\hline 9 & $\mathrm{X}$ & & $x$ & & & $\mathrm{X}$ & $x$ & & $\mathrm{X}$ & & \\
\hline 10 & $x$ & & $\mathrm{X}$ & & & $\mathrm{X}$ & $x$ & & $\mathrm{X}$ & & \\
\hline 11 & $x$ & & $\mathrm{X}$ & & & $\mathrm{X}$ & $x$ & & $\mathrm{X}$ & & \\
\hline 12 & $x$ & & $x$ & & & $X$ & $x$ & & $\mathrm{X}$ & & \\
\hline 13 & $\mathrm{X}$ & & $\mathrm{X}$ & & & $\mathrm{X}$ & $x$ & & $\mathrm{X}$ & & \\
\hline 14 & $x$ & & $x$ & & & $X$ & $x$ & & $\mathrm{X}$ & & \\
\hline 15 & $\mathrm{X}$ & & $X$ & & & $\mathrm{X}$ & $\mathrm{X}$ & & $\mathrm{X}$ & & $\begin{array}{l}\text { ¿Es el gasto por persona } \\
\text { en la vivienda o el gasto } \\
\text { total? }\end{array}$ \\
\hline 16 & $\mathrm{X}$ & & $\mathrm{X}$ & & & $\mathrm{X}$ & $x$ & & $\mathrm{X}$ & & \\
\hline 17 & $\mathrm{X}$ & & $\mathrm{X}$ & & & $\mathrm{X}$ & $\mathrm{X}$ & & $\mathrm{X}$ & & \\
\hline 18 & $\mathrm{X}$ & & $\mathrm{X}$ & & & $\mathrm{X}$ & $X$ & & $\mathrm{X}$ & & \\
\hline 19 & $\mathrm{X}$ & & $\mathrm{X}$ & & & $\mathrm{X}$ & $x$ & & $\mathrm{X}$ & & ¿Y si no consume? \\
\hline 20 & $X$ & & $\mathrm{X}$ & & & $\mathrm{X}$ & $x$ & & $\mathrm{X}$ & & \\
\hline 21 & $\mathrm{X}$ & & $\mathrm{X}$ & & & $\mathrm{X}$ & $\mathrm{X}$ & & $\mathrm{X}$ & & \\
\hline \multicolumn{9}{|c|}{ Aspectos Generales } & Sí & No & $\ldots \ldots \ldots$ \\
\hline \multicolumn{9}{|c|}{$\begin{array}{c}\text { El instrumento contiene instrucciones claras y precisas } \\
\text { para responder el cuestionario }\end{array}$} & $X$ & & \\
\hline \multicolumn{9}{|c|}{$\begin{array}{c}\text { Los ítems permiten el logro del objetivo de la } \\
\text { investigación }\end{array}$} & $x$ & & \\
\hline \multicolumn{9}{|c|}{$\begin{array}{l}\text { Los ítems están distribuidos en forma lógica y } \\
\text { secuencial. }\end{array}$} & $\mathrm{x}$ & & \\
\hline
\end{tabular}




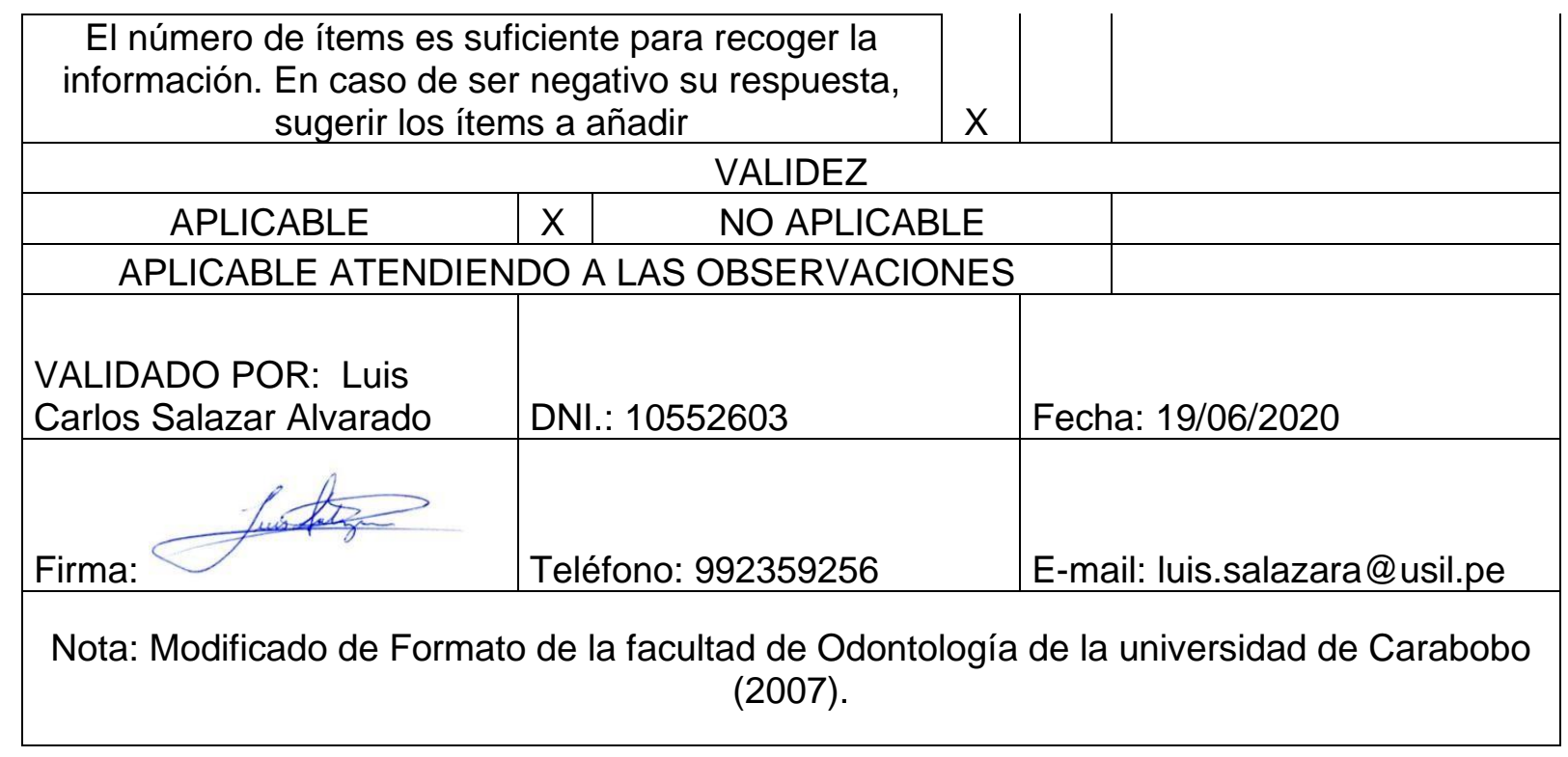

